\title{
Development and Demonstration of Advanced Tooling Alloys for Molds and Dies
}

Kevin M. McHugh

Enrique J. Lavernia

January 2006

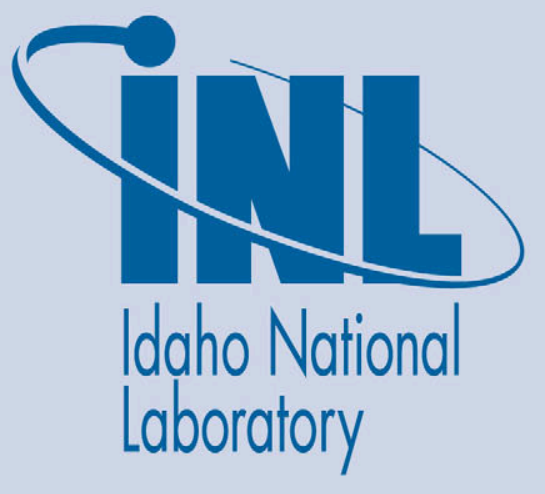

The INL is a U.S. Department of Energy National Laboratory operated by Battelle Energy Alliance 
INL/EXT-06-01079

\title{
Development and Demonstration of Advanced Tooling Alloys for Molds and Dies
}

Kevin M. McHugh

Enrique J. Lavernia

January 2006

\author{
Idaho National Laboratory \\ Idaho Falls, Idaho 83415
}

Prepared for the

U.S. Department of Energy

Assistant Secretary for Energy Efficiency and Renewable Energy

Under DOE Idaho Operations Office

Contract DE-AC07-05ID14517 
INL/EXT-06-01079

\title{
Final Technical Report
}

\section{on \\ Development and Demonstration of Advanced Tooling Alloys for Molds and Dies}

\author{
DOE Award Number: CPS Number 1790, FWP Number 42C5-02
}

Project Period: October 2001-September 2005

\author{
Kevin M. McHugh, Idaho National Laboratory \\ Phone: 208-525-5713 \\ E-mail: kevin.mchugh@inl.gov \\ Enrique J. Lavernia, University of California, Davis \\ Phone: 530-752-0554 \\ E-mail: lavernia@ucdavis.edu \\ Recipient: Idaho National Laboratory, \\ P. O. Box 1625, Idaho Falls, ID 83415 \\ Other Project Team \\ Members: \\ General Aluminum Manufacturing Company \\ Glass Manufacturing Industry Council \\ RSP Tooling, LLC
}

January 2006

Prepared for the

U.S. Department of Energy

Office of Energy Efficiency and Renewable Energy

Under DOE Idaho Operations Office

Contract DE-AC07-05ID14517 



\section{ABSTRACT}

This report summarizes research results in the project Development and Demonstration of Advanced Tooling Alloys for Molds and Dies. Molds, dies, and related tooling are used to manufacture most of the plastic and metal products we use every day. Conventional fabrication of molds and dies involves a multiplicity of machining, benching, and heat treatment unit operations. This approach is very expensive and time consuming.

Rapid Solidification Process (RSP) Tooling ${ }^{\mathrm{TM}}$ is a spray-forming technology tailored for producing molds and dies. The approach combines rapid solidification processing and net-shape materials processing in a single step. An atomized spray of a tool-forming alloy, typically a tool steel, is deposited onto an easy-to-form tool pattern to replicate the pattern's shape and surface features. By so doing, the approach eliminates many machining operations in conventional mold making, significantly reducing cost, lead time, and energy. Moreover, rapid solidification creates unique microstructural features by suppressing carbide precipitation and growth, and creating metastable phases. This can result in unique material properties following heat treatment. Spray-formed and aged tool steel dies have exhibited extended life compared to conventional dies in many forming operations such as forging, extrusion, and die casting. RSP Tooling technology was commercialized with the formation of RSP Tooling, LLC in Solon, $\mathrm{OH}$.

\section{ACKNOWLEDGMENTS}

This report is based on work supported by the U.S. Department of Energy under Award CPS Number 1790, FWP Number 42C5-02.

\section{DISCLAIMER}

Any findings, opinions, and conclusions or recommendations expressed in this report are those of the authors and do not necessarily reflect the views of the U. S. Department of Energy.

\section{PROPRIETARY DATA NOTICE}

This report is classified as an Unlimited Announcement. 


\section{TABLE OF CONTENTS}

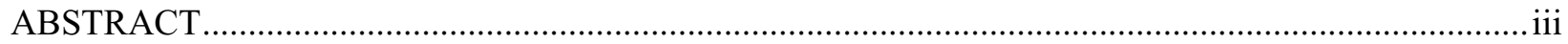

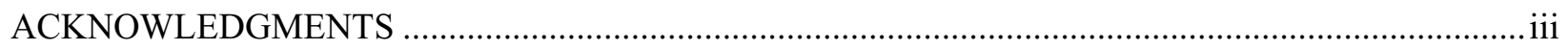

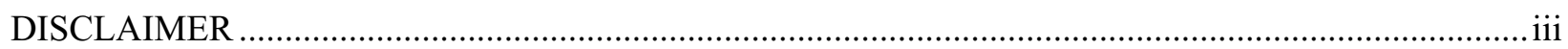

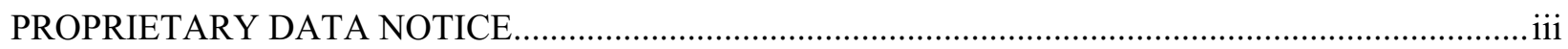

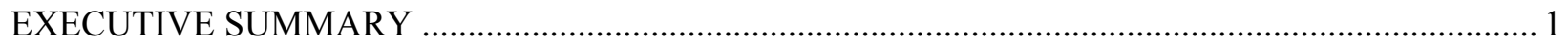

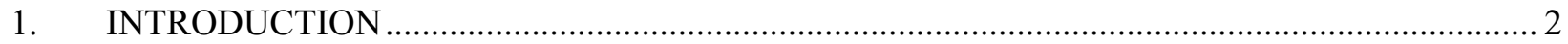

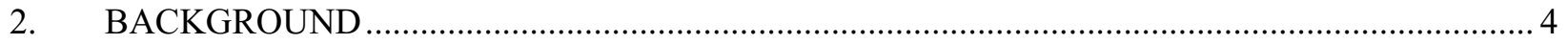

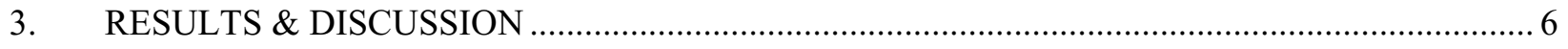

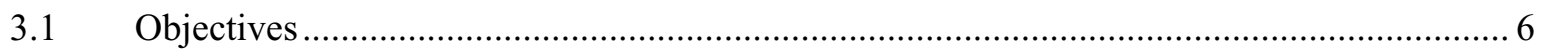

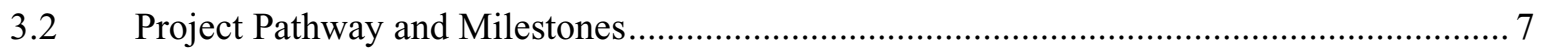

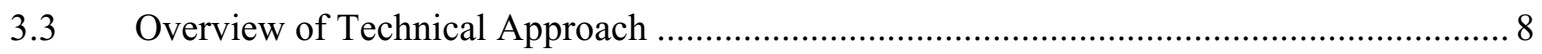

3.4 Production, Analysis, and Testing of Molds and Dies ............................................. 10

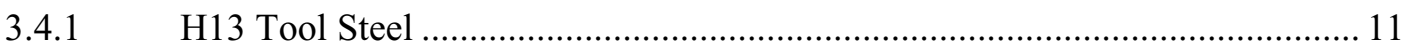

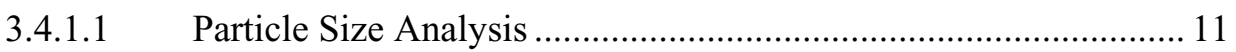

3.4.1.2 Particle Velocity and Solid Fraction........................................... 11

3.4.1.3 Die Surface Roughness and Accuracy ........................................ 12

3.4.1.4 Chemistry Analysis...................................................................... 12

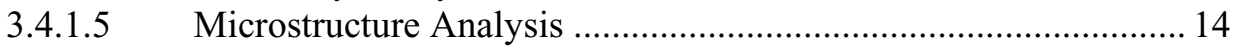

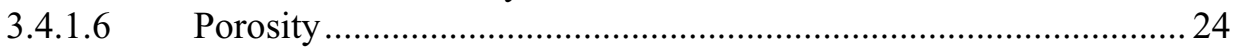

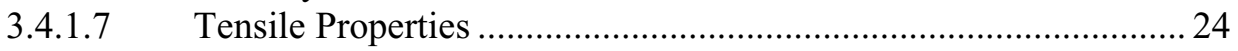

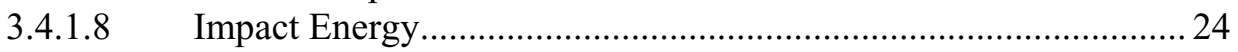

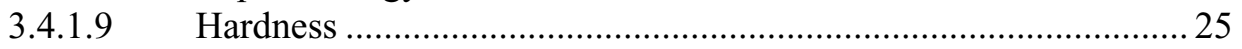

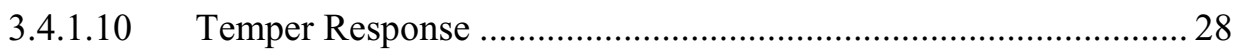

3.4.1.11 Differential Thermal Analysis ............................................ 28

3.4.1.12 Residual Stress Analysis.......................................................... 28

3.4.1.13 Results of Production Runs with Spray-Formed H13 Dies ........... 31

3.4.1.14 Modeling Results for Spray-Formed H13 Tool Steel.................... 31

3.4.1.14.1. Modeling Heat Transfer and Solidification ............. 31

3.4.1.14.2. Influence of the Substrate Preheat Temperature on Solidification and Cooling........................................ 33

3.4.1.14.3. Influence of the Deposit Growth Rate on Solidification and Cooling....................................... 33

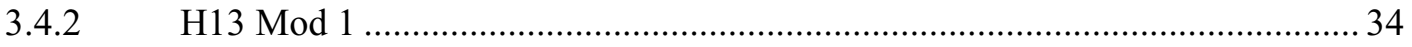

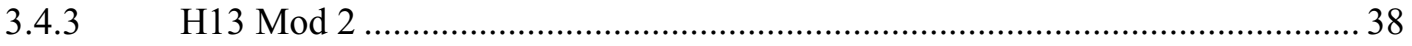




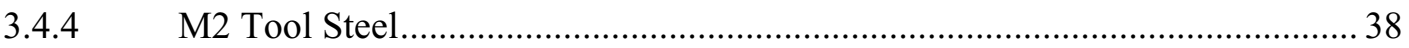

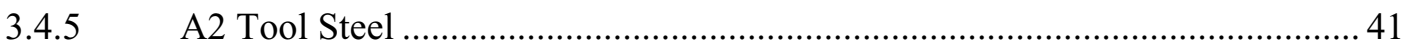

3.4.5.1 Hardness and Microstructure ................................................... 41

3.4.5.2 Numerical Analysis of Residual Stresses in A2 Tool Steel........... 49

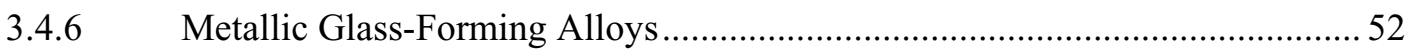

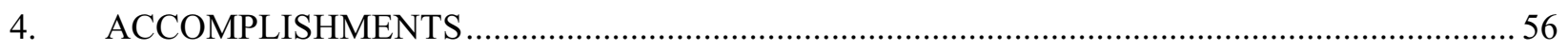

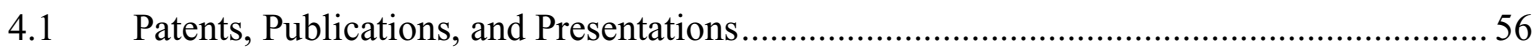

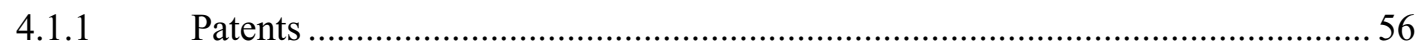

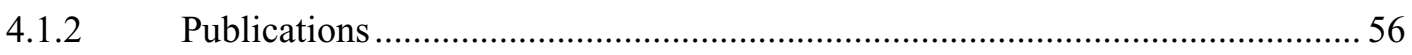

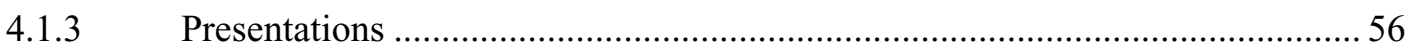

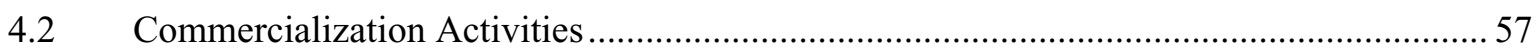

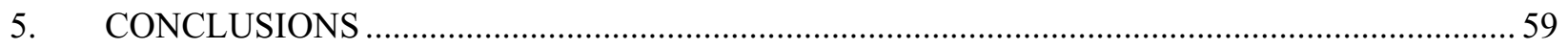

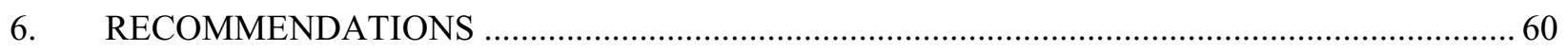

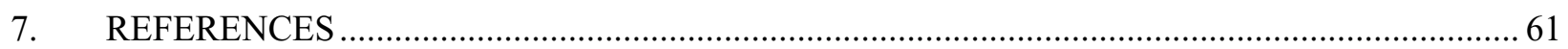

\section{LIST OF FIGURES}

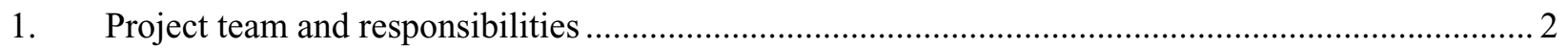

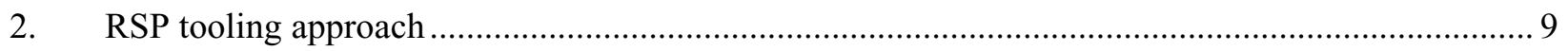

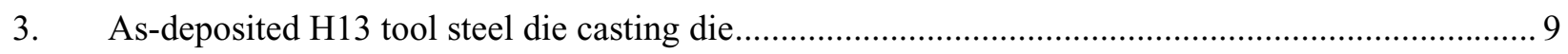

4. Cumulative mass and mass frequency plots of particles in $\mathrm{H} 13$ tool steel sprays.......................... 12

5. Calculated particle and gas behavior in nozzle and free jet regions ........................................... 12

6. Examples of spray-formed H13 tool steel dies for various applications ...................................... 13

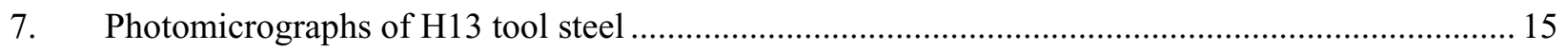

8. Photomicrographs of H13 tool steel following a conventional heat treatment.............................. 15

9. Photomicrographs of spray-formed/forced convection cooled H13 .......................................... 16

10. Microstructure of an H13 tool steel die that was spray formed in still nitrogen ........................... 16

11. Photomicrographs of spray-formed and water-quenched $\mathrm{H} 13$ tool steel. .................................... 17

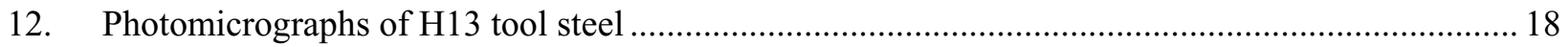


13. SEM photomicrograph (BSE mode) of as-deposited H13 tool steel showing adjacent

V-rich (dark) and Mo/Cr-rich (light) carbides

14. SEM photomicrograph (BSE mode) of spray-formed $\mathrm{H} 13$ tool steel aged at $500^{\circ} \mathrm{C}$ for $2 \mathrm{~h}$.

15. Microstructures of as-deposited H13.......

16. High magnification SEM micrographs of (a) lower bainite and (b) martensite 20

17. TEM micrograph of lower bainite 20

18. TEM micrograph of martensite 21

19. TEM micrograph showing retained austenite 21

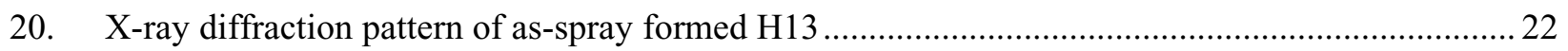

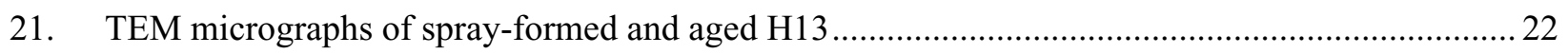

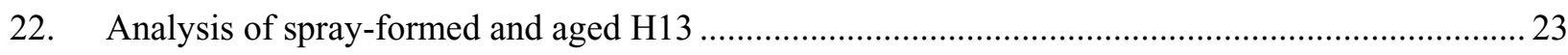

23. Hardness of artificially-aged spray-formed H13 tool steel following 1-h soaks at temperature

24. Rockwell C hardness of $\mathrm{H} 13$ tool steel

25. Vickers hardness profile through a spray-formed, free-convection-cooled, H13 tool steel die.

26. Hardness of spray-formed and commercial $\mathrm{H} 13$ tool steel following soaks at $500^{\circ} \mathrm{C}$

27. Temper response of heat treated H13 tool steel.

28. DTA scans on austenitized $\left(1015^{\circ} \mathrm{C}\right)$ and air-quenched $\mathrm{H} 13$ tool steel samples. 30

29. H13 tool steel sample fabricated by spray forming (top) and residual stresses (bottom) of the step feature in the bottom right corner of the sample.....

30. Spray-formed H13 tool steel die casting dies

31. Calculated temperature as a function of time in spray-formed $\mathrm{H} 13$ tooling

32. Calculated liquid fraction as a function of time in spray-formed H13 tooling derived from Figure 31.

33. Calculated temperature as a function of time in the temperature region of austenite decomposition.

34. Calculated temperature as a function of time in spray-formed H13 tooling 35

35. Calculated temperature as a function of time in spray-formed H13 tooling with and without substrate preheating. 
36. Liquid fraction at the deposit/substrate interface under two deposit growth rates

37. The temperature history, below $1100^{\circ} \mathrm{C}$, of materials deposited at 0.242 and $1.0 \mathrm{~mm} / \mathrm{s} \ldots \ldots \ldots \ldots \ldots . . . . .36$

38. Comparison of aging curves of alloys processed in this project................................................. 36

39. Comparison of as-deposited hardness and peak-aged hardness of spray-formed tool steels ........... 36

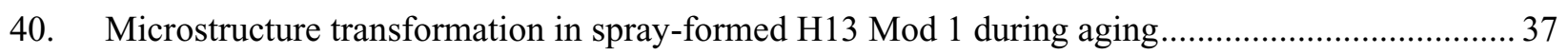

41. Microstructure transformation in spray-formed H13 Mod 2 during aging..................................... 39

42. Temper and aging response of spray-formed H13 Mod 2 …................................................ 40

43. Spray-formed M2 tool steel forging die with forged steel gear................................................ 40

44. Photomicrographs of (a) cast, (b) commercial forged, (c) spray formed, and (d) sprayformed/pressed M2 tool steel

45. As-deposited A2 tool steel glass-forming dies and stereolithography master............................... 42

46. Microstructure at the surface and interior of an as-deposited A2 tool steel mold ......................... 42

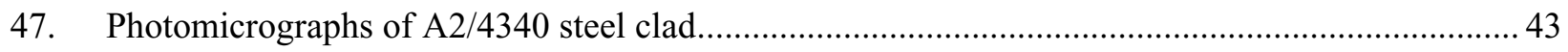

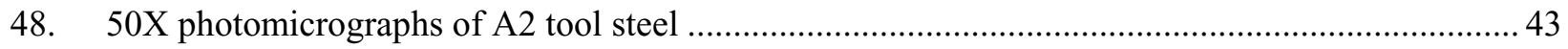

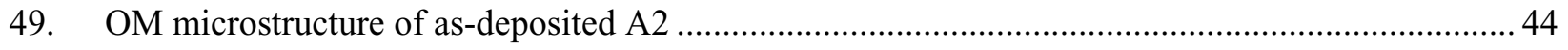

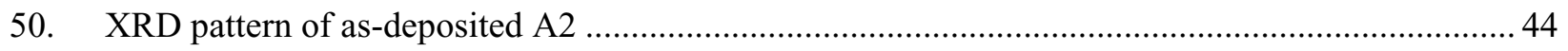

51. Microstructure transformation of spray-formed A2 during aging ............................................ 45

52. Photomicrographs of conventionally heat treated (austenitized/quenched/tempered) A2 ............. 46

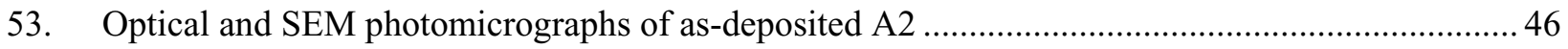

54. Optical and SEM photomicrographs of spray-formed A2 following an aging heat treatment ........ 47

55. SEM photomicrographs of commercial A2 following a conventional heat treatment ................... 47

56. SEM photomicrographs of spray-formed A2 following a conventional heat treatment................. 48

57. Temper curves for commercial forged and spray-formed A2 tool steel..................................... 48

58. Spray-formed A2 tool steel (left) and axisymmetric finite element mesh for this part (right)........ 50

59. Von Mises stress distribution of spray-formed A2 tool steel ................................................... 50

60. Radial stress distribution of spray-formed A2 tool steel ..................................................... 50

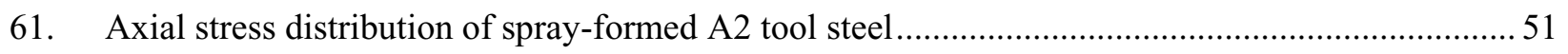


62. Shear stress distribution of spray-formed A2 tool steel........................................................... 51

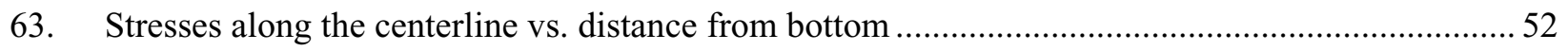

64. Stress distribution along the bottom line and top surface .......................................................... 53

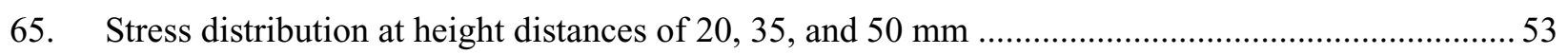

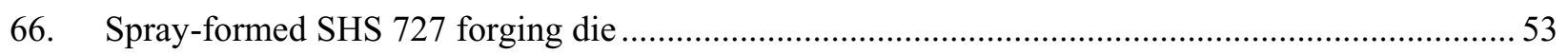

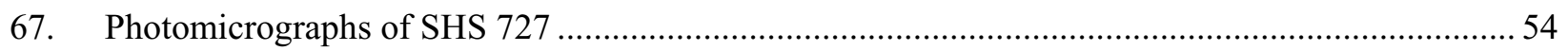

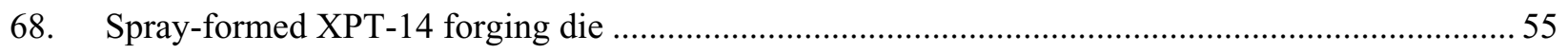

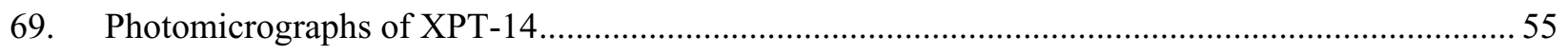

70. Commercial RSP tooling machine and industry participants .................................................. 58

71. Textured H13 tool steel sample made on commercial RSP tooling machine.................................58

72. Die inserts manufactured on the commercial RSP tooling machine ......................................... 58

\section{LIST OF TABLES}

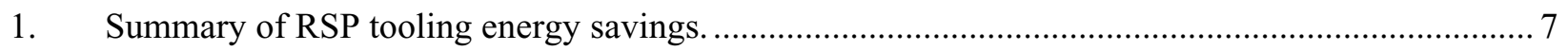

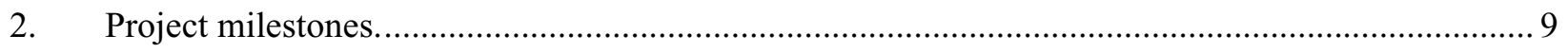

3. Alloy selections by industry partners, applications, and tooling requirements. .......................... 10

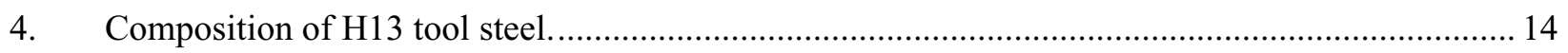

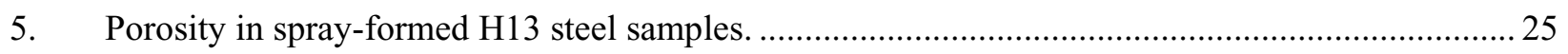

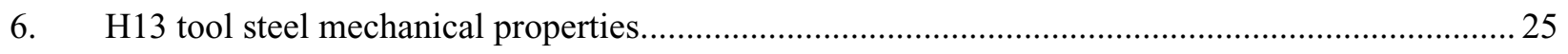

7. Summary of die life studies in forging, extrusion and die casting H13 tool steel dies.................... 32

\section{LIST OF APPENDICES}

Appendix A

Modeling Analysis of Heat Transfer and Solidification Phenomena 


\section{ACRONYMS}

\begin{tabular}{|c|c|}
\hline $\mathrm{ADE}$ & alternating-direction explicit \\
\hline BSE & backscattered electron \\
\hline $\mathrm{CNC}$ & computer numerical control \\
\hline DOE & Department of Energy \\
\hline DTA & differential thermal analysis \\
\hline EDM & Electron discharge machining \\
\hline EDS & energy-dispersive spectroscopy \\
\hline EERE & Energy Efficiency and Renewable Energy \\
\hline HRC & Rockwell C hardness \\
\hline IMF & Industrial Materials for the Future \\
\hline INL & Idaho National Laboratory \\
\hline IOF & Industries of the Future \\
\hline ITP & Industrial Technologies Program \\
\hline $\mathrm{OM}$ & optical microscope \\
\hline $\mathrm{R} \& \mathrm{D}$ & research and development \\
\hline RSP & Rapid Solidification Process \\
\hline RT & rapid tooling \\
\hline RTV & room temperature vulcanizing (silicone rubber) \\
\hline SAD & selected area diffraction \\
\hline SEM & scanning electron microscopy \\
\hline TEM & transmission electron microscopy \\
\hline $\mathrm{UCD}$ & University of California, Davis \\
\hline $\mathrm{XRD}$ & $\mathrm{x}$-ray diffraction \\
\hline
\end{tabular}




\section{Development and Demonstration of Advanced Tooling Alloys for Molds and Dies \\ EXECUTIVE SUMMARY}

Molds, dies, and related tooling are used in manufacturing many products we use every day. Conventional methods for fabricating molds and dies involve many steps and are very expensive and time consuming because:

- $\quad$ Each mold or die is custom made.

- $\quad$ The materials used to make tooling are difficult to machine and work with.

- $\quad$ Tooling must be machined accurately.

Although there have been incremental improvements in these methods over the years, the time lag from when a design is finalized to the time a tool is in production has remained essentially the same. As a result, there is increasing interest in technologies that shorten the design-to-part cycle and reduce the cost of dies. This project featured the development and demonstration of a unique rapid tooling technology, Rapid Solidification Process (RSP) Tooling, which was shown to significantly reduce cost, lead time, and energy use by eliminating most of these operations.

During the project, it was found that rapid solidification of steel tooling alloys imparts the ability to tailor the properties of dies by artificial aging in addition to conventional heat treatment. Unique combinations of hardness, strength, thermal fatigue resistance, and other properties were demonstrated in this project that were achieved by aging and are not possible with commercial forged steel. This is because at the steel mill, steel is cast into ingots that cool slowly and form carbide-rich segregates, particularly near the center of the ingot. As a result of slow cooling, conventionally processed tool steels can not be artificially aged. The segregate is broken up and redistributed by hot working operations such as forging. In contrast, rapid solidification during spray forming inhibits carbide precipitation and growth. The alloying additions to iron in tool steels that ultimately form carbides, such as vanadium, molybdenum, and chromium, can be held in solution. During artificial aging, which is similar to tempering, diffusion of these elements results in the formation of ultra-fine carbides that are uniformly distributed in the matrix. The size, shape, type, and distribution of carbides in tool steels, in concert with the nature of the matrix phase, dictate the properties of the steel. Artificial aging was also shown to bypass the specific volume changes that occur during conventional heat treatment of many steel tooling alloys, essentially eliminating the risk of tool distortion.

As a result of microstructure and property improvements in steels that result from rapid solidification and unique heat treatment, die life extension was demonstrated by industry partners in a variety forming operations. In addition, new steel alloys were developed and demonstrated that show promise for enhanced performance. RSP Tooling technology developed in this project was commercialized with the formation of RSP Tooling, LLC in Solon, OH. 


\section{INTRODUCTION}

The U. S. Department of Energy's (DOE) Office of Energy Efficiency and Renewable Energy (EERE) seeks to improve U. S. industrial energy efficiency while improving productivity. EERE's Industrial Technologies Program (ITP) develops, manages, and implements a balanced portfolio of R\&D projects in support of various energy-intensive Industries of the Future (IOF) such as aluminum, steel, chemicals, and mining. ${ }^{1}$

The project Development and Demonstration of Advanced Tooling Alloys for Molds and Dies was awarded following a competitive solicitation as part of ITP's Industrial Materials for the Future (IMF) program. The mission of the IMF program is to lead a national effort to research, design, develop, engineer, and test new and improved materials for the IOFs. The project summarized in this report involved the development and commercialization of a new fabrication process (RSP Tooling) for molds, dies, and related tooling, as well as new tooling alloys and heat treatment practices to reduce energy expenditure, cost, and lead time in the manufacture of molds and dies. RSP Tooling is an additive spraydeposition technology in which an atomized spray of a tool steel or other alloy is deposited onto a tool pattern, imaging its shape and surface details. The deposited material is separated from the pattern and mounted in a standard mold base or holding block. The ability of the sprayed metal to accurately replicate the details of the tool pattern eliminates the need for most machining and benching unit operations. The project team that developed this technology consisted of Idaho National Laboratory (INL, Idaho Falls, ID), University of California-Davis (UCD, Davis, CA), General Aluminum Manufacturing Company (Conneaut, OH), the Glass Manufacturing Industry Council (Westerville, OH), and RSP Tooling, LLC (Solon, $\mathrm{OH}$ ). Process development, material analysis and multiphase flow modeling was conducted at INL. Die microstructure and material property analysis and process modeling were conducted at UCD. Industry partners provided project guidance, die designs, die material recommendations, property analysis of spray-formed dies, and in-service analysis of die performance during production runs. Industry partners compared failure modes of spray-formed dies (heat checking, washout, soldering, etc.) with those of conventional dies. Figure 1 provides a schematic of the project team and responsibilities. Benefits from this R\&D are crosscutting for the IOFs and other U. S. manufacturing industries. The IOFs and supporting industries most closely benefiting from this research are glass, metal casting, steel, forging, and heat treating.

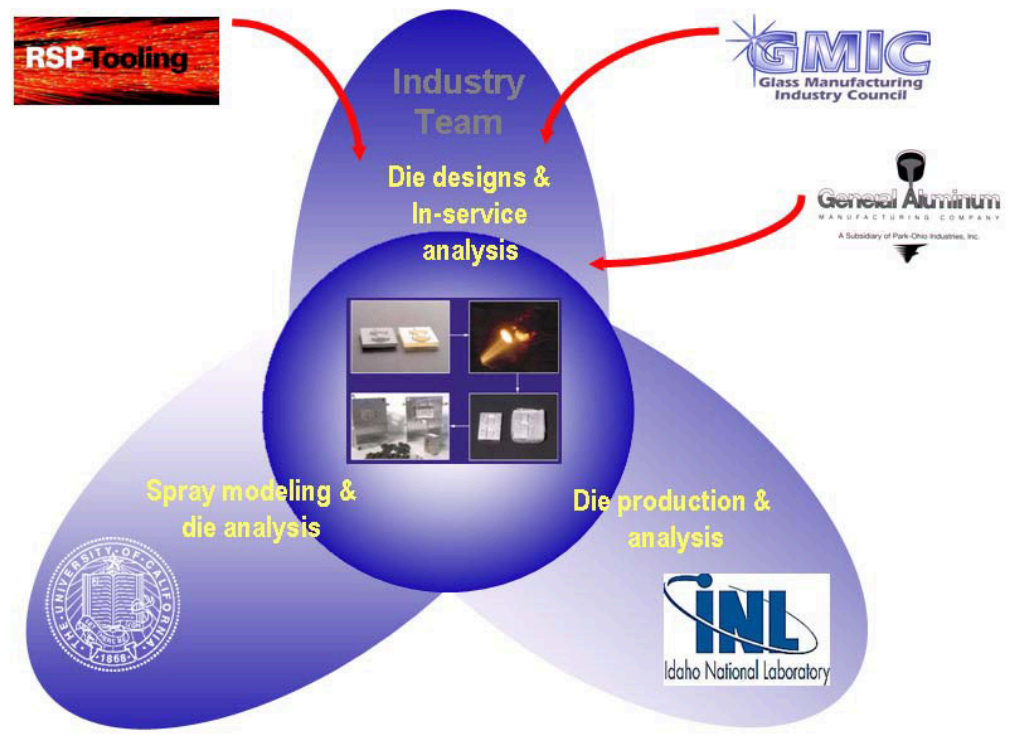

Figure 1. Project team and responsibilities. 
As a result of rapid solidification and unique heat treatment practices, improvements in room temperature and elevated temperature strength, hardness, wear resistance, thermal fatigue resistance, resistance to die soldering, and other properties with respect to those of conventional tool steels were demonstrated. Production runs were conducted by industry in die casting, forging, extrusion, and other applications for comparison with conventional dies. In all cases, RSP Tooling dies were found to meet or exceed conventional die performance while reducing cost and lead time by $20-70 \%$ for small dies. Time and cost savings increased as the size and complexity of the dies increased.

With implementation of RSP Tooling technology, industrial energy savings are forecast to be $0.14 \mathrm{TBtu} / \mathrm{yr}$ in 2010 and $5.56 \mathrm{TBtu} / \mathrm{yr}$ in $2020 .^{2}$ The major areas of energy savings are:

- $\quad$ Elimination of steel mill unit operations for producing forged plate, rod, bar, etc. of tool steels used to manufacture molds and dies.

- Elimination of machining and benching operations used to convert forged steel into dies.

- Die life extension that results from the unique microstructure created during rapid solidification.

- Substitution of a relatively low temperature artificial aging thermal treatment for the conventional austenitization/quench/temper heat treatment.

RSP Tooling technology developed in this project was commercialized with the formation of RSP Tooling, LLC in 2002. 


\section{BACKGROUND}

Molds, dies, and related tooling are used to manufacture most of the plastic and metal products we use every day. Conventional fabrication of molds and dies involves machining the negative of a desired part shape (core and cavity) from a forged tool steel block, adding cooling channels, vents, and other mechanical features, and then benching, heat treating, and finishing. This approach is very expensive and time consuming because:

- $\quad$ Each mold or die is custom made, reflecting the shape and texture of the desired part.

- The materials used to make tooling are difficult to machine and work with. Tool steels are the workhorse of industry for long production runs. Machining tool steels is capital equipment intensive because specialized equipment is often needed for individual machining steps.

- $\quad$ Tooling must be machined accurately. Oftentimes many individual components must fit together correctly for the final product to function properly.

The conventional method used to construct molds and dies has seen incremental improvements over the years. However, the time lag from when a design is finalized to the time a tool is in production has remained essentially the same. The two main causes for the bottleneck are the need to qualify a part design by making prototypes (usually with a different process) and the production tooling lead time after the prototypes are approved. Production tooling costs are high due to the labor and equipment costs associated with transforming a forged block of tool steel into a finished tool. CNC (computer numerical control) machining, sink EDM (electron discharge machining), benching, engraving, and heat treatment unit operations are typically involved. As a result, there is increasing interest in rapid tooling (RT) technologies that shorten the design-to-part cycle and reduce the cost of dies.

More than twenty RT methods are being developed and refined around the world. ${ }^{3}$ But nearly all these RT approaches are intended for low-volume prototype work, which does not require the same durability as production tooling., An RT technology that makes production-quality tooling in the time it normally takes for prototype tooling is highly desirable. In fact, there would be no need for prototype tooling. True prototype parts could be made using the same processing conditions and materials that are intended for production. Qualification of the prototype part would allow the manufacturer to go directly into production with the same tool. Rapid Solidification Process (RSP) Tooling, developed at the Idaho National Laboratory (INL), is capable of making production-quality tooling in an RT timeframe. ${ }^{4-7}$

Use of INL spray forming technology to produce complex shaped articles in low melting point alloys began in the early 1990s. ${ }^{8,9}$ Projects in the mid 1990s allowed the process to begin to transition from low melting point prototype (Kirksite) tooling to the more difficult tool steels intended for demanding applications and production runs. ${ }^{10-13}$ The technology was further developed to the point where it was mature enough for commercialization with the help of funding from two projects sponsored by DOE's Office of Energy Efficiency and Renewable Energy, Industrial Technologies Program:

- $\quad$ Integrating RSP Tooling and Rapid Prototyping in Die Casting ${ }^{14}$

- $\quad$ Development and Demonstration of Advanced Tooling Alloys for Molds and Dies ${ }^{15}$

These projects supported the mission of ITP to decrease the energy intensity of the industrial sector through a coordinated program of research and development, validation, and dissemination of energyefficiency technologies and operating practices. 
The potential for energy savings and commercial application of RSP Tooling technology has resulted in an R\&D 100 Award in 1998, a DOE Energy@23 Award in 2000 (recognizing innovations that best demonstrate benefits to the American public, contribute to U.S. competitiveness in the global marketplace, and demonstrate the potential for significant future growth), and a Federal Laboratory Consortium (FLC) Award in 2001. In addition, RSP Tooling has been awarded three U.S. patents:

- $\quad$ U. S. Patent 5,718,863: Spray Forming Process for Producing Molds, Dies and Related Tooling issued February 17, 1998.

- $\quad$ U. S. Patent 6,074,194: Spray Forming System for Producing Molds, Dies and Related Tooling issued June 13, 2000.

- U. S. Patent 6,746,225: Rapid Solidification Processing System for Producing Molds, Dies, and Related Tooling issued June 8, 2004

Development activities culminated with the commercialization of the technology. RSP Tooling, LLC (Solon, OH) was formed in 2002 to design, build, use, and sell machines that manufacture tooling using this process. ${ }^{16,17}$ Their strategy was to find corporation partners who were active stakeholders in the tooling industry, not just investors. Start-up funding for RSP Tooling, LLC was raised and a field-of-use license agreement was negotiated with INL. A beta RSP Tooling machine was built and is being used to manufacture dies and molds for commercial testing and use. It also is being used as a springboard for further machine development activities and process scale-up. 


\section{RESULTS \& DISCUSSION}

\subsection{Objectives}

The objectives of this project were established to respond to research and development needs for improved mold and die materials and reduced energy consumption expressed in the Industries of the Future (IOF) Technology Roadmaps for steel, glass, metal casting, forging, and heat treating. The main objectives were:

Objective One: $\quad$ Reduce cost and lead time for production tooling.

Objective Two: Increase die life by a minimum of $20 \%$.

Objective Three: Reduce energy consumption associated with the manufacture and heat treatment of dies by a minimum of $25 \%$.

Objective One was accomplished by developing and demonstrating a new rapid tooling technology, RSP Tooling, for manufacturing molds, dies, and related tooling. This spray forming approach was shown to reduce the cost and lead time by eliminating many of the unit operations currently employed in mold and die manufacture. Industry partners quantified cost and time savings and found that these savings depended on the complexity of the die. For an average die insert, these savings were approximately $30 \%$. Cost and lead time savings as high as $70 \%$ were documented by industry partners for complex tooling inserts. It was also determined that use of RSP Tooling technology is not warranted for simple die designs that are easy to machine.

For Objective Two, we demonstrated that spray forming provides a powerful means to control segregation of alloying elements during solidification and carbide formation, and the ability to create beneficial metastable phases in many popular tool steels. As a result, relatively low temperature aging heat treatments can be used to tailor properties such as hardness, toughness, thermal fatigue resistance, and strength. Some alloys, such as H13 tool steel, were shown to respond well to artificial aging. As a result, we demonstrated die life extension with this alloy in aluminum die casting $(\sim 20 \%)$ and extrusion of steel bar $(\sim 50 \%)$. Some alloys, such as M2, did not respond as well to aging heat treatments. For these alloys, it was determined that higher than normal cooling rates would be beneficial. Spray-formed M2 steel dies that were conventionally heat treated were found to perform about the same as a conventional die, i.e., die life extension was not observed.

Energy savings in the manufacture of molds and dies of $25 \%$ or more were established, meeting Objective Three. As with cost and lead time savings, energy savings result from process simplification and the elimination of unit operations, namely:

1. Eliminating steel mill unit operations for producing forged plate, rod, bar, etc.

2. Eliminating many of the machining, grinding, and polishing unit operations necessary to transform the forged steel into molds and dies for die casting, forging, stamping, and glass manufacture.

3. Extending die life as a result of unique microstructural qualities found in rapidly solidified tool steel and the potential to develop tooling alloys tailored to the process.

4. Providing the means to heat treat the tool steel using relatively low temperature artificial aging rather than conventional austenitization/quench/temper heat treatment.

Table 1 summarizes energy savings of RSP Tooling compared to conventional machining of die casting dies. 
Table 1. Summary of RSP tooling energy savings.

\begin{tabular}{|l|c|c|}
\hline \multicolumn{1}{|c|}{ Processing Step } & Energy Loss & Energy Savings \\
\hline $\begin{array}{l}\text { Elimination of steel mill unit } \\
\text { operations }\end{array}$ & - & $1.0 \times 10^{7} \mathrm{BTU} /$ ton tool steel \\
\hline Gas-related energy usage & $0.33 \times 10^{6} \mathrm{BTU} /$ ton tool steel & - \\
\hline $\begin{array}{l}\text { Elimination of machining unit } \\
\text { operations }\end{array}$ & - & $1.8 \times 10^{12} \mathrm{BTU} /$ year nationwide \\
\hline Potential for die life extension & - & $2.3 \times 10^{11} \mathrm{BTU} /$ year nationwide \\
\hline Post processing heat treatment & - & $5.8 \times 10^{6} \mathrm{BTU} /$ ton tool steel \\
\hline
\end{tabular}

\subsection{Project Pathway and Milestones}

The pathway used to develop RSP Tooling technology and achieve the objectives described in Section 3.1 was to:

- Modify a bench-scale spray-forming apparatus.

- $\quad$ Select popular production alloys used in stamping, forging, die casting, and glass component manufacture.

- $\quad$ Benchmark microstructure and material properties of production tooling processed by spray forming and evaluate material response to artificial aging and conventional heat treatment.

- Model heat transfer, solidification, and momentum phenomena associated with spray forming of dies.

- Develop ceramic casting materials and procedures for tool patterns.

- Tailor alloy chemistry and heat treatment to processing by spray forming.

- $\quad$ Perform in-service lifetime and failure mode analysis.

- Demonstrate/document reduced energy consumption and scrap.

- $\quad$ Transfer technology to industry partners.

To accomplish the project objectives, it was necessary to develop an understanding of how conventional tool steels, selected by industry participants, responded to processing by rapid solidification and subsequent heat treatment. A wide variety of analytical tools were used to assess this response, including tensile testing, hardness measurement, toughness measurement, scanning electron microscopy (SEM), energy-dispersive spectroscopy (EDS), transmission electron microscopy (TEM), differential thermal analysis (DTA), optical microscopy, x-ray diffraction, and neutron diffraction. In addition to analytical tools, modeling tools and computational techniques were used to help develop an understanding of the interplay of the characteristics of the spray plume (droplet thermo-physical properties, size distribution, velocity, heat content, flux, and spray pattern) with those of the tool pattern during tool formation. Accomplishments include modeling multiphase flow behavior of atomized droplet-laden flows within the atomization and free-jet regions, modifying a spray-forming apparatus to process tooling alloys, extensive property analysis of spray-formed and heat-treated tooling alloys to benchmark properties prior to alloy development work, and the production of sample dies for in-service analysis by industry. 
Alloy property response to artificial aging was analyzed and documented. Researchers at University of California, Davis and Idaho National Laboratory used a variety of techniques to establish microstructure/property relationships and study microstructure transformation in spray-formed tool steels during low temperature heat treatment and conventional heat treatment, particularly carbide precipitation and growth. Results were used to tailor tool steel heat treatment to the rapid solidification conditions during spray-deposition. Researchers assessed the influence of alloy additions on microstructure and tooling properties. Modified alloys were developed, spray formed, and sectioned for microstructure and property analysis.

Structure/property assessment of modified tool steel alloys was completed and property improvements were verified. Evaluation of the effects of alloy additions on carbide stability, size, and distribution before and after heat treatment was completed. Industry participants supplied die designs and solid models of dies to INL for use in casting ceramic patterns. Using modified tooling alloys, sprayformed tooling inserts were produced and sent to industry participants for analysis and in-service evaluation of dies, including lifetime studies and evaluation of failure modes. Results were compared with commercial machined dies of the same geometry. The turnaround time and cost for producing sprayformed dies was quantified and compared with those of conventionally processed dies.

Project milestones, summarized in Table 2, were accomplished on schedule without any major modifications.

\subsection{Overview of Technical Approach}

The INL-developed RSP Tooling technology was used throughout the project. RSP Tooling is a spray-forming technology in which atomized metal droplets are deposited onto a pattern to additively build inserts. ${ }^{18-21}$ A summary of the processing steps is given in Figure 2. A CAD (computer-aided design) model of the desired die design is used to create a physical model (master), usually using a suitable rapid prototyping technology such as stereolithography. A ceramic impression is then cast in alumina. This is followed by spray forming a thick deposit of tool steel (or other alloy) on the ceramic pattern to capture the desired shape, surface texture, and detail. The deposit is cooled to room temperature and separated from the pattern. Typically, the deposit's exterior walls are machined square (or round) using wire electron discharge machining, and bolt holes and water lines are added. The finished insert is mounted in a standard holding block or mold base.

The spray-forming step is at the heart of the RSP Tooling process. Spray forming involves atomizing a molten metal, i.e., breaking up a molten metal stream into small droplets using a high velocity gas jet. Aerodynamic forces overcome surface tension forces, producing droplets in an array of sizes that are entrained by the jet and deposited onto the pattern. As the droplets traverse the distance separating the atomizer and ceramic tool pattern, they cool at very high rates that are a function of spray conditions and their size and trajectory in the flow field. As a result, a combination of liquid, solid, and "slushy" droplets impacts the ceramic and "welds" together to form a coherent deposit. The metal rapidly solidifies and cools at the pattern, greatly limiting atomic diffusion. Erosive interaction of the metal and ceramic tool pattern is largely nullified, allowing the deposited metal to accurately capture surface details of the ceramic. Figure 3 shows an example of a spray-formed H13 tool steel deposit. Normally the molding surface requires little, if any, benching.

To spray form a die, tool steel was induction melted under a nitrogen atmosphere, superheated about $100^{\circ} \mathrm{C}$, and pressure-fed into a bench-scale atomizer designed and built in-house. An inert gas atmosphere within the spray apparatus minimized in-flight oxidation of the atomized droplets as they deposited onto a ceramic pattern at a rate of about 100 to $250 \mathrm{~kg} / \mathrm{h}$ to form a deposit about $100 \mathrm{~mm}$ thick. 
Table 2. Project milestones.

\begin{tabular}{|c|l|c|c|}
\hline ID Number & \multicolumn{1}{|c|}{ Task / Milestone Description } & Planned Completion & Actual Completion \\
\hline 1 & Modify spray-forming equipment & $1 / 1 / 02$ & $12 / 20 / 01$ \\
\hline 2 & Model multiphase flow & $4 / 1 / 02$ & $4 / 1 / 02$ \\
\hline 3 & Produce tool steel deposits & $6 / 1 / 02$ & $6 / 1 / 02$ \\
\hline 4 & Benchmark microstructure & $4 / 1 / 03$ & $4 / 1 / 03$ \\
\hline 5 & Benchmark material properties & $7 / 1 / 03$ & $7 / 1 / 03$ \\
\hline 6 & Model spray process & $10 / 1 / 03$ & $10 / 1 / 03$ \\
\hline 7 & Evaluate properties of heat treated alloys & $2 / 1 / 04$ & $2 / 1 / 04$ \\
\hline 8 & Modify alloy chemistry & $12 / 1 / 04$ & $12 / 1 / 04$ \\
\hline 9 & Design/build solid models & $10 / 1 / 04$ & $10 / 1 / 04$ \\
\hline 10 & Evaluate properties of modified alloys & $7 / 1 / 05$ & $6 / 30 / 05$ \\
\hline 11 & Produce dies from modified alloys & $7 / 1 / 05$ & $6 / 30 / 05$ \\
\hline 12 & Complete evaluation of modified dies & $9 / 1 / 05$ & $8 / 30 / 05$ \\
\hline
\end{tabular}
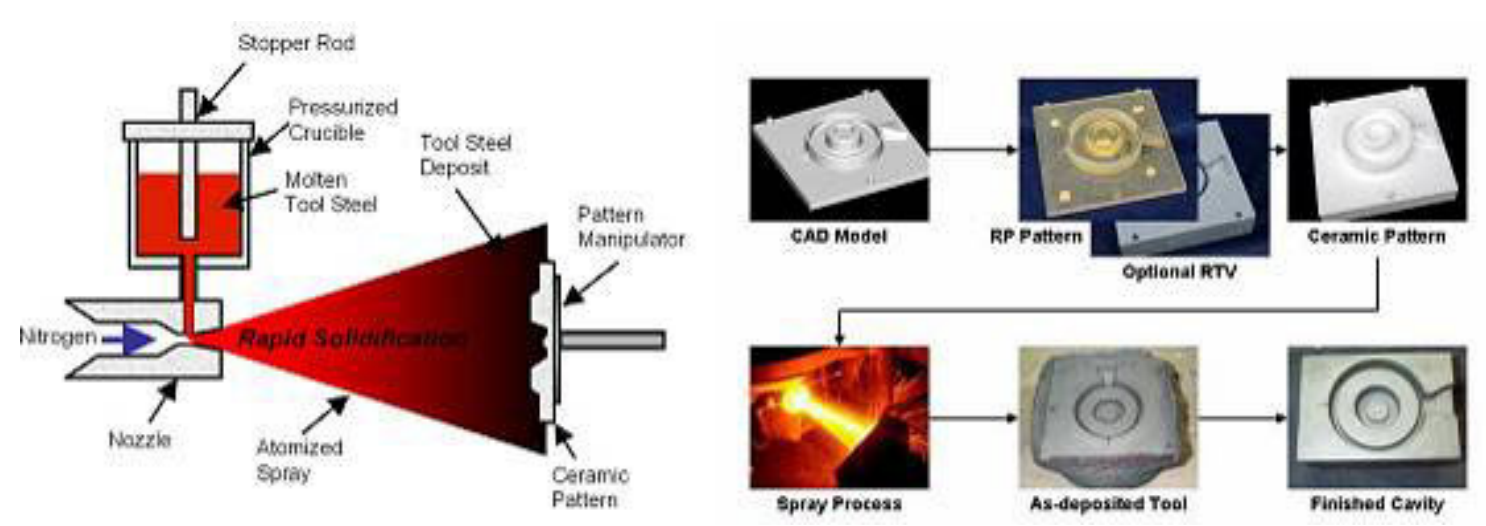

Figure 2. RSP tooling approach.

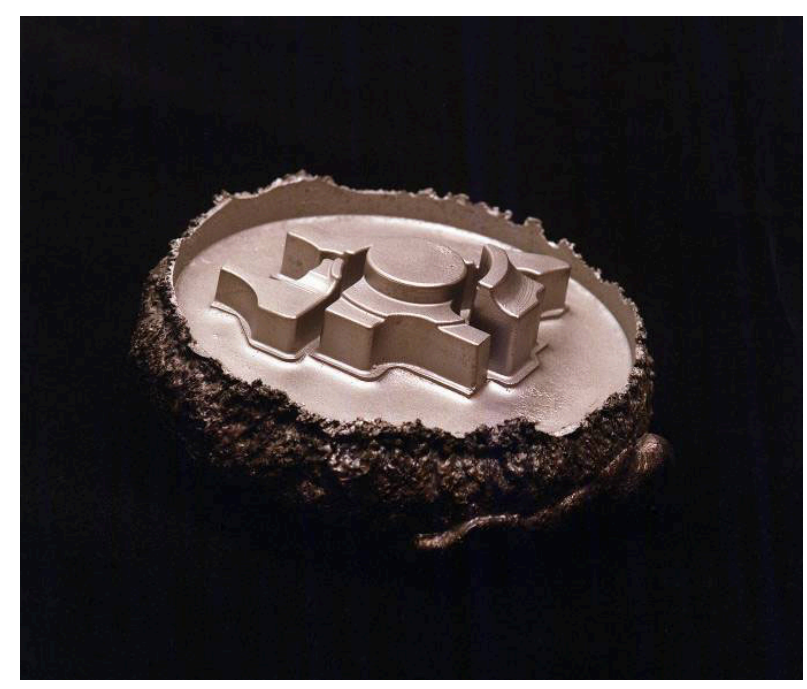

Figure 3. As-deposited H13 tool steel die casting die. 


\subsection{Production, Analysis, and Testing of Molds and Dies}

This project was crosscutting and addressed tooling needs in Glass, Forging, Metal Casting, and Steel Industries of the Future (IOFs). Discussions with industry participants led to the selection of alloys, tooling requirements, and applications that are summarized in Table 3.

Extensive microstructure and material property analysis was conducted on these alloys after processing by spray forming. Particular emphasis was given to H13 tool steel due to its popularity for many forming operations.

For tensile property, impact energy, and hardness measurements, the spray-formed material was sectioned using wire EDM and surface ground to remove the 80 micron thick heat-affected zone. Samples were heat treated in a furnace that was purged with nitrogen. Each sample was coated with boron nitride and placed in a sealed metal foil packet as a precautionary measure to prevent decarburization. Artificially aged samples were soaked for $2 \mathrm{~h}$ at temperatures ranging from 300 to $700^{\circ} \mathrm{C}$ and air cooled. Conventionally heat-treated steels were austenitized at the appropriate temperature for that alloy (950 to $\left.1052^{\circ} \mathrm{C}\right)$ for $40 \mathrm{~min}$, air quenched, and double tempered $(2 \mathrm{~h}$ plus $2 \mathrm{~h})$ at temperatures ranging from about 300 to $800^{\circ} \mathrm{C}$.

Microhardness was measured at room temperature using a Shimadzu Type M Vickers Hardness Tester by averaging ten microindentation readings. Hardness was also measured using a Series 500 Wilson Rockwell C Hardness Tester by averaging eight indentations. Microstructure was evaluated optically using an Olympus Model PME-3 metallograph and a Philips XL-30 ESEM scanning electron microscope. Phase composition was analyzed via energy-dispersive spectroscopy. Tensile testing was performed with an Instron 4505 screw-driven test machine following the ASTM E-8 procedure. Differential thermal analysis was performed with a Rheometrics Model DTA 1500 using a scan rate of $20^{\circ} \mathrm{C} / \mathrm{min}$. The size distribution of overspray powder was analyzed with a Microtrac Full Range Particle Analyzer after powder samples were sieved at $200 \mu \mathrm{m}$ to remove coarse flakes. Sample density was evaluated by water displacement using Archimedes' principle and a Mettler balance (Model AE100). Density (porosity) was also evaluated using optical microscopy in conjunction with Analysis ${ }^{\mathrm{TM}}$ software on polished and unetched samples. Surface roughness was measured using a Mitutoyo Surftest Model 301 surface profilometer by averaging five scans.

An alumina-based ceramic was slurry cast under vacuum using a silicone rubber master die, or freeze cast using a stereolithography master. After setting up, ceramic patterns were demolded, fired in a kiln, and cooled to room temperature. A tooling alloy was induction melted under a nitrogen atmosphere,

Table 3. Alloy selections by industry partners, applications, and tooling requirements.

\begin{tabular}{|l|l|l|l|}
\hline \multicolumn{1}{|c|}{ IOF } & \multicolumn{1}{|c|}{ Example Alloys } & \multicolumn{1}{c|}{ Application } & \multicolumn{1}{c|}{ Tooling Requirements } \\
\hline Glass & A2 & Glass molds & $\begin{array}{l}\text { High thermal conductivity, } \\
\text { thermal shock resistance }\end{array}$ \\
\hline Forging & M2, H13, SHS 727, XPT 14 & Hot forming dies & $\begin{array}{l}\text { High temperature strength, } \\
\text { wear resistance, toughness }\end{array}$ \\
\hline $\begin{array}{l}\text { Metal } \\
\text { Casting }\end{array}$ & H13 & Die casting dies & $\begin{array}{l}\text { Thermal fatigue resistance, } \\
\text { high temperature strength, } \\
\text { wear resistance, toughness }\end{array}$ \\
\hline Steel & A2, H13, XPT 14, SHS 727 & $\begin{array}{l}\text { Cold forming (stamping) } \\
\text { dies for sheet metal }\end{array}$ & $\begin{array}{l}\text { Wear resistance, toughness, } \\
\text { compressive strength }\end{array}$ \\
\hline
\end{tabular}


superheated about $100^{\circ} \mathrm{C}$, and pressure-fed into a bench-scale atomizer designed and constructed by INL. An inert gas atmosphere within the spray apparatus minimized in-flight oxidation of the atomized droplets as they deposited onto the tool pattern at a rate of about $100-250 \mathrm{~kg} / \mathrm{h}$. The gas-to-metal mass flow ratio was approximately 0.5 .

A quasi 1-D computer code developed at INL was used to evaluate multiphase flow behavior inside the nozzle and free jet regions. The code's basic numerical technique solved the steady-state gas flow field through an adaptive grid, conservative variables approach and treated the droplet phase in a Lagrangian manner with full aerodynamic and energetic coupling between the droplets and transport gas. The liquid metal injection system was coupled to the throat gas dynamics, and effects of heat transfer and wall friction were included. The code also included a nonequilibrium solidification model that permitted droplet undercooling and recalescence. The code was used to map out the temperature and velocity profile of the gas and atomized droplets within the nozzle and free jet regions.

\subsubsection{H13 Tool Steel}

AISI H13 tool steel is a chromium hot-work tool steel. The chemistry is designed to withstand the temperature, pressure, abrasion, and thermal cycling associated with demanding applications such as die casting. The steel has low carbon content $(0.4 \mathrm{wt} \%)$ to promote toughness, medium chromium content ( $5 \mathrm{wt} \%$ ) to provide good resistance to high temperature softening, $1 \mathrm{wt} \% \mathrm{Si}$ to improve high temperature oxidation resistance, and small molybdenum and vanadium additions (about 1\%) that form stable carbides to increase resistance to erosive wear. H13 is one of the most popular tool steels in the U.S., finding use in plastic injection molding, die casting, forging, and other applications.

3.4.1.1 Particle Size Analysis. An understanding of particle size distribution in the spray jet provides input on atomization efficiency and droplet cooling rate in the spray. The latter also provides input for estimating the solid fraction during deposition because the cooling rate of atomized particles depends strongly on their size. The solid fraction during deposition influences the solidification rate and hence the microstructural quality of the spray-formed tool. An estimate of the average particle size in the spray was obtained by collecting and sizing overspray powder. Particle mass frequency and cumulative mass distribution plots for $\mathrm{H} 13$ tool steel sprays are given in Figure 4. The mass median diameter was determined to be $56 \mu \mathrm{m}$ by interpolation of size corresponding to $50 \%$ cumulative mass. The area mean diameter and volume mean diameter were calculated to be $53 \mu \mathrm{m}$ and $139 \mu \mathrm{m}$, respectively. The geometric standard deviation of the size distribution, $\sigma_{\mathrm{d}}=\left(\mathrm{d}_{84} / \mathrm{d}_{16}\right)^{1 / 2}$, was 1.8 , where $\mathrm{d}_{84}$ and $\mathrm{d}_{16}$ are particle diameters corresponding to $84 \%$ and $16 \%$ cumulative mass in Figure 4.

3.4.1.2 Particle Velocity and Solid Fraction. Figure 5 gives computational results for the multiphase velocity flow field (Figure 5a) and H13 tool steel solid fraction (Figure 5b) inside the nozzle and free jet regions. Gas velocity increased until reaching the location of the shock front. It then precipitously decreased, and eventually decayed exponentially outside the nozzle. Small droplets (about $30 \mu \mathrm{m}$ diameter) were easily perturbed by the velocity field, accelerating inside the nozzle and decelerating outside. After reaching their terminal velocity, larger droplets $(\sim 150 \mu \mathrm{m})$ were less perturbed by the flow field due to their greater momentum.

Due to the high particle cooling rates in the spray jet $\left(10^{3}-10^{6}{ }^{\circ} \mathrm{C} / \mathrm{s}\right)$, most of the particles in the spray had undergone recalescence, resulting in a solid fraction of about 0.75 at impact with the tool pattern. Calculated solid fraction profiles of small $(\sim 30 \mu \mathrm{m})$ and large $(\sim 150 \mu \mathrm{m})$ droplets with distance from the nozzle inlet are shown in Figure 5.

After choosing appropriate atomization and droplet cooling rate conditions, $\mathrm{H} 13$ tool steel was spray formed for use as forging dies, die casting dies, extrusion dies, and embossing dies. Examples of 
spray-formed dies, tool patterns, RTV (room temperature vulcanizing [silicone rubber]) molds, and stereolithography masters are given in Figure 6. The high solidification rate during spray forming reduced erosion effects at the surface of the tool pattern. This allowed relatively soft, castable ceramic pattern materials to be used even though they would not be satisfactory candidates for conventional metal casting processes. With suitable processing conditions, fine surface detail was successfully transferred from the pattern to the spray-formed mold.

3.4.1.3 Die Surface Roughness and Accuracy. A die's surface roughness was found to be pattern dependent. Slurry-cast commercial ceramics yielded a surface roughness of about $1 \mu \mathrm{m} \mathrm{Ra}$, suitable for many molding applications. Freeze-cast ceramics were smoother and yielded a die surface roughness of about $0.5 \mu \mathrm{m} \mathrm{Ra}$. Dimensional accuracy of the dies is similar to that obtained in conventional tool-making practices $( \pm 0.05 \mathrm{~mm})$ with excellent repeatability with a given master pattern.

3.4.1.4 Chemistry Analysis. Preservation of the chemistry of a tool steel during spray processing is critical. Composition analysis was performed on $\mathrm{H} 13$ tool steel stock material and spray-formed dies. Results, summarized in Table 4, indicate that no significant variation in chemistry occurs during spray forming.

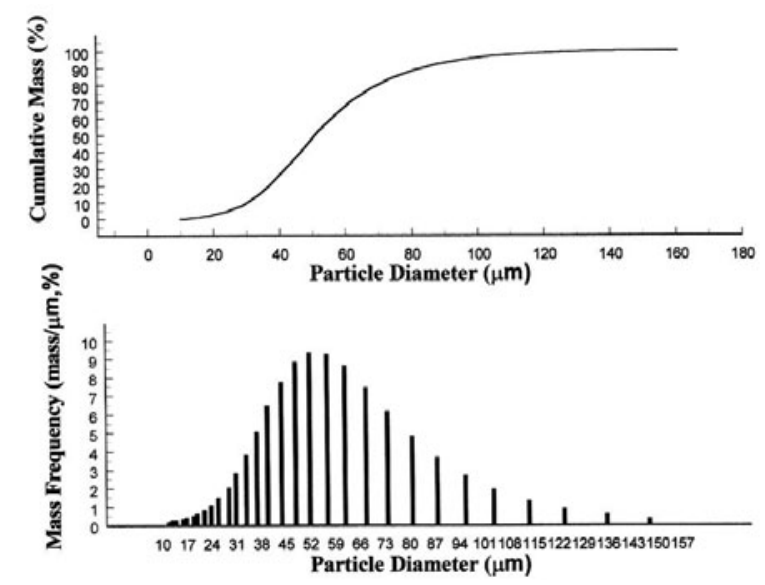

Figure 4. Cumulative mass and mass frequency plots of particles in H13 tool steel sprays.
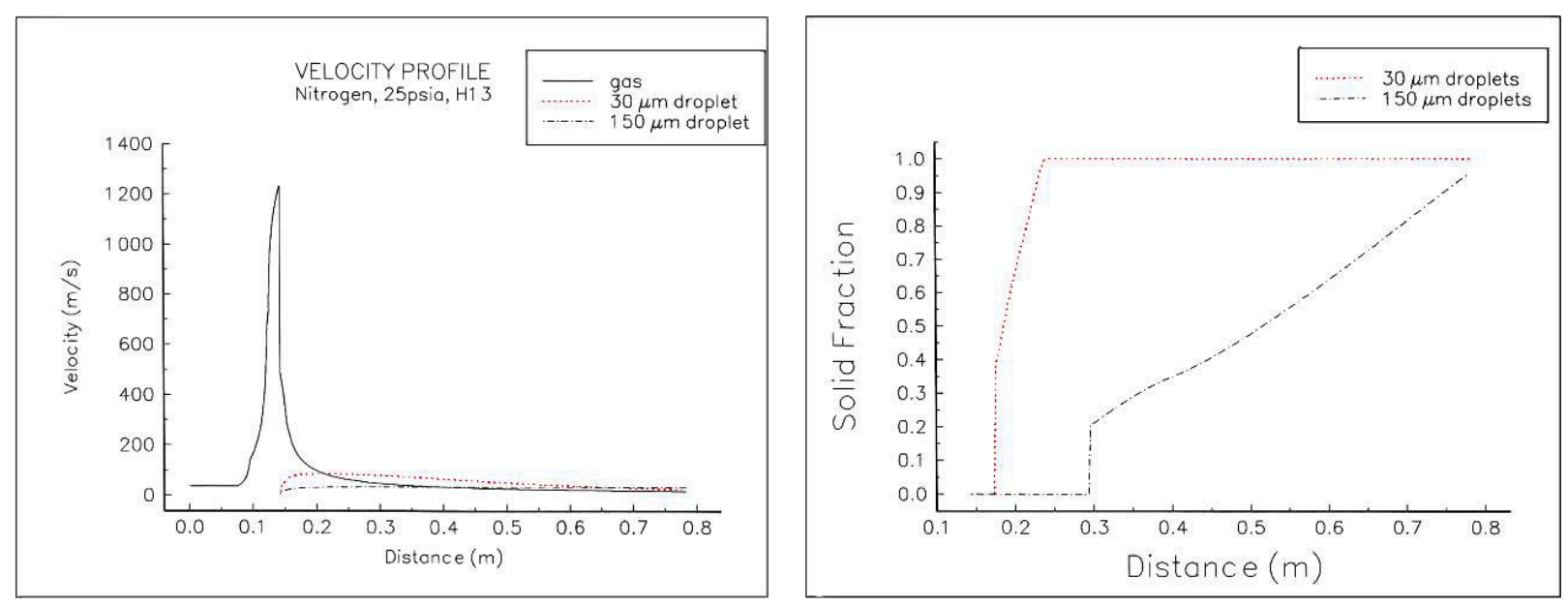

Figure 5. Calculated particle and gas behavior in nozzle and free jet regions. (a) Velocity profile. (b) Solid fraction. 

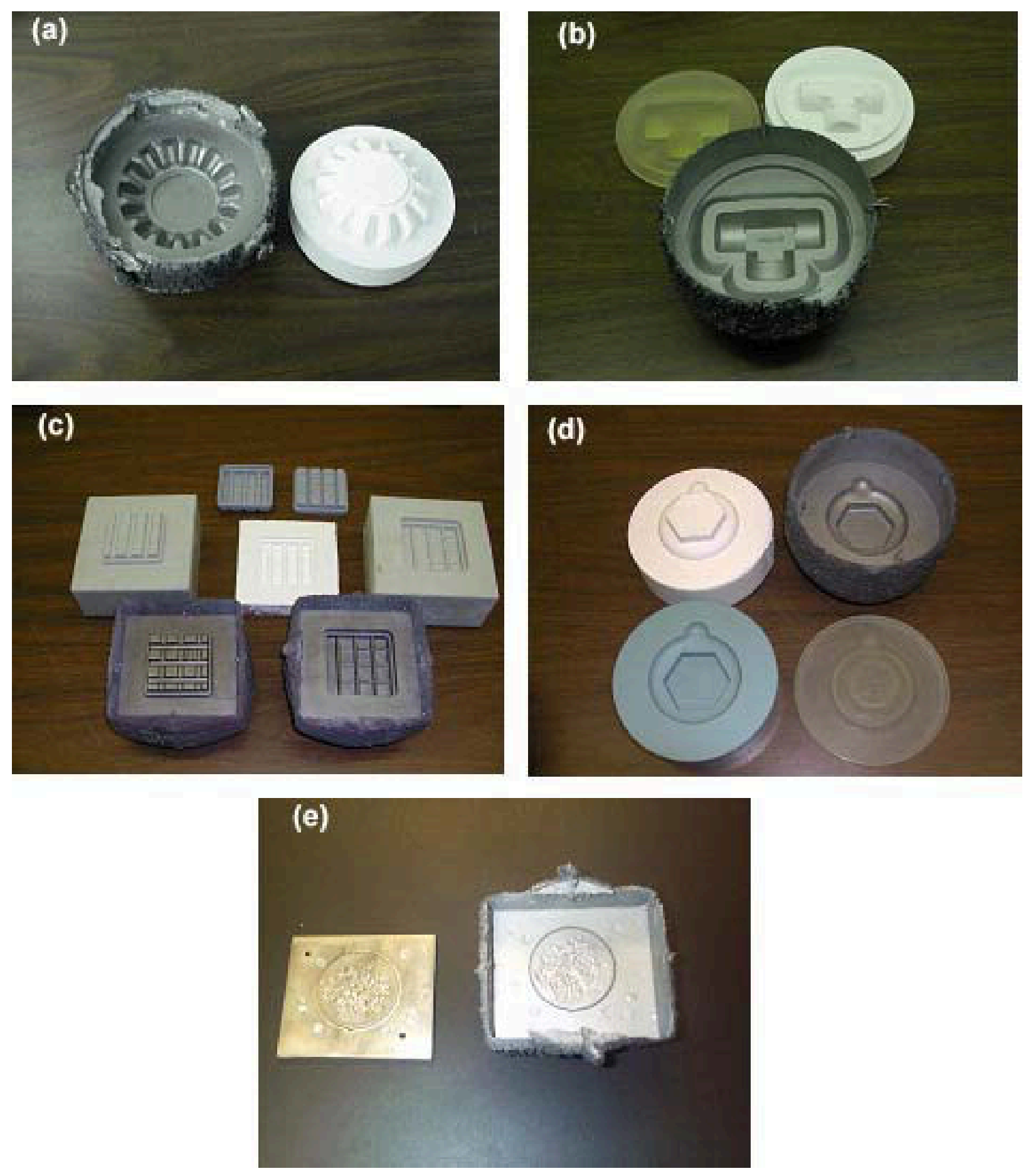

Figure 6. Examples of spray-formed H13 tool steel dies for various applications. (a) Forging die and ceramic tool pattern. (b) Forging die with stereolithography master and ceramic tool pattern. (c) Die casting dies, ceramic tool pattern, RTV molds, and stereolithography masters. (d) Die-casting die, ceramic tool pattern, RTV mold, and stereolithography master. (e) Embossing die and master. 
Table 4. Composition of H13 tool steel.

\begin{tabular}{lccccccc}
\hline Element & $\mathrm{C}$ & $\mathrm{Mn}$ & $\mathrm{Cr}$ & $\mathrm{Mo}$ & $\mathrm{V}$ & $\mathrm{Si}$ & $\mathrm{Fe}$ \\
\hline Stock H13 & 0.41 & 0.39 & 5.15 & 1.41 & 0.9 & 1.06 & Bal. \\
Spray-formed H13 & 0.41 & 0.38 & 5.10 & 1.42 & 0.9 & 1.08 & Bal. \\
\hline
\end{tabular}

3.4.1.5 Microstructure Analysis. The microstructure (nature and distribution of phases) and properties (hardness, strength, impact energy, etc.) of spray-formed H13 and other tool steel dies were found to be dictated by spray conditions (particularly cooling rate during deposition), post-deposition cooling rate of the die, and subsequent heat treatment of the die. Rapid cooling and solidification were found to suppress carbide precipitation and growth, allowing many tool steels to be artificially aged as an alternative to conventional heat treatment. Resultant properties of aged tool steels were unique and offered distinct benefits such as die life extension. The microstructure transformations that occur during spray forming and heat treatment of $\mathrm{H} 13$ tool steel are described below.

Figure 7 illustrates how the microstructure of $\mathrm{H} 13$ tool steel can be controlled by varying the cooling rate of the metal. It compares the microstructure of cast H13 tool steel (Figure 7a), which approached equilibrium solidification conditions, with as-deposited H13 that was rapidly cooled using forced-convection cooling (Figure 7b), or slowly cooled in still nitrogen (Figure 7c). Extensive interdendritic segregation, coarse carbides, and shrinkage voids characterize the cast material. Slow cooling of the spray-formed H13 generated a combination of bainite, martensite, retained austenite, and primary carbides. Rapid solidification of as-deposited $\mathrm{H} 13$ resulted in a high degree of supersaturation, the formation of martensite as the primary metallic phase, some lower bainite, and few primary carbides. Conventional heat treatment (austenitization/quench/temper) of the spray-formed sample of Figure $7 \mathrm{~b}$ generated a microstructure similar to forged H13 (Figure 7d). The higher magnification photomicrographs of Figure 8 illustrate the similarity in microstructure of commercial forged $\mathrm{H} 13$ and spray-formed $\mathrm{H} 13$ following a conventional heat treatment. Both samples were austenitized at $1010^{\circ} \mathrm{C}$ for $40 \mathrm{~min}$, air cooled, and double tempered $(2 \mathrm{~h}+2 \mathrm{~h})$ at $540^{\circ} \mathrm{C}$. The microstructure in both cases consisted of a few spheroidal carbide particles in a matrix of tempered martensite.

In general, refined microstructures consisting primarily of martensite with few primary carbides were obtained by forced convection cooling a spray-formed $\mathrm{H} 13$ tool steel die during deposition or by decreasing the deposition rate. The photomicrograph in Figure 9a illustrates the microstructure at the interior of a tool that was spray formed at a deposition rate of $2.7 \mathrm{~kg} / \mathrm{min}$. Figure 9 also shows the microstructure of the same material following a 2-h soak at $500^{\circ} \mathrm{C}$ (Figure 9b), aging for $1 \mathrm{~h}$ at $540^{\circ} \mathrm{C}$ and $1 \mathrm{~h}$ at $580^{\circ} \mathrm{C}$ (Figure9c), and following a 2-h soak at $650^{\circ} \mathrm{C}$ (Figure 9d). Material was also conventionally heat treated by austenitizing at $1010^{\circ} \mathrm{C}$ for $40 \mathrm{~min}$, quenching in air, and double tempering $(2 \mathrm{~h}+2 \mathrm{~h})$ at $540^{\circ} \mathrm{C}$ to yield the microstructure shown in Figure 9e. The microstructure in all these samples appears to largely be martensite with a few spheroidal particles of carbide. Similar microstructural results were obtained for an $\mathrm{H} 13$ tool steel die that was spray formed at an average deposition rate of $2.2 \mathrm{~kg} / \mathrm{min}$ in still nitrogen. Figure 10 illustrates the sectioned die (Figure 10a) and presents photomicrographs taken near the deposit/substrate interface (Figure 10b) and near the exposed surface (Figure 10c). Note the similarity in microstructure.

Quenching spray-formed H13 after solidification — in oil, water, or by forced convection - was less effective at refining microstructural features than quenching the material during deposition. Figure 11 compares the microstructure at the deposit/substrate interface and the interior of spray-formed H13 that was quenched in water immediately following deposition at a rate of about $3.0 \mathrm{~kg} / \mathrm{min}$. The microstructure near the deposit/substrate interface (Figures 11a and 11b) contained more martensite and fewer large primary carbides than the interior of the sample (Figure 11c) due to the higher cooling rate. 

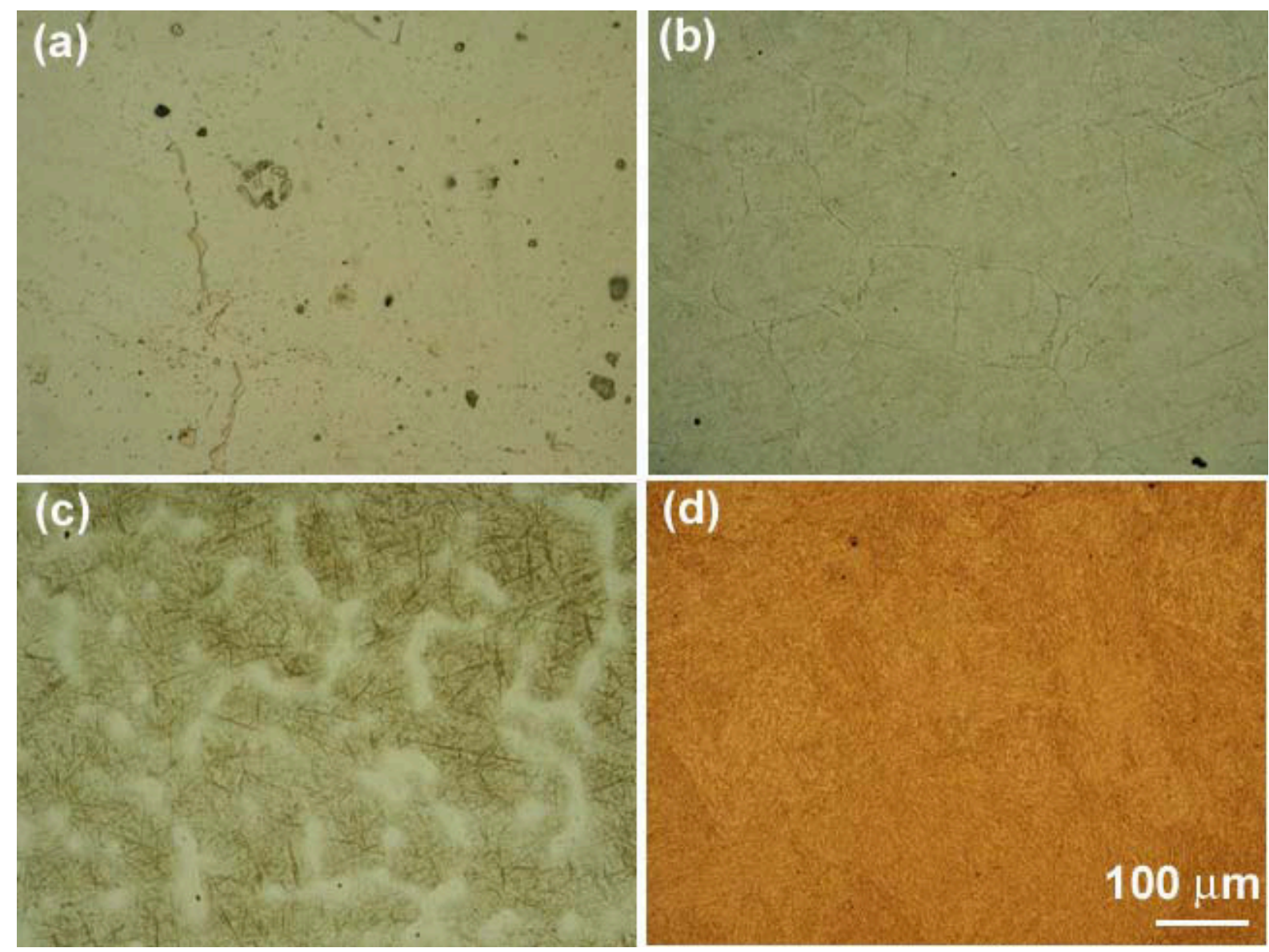

Figure 7. Photomicrographs of H13 tool steel. 3\% nital etch, 200X. (a) Cast. (b) As-deposited ("high" cooling rate). (c) As-deposited ("low" cooling rate). (d) Spray formed following conventional (austenitization/quench/temper) heat treatment.
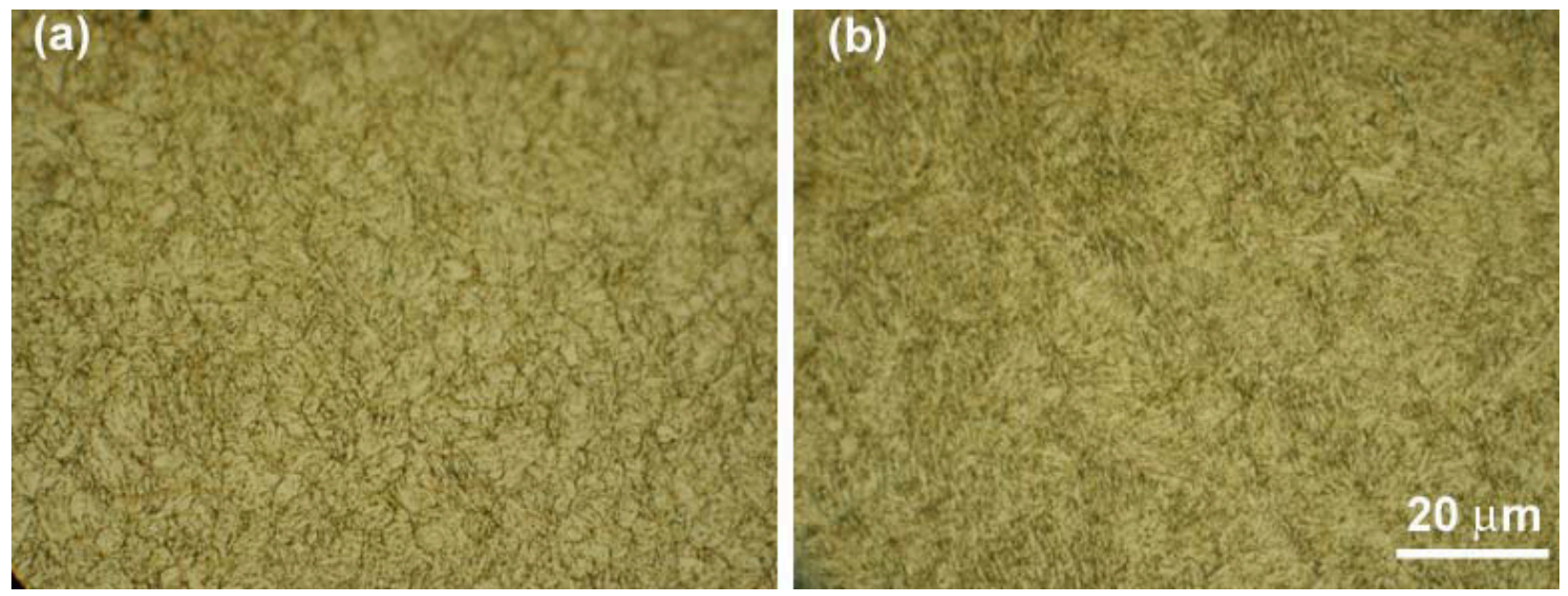

Figure 8. Photomicrographs of H13 tool steel following a conventional heat treatment. (a) Commercial forged. (b) Spray-formed. 


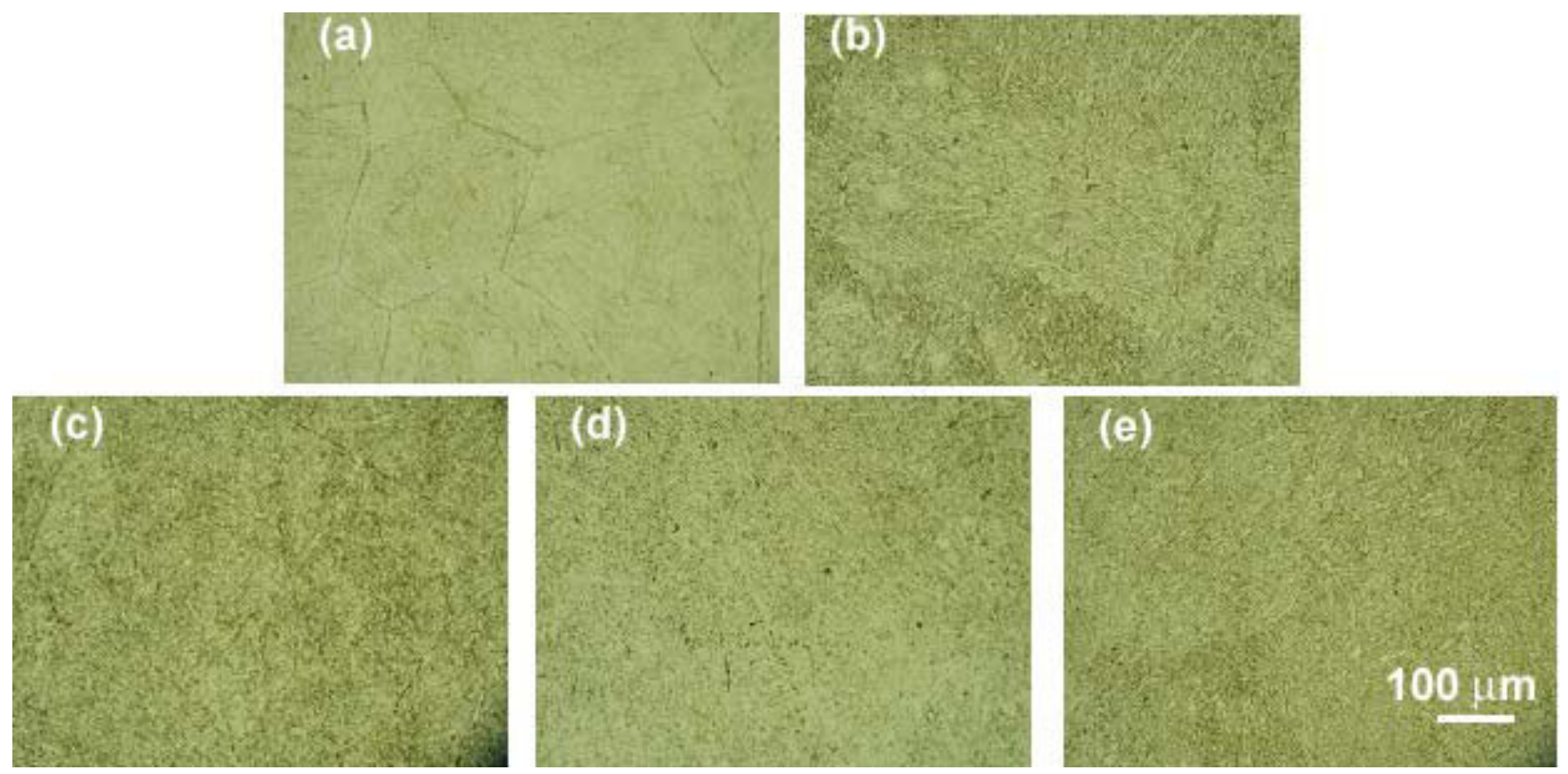

Figure 9. Photomicrographs of spray-formed/forced convection cooled H13. (a) As-deposited. (b) Aged at $500^{\circ} \mathrm{C}(2 \mathrm{~h})$. (c) Aged at $540^{\circ} \mathrm{C}(1 \mathrm{~h})$ and $580^{\circ} \mathrm{C}(1 \mathrm{~h})$. (d) Aged at $650^{\circ} \mathrm{C}(2 \mathrm{~h})$. (e) Conventional heat treatment.

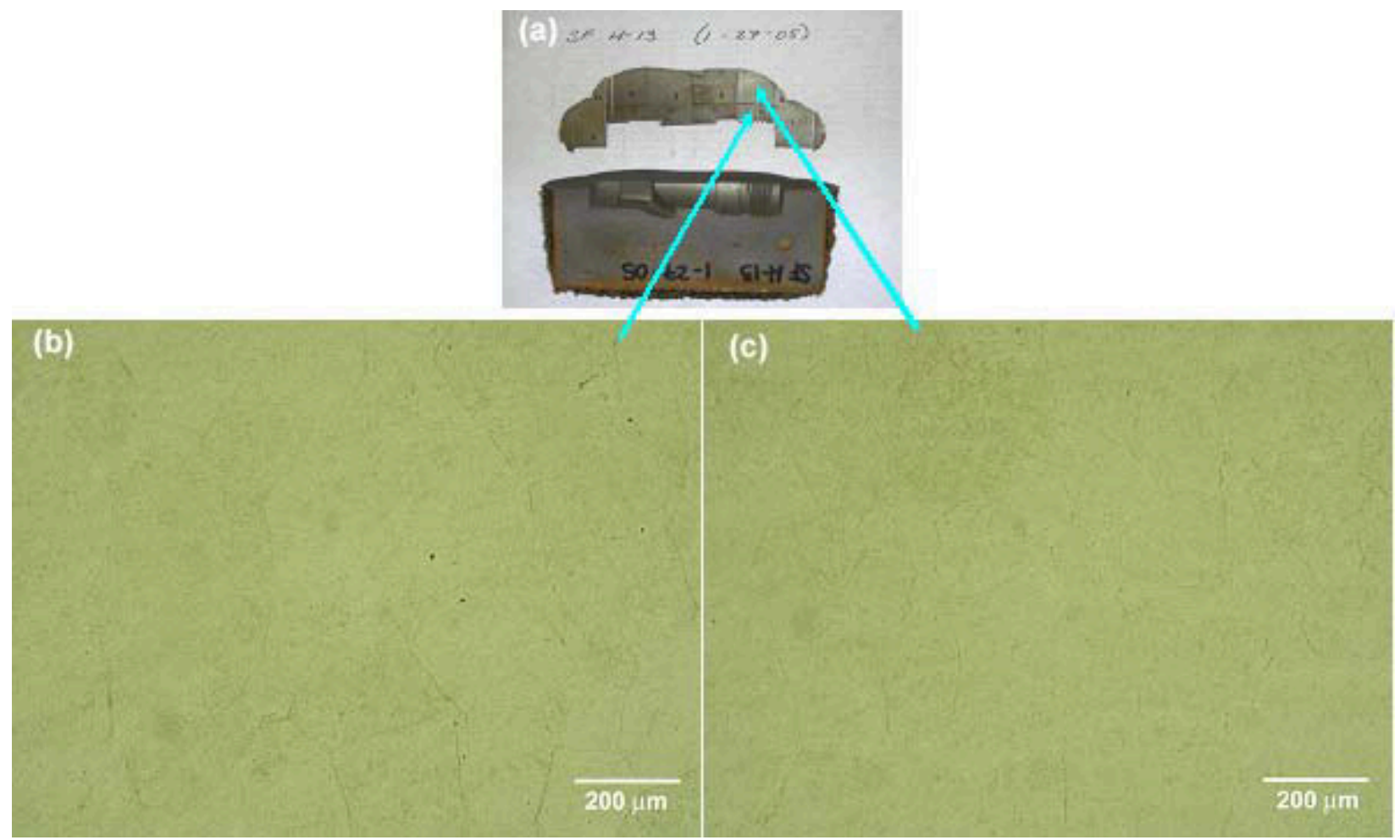

Figure 10. Microstructure of an $\mathrm{H} 13$ tool steel die that was spray formed in still nitrogen. (a) H13 tool steel die spray formed at $2.2 \mathrm{~kg} / \mathrm{min}$. (b) Photomicrograph near the deposit/substrate interface. (c) Photomicrograph near the exposed surface. 


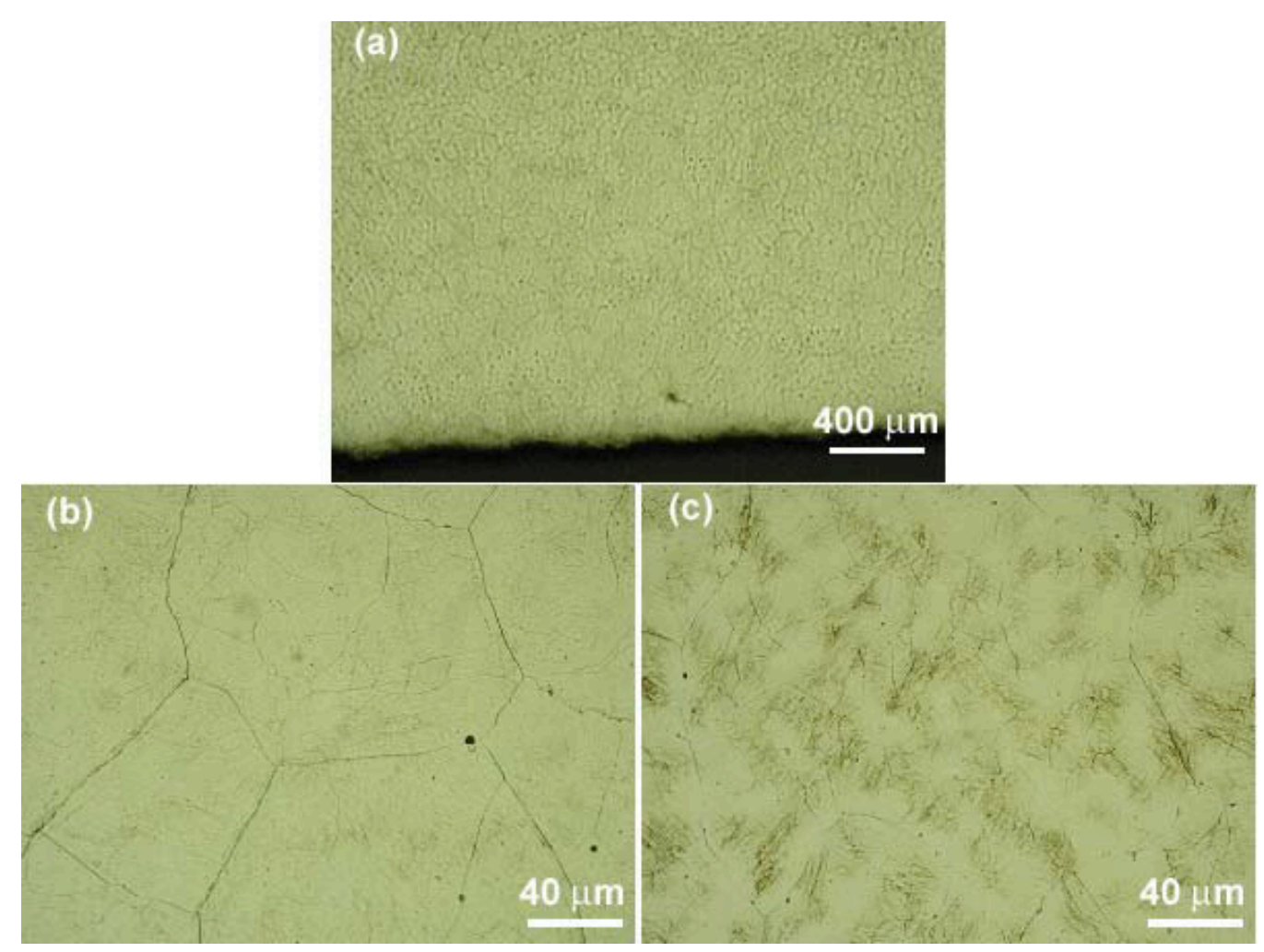

Figure 11. Photomicrographs of spray-formed and water-quenched H13 tool steel. (a),(b) Deposit/substrate interface. (c) Interior.

Figure 12 compares the microstructure of spray-formed H13 tool steel that was cooled rapidly by forced convection cooling (Figure 12a) and relatively slowly by free convection cooling in still nitrogen (Figure 12b) with commercial forged material that was cooled slowly from the austenitization region (Figure 12c) or slow cooled from the supersolidus region (Figure 12d). The microstructure in Figure 12a is largely martensite with few primary carbides, and less bainite and retained austenite than found in Figure $12 \mathrm{~b}$.

The cooling rates of samples shown in Figures $12 \mathrm{~b}$ and $12 \mathrm{~d}$ were the same and their microstructure is similar except that the scale of features observed for the spray-formed material was finer. Interestingly, the hardness of both as-deposited H13 samples was the same (55 HRC) and was significantly higher than that of the commercial forged H13 cooled from the supersolidus region (49 HRC).

An SEM image (backscattered electron [BSE] mode) of as-deposited H13 tool steel is shown in Figure 13. Energy-dispersive spectroscopic composition analysis of some features in the photomicrographs is also given. While exact quantitative data are not possible due to sampling volume limitations, results suggest that grain boundaries are particularly rich in V. Intragranular (matrix) regions are homogeneous and rich in Fe. BSE imaging clearly differentiates adjacent V-rich (dark) and Mo/Cr-rich carbides (light).

Figure 14 illustrates the microstructure of spray-formed $\mathrm{H} 13$ aged at $500^{\circ} \mathrm{C}$ for $2 \mathrm{~h}$. The most prominent change is the appearance of very fine carbide precipitates, particularly VC. The precipitation of these small carbide particles is accompanied by a rise in hardness of about 3 units on the Rockwell $\mathrm{C}$ scale. The surrounding matrix remained enriched in Fe. Increasing the soak temperature to $700^{\circ} \mathrm{C}$ resulted in prominent carbide coarsening, the formation of $\mathrm{M}_{7} \mathrm{C}_{3}$ and $\mathrm{M}_{6} \mathrm{C}$ carbides, and a decrease in hardness. 

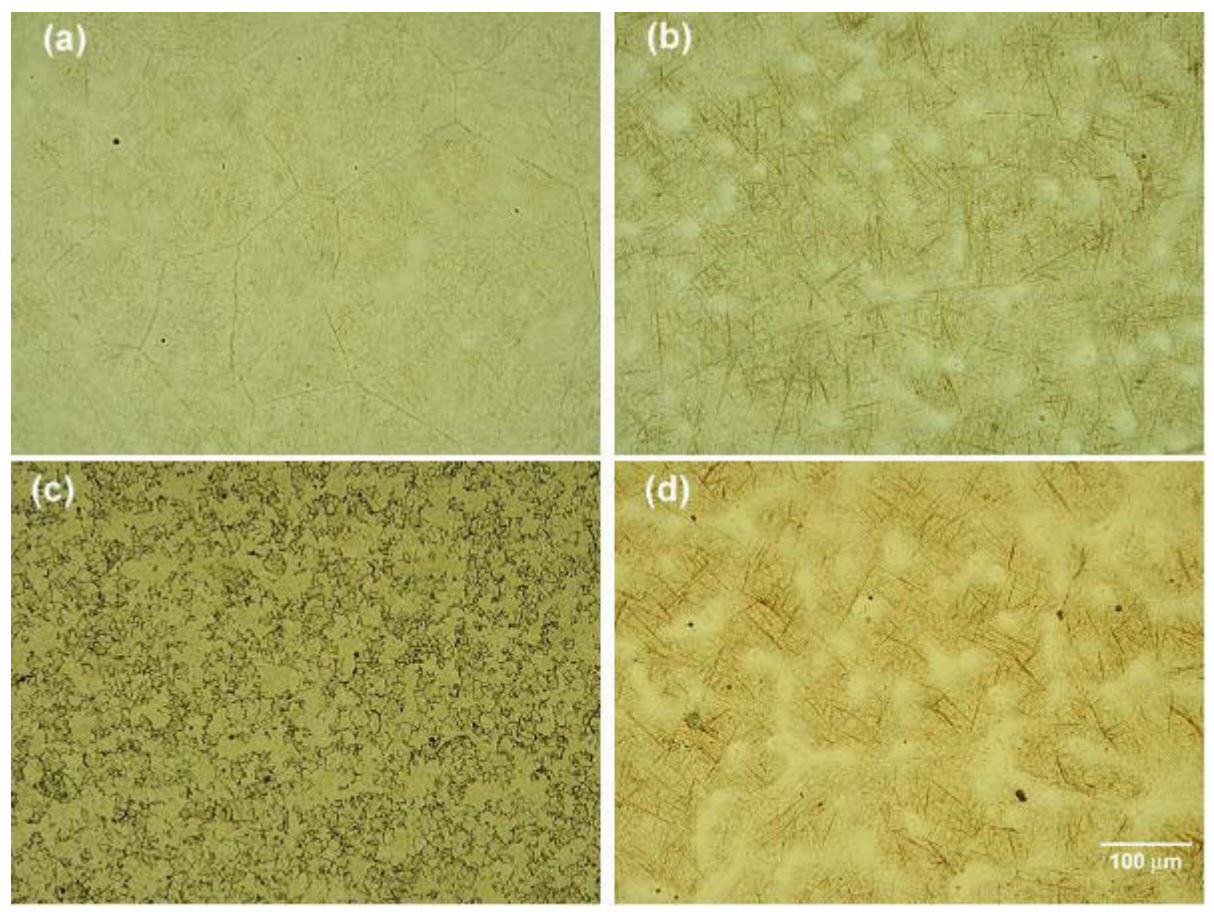

Figure 12. Photomicrographs of H13 tool steel. (a) As-deposited, forced convection cooled, 55 HRC. (b) As-deposited, free-convection-cooled, $55 \mathrm{HRC}$. (c) Commercial forged, slow cooled from $1050^{\circ} \mathrm{C}$, 40 HRC. (d) Commercial forged, slow cooled from $1423^{\circ} \mathrm{C}, 49 \mathrm{HRC}$.

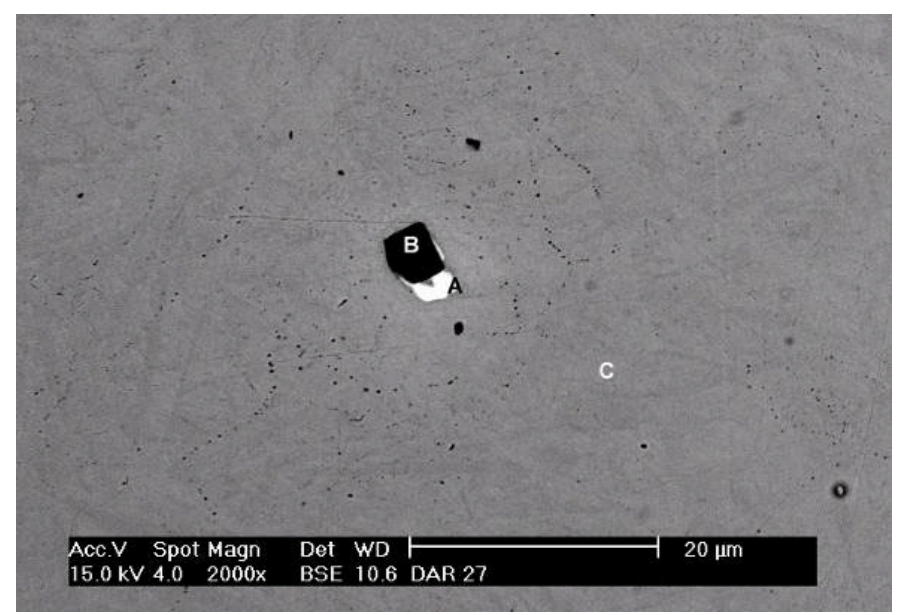

\begin{tabular}{|c|c|c|c|c|c|c|}
\hline Spot & $\begin{array}{c}\mathrm{Fe} \\
(\mathrm{wt} \%)\end{array}$ & $\begin{array}{c}\mathrm{Cr} \\
(\mathrm{wt} \%)\end{array}$ & $\begin{array}{c}\mathrm{V} \\
(\mathrm{wt} \%)\end{array}$ & $\begin{array}{c}\mathrm{Mo} \\
(\mathrm{wt} \%)\end{array}$ & $\begin{array}{c}\mathrm{Mn} \\
(\mathrm{wt} \%)\end{array}$ & $\begin{array}{c}\mathrm{Si} \\
(\mathrm{wt} \%)\end{array}$ \\
\hline $\mathrm{A}$ & 81.65 & 7.55 & 1.11 & 6.86 & 1.47 & 1.36 \\
\hline $\mathrm{B}$ & 3.25 & 8.19 & 84.40 & 4.07 & 0 & 0.09 \\
\hline $\mathrm{C}$ & 89.38 & 5.16 & 1.01 & 1.73 & 1.45 & 1.27 \\
\hline
\end{tabular}

Figure 13. SEM photomicrograph (BSE mode) of as-deposited H13 tool steel showing adjacent V-rich (dark) and Mo/Cr-rich (light) carbides. Table gives EDS composition of features. 


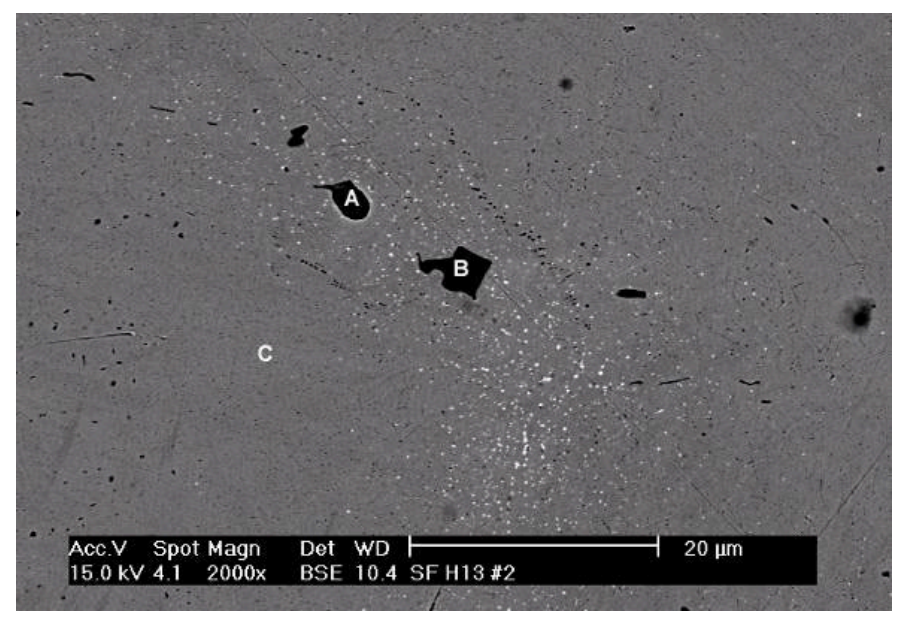

\begin{tabular}{|c|c|c|c|c|c|c|}
\hline Spot & $\begin{array}{c}\mathrm{Fe} \\
(\mathrm{wt} \%)\end{array}$ & $\begin{array}{c}\mathrm{Cr} \\
(\mathrm{wt} \%)\end{array}$ & $\begin{array}{c}\mathrm{V} \\
(\mathrm{wt} \%)\end{array}$ & $\begin{array}{c}\mathrm{Mo} \\
(\mathrm{wt} \%)\end{array}$ & $\begin{array}{c}\mathrm{Mn} \\
(\mathrm{wt} \%)\end{array}$ & $\begin{array}{c}\mathrm{Si} \\
(\mathrm{wt} \%)\end{array}$ \\
\hline $\mathrm{A}$ & 10.40 & 2.95 & 0.47 & 49.88 & 36.17 & 0.13 \\
\hline $\mathrm{B}$ & 3.15 & 5.90 & 89.02 & 0.90 & 0.52 & 0.51 \\
\hline $\mathrm{C}$ & 89.44 & 5.02 & 0.95 & 1.80 & 1.35 & 1.44 \\
\hline
\end{tabular}

Figure 14. SEM photomicrograph (BSE mode) of spray-formed $\mathrm{H} 13$ tool steel aged at $500^{\circ} \mathrm{C}$ for $2 \mathrm{~h}$. Table gives results of EDS analysis of features.

The optical microscope (OM) image of as-deposited $\mathrm{H} 13$ deposited at a rate of $2.7 \mathrm{~kg} / \mathrm{min}$ in still nitrogen (Figure 15a) exhibits dark acicular features separated by bright regions. The SEM image, Figure 15b, reveals the details of theses features. In Region A of Figure 15b, corresponding to the dark acicular features, carbides can be seen between and inside ferrite, indicating a typical lower bainite structure. In Region B of Figure 15b, corresponding to white regions in Figure 15a, a needle-like martensite structure can be observed. Also, proeutectoid carbides can be observed (white particles indicated by arrows) in Figure 15b. Figures 16a and 16b show high magnification SEM micrographs with enhanced resolution of lower bainite and martensite. To confirm the above SEM observation, TEM analysis was performed. The TEM bright field image in Figure 17 exhibits typical lower bainite morphology: bainitic ferrite (labeled "A"), $(\mathrm{Fe}, \mathrm{M})_{3} \mathrm{C}$ carbides (where $\mathrm{M}$ represents the alloying elements $\mathrm{Cr}, \mathrm{V}$, and Mo substituting for $\mathrm{Fe}$ in the lattice of $\mathrm{Fe}_{3} \mathrm{C}$ carbide) between bainitic ferrite and inside bainitic ferrite. Figure 18 shows the TEM bright field image of martensite and the corresponding diffraction pattern. Figure 19 shows the TEM morphology of retained austenite. X-ray diffraction (XRD) analysis was also performed to identify the phases in as-deposited H13, as shown in Figure 20. Only the peaks corresponding to ferrite in lower bainite and martensite can be detected. No peaks correspond to carbides and retained austenite.

Spray-formed $\mathrm{H} 13$ was artificially aged at $630^{\circ} \mathrm{C}$ for $2 \mathrm{~h}+2 \mathrm{~h}$ and characterized using TEM. The low magnification TEM micrograph in Figure 21a shows the overall morphology of the aged H13. The needles in tempered lower bainite regions are wider than those in the tempered martensite and retained austenite, since the former is formed at a higher temperature than the latter. Figures $21 \mathrm{~b}$ and $21 \mathrm{c}$ show the higher magnification TEM micrographs corresponding to tempered lower bainite, and tempered martensite and retained austenite, respectively. Comparing Figure 17 with Figure 22b, it is seen that the needle-like morphology for carbides does not exist anymore. Figures $22 \mathrm{a}$ and $22 \mathrm{~b}$ indicate that needlelike (Fe, $\mathrm{M})_{3} \mathrm{C}$ decomposes during aging and the remaining $(\mathrm{Fe}, \mathrm{M})_{3} \mathrm{C}$ exhibits either short rod-like or granular geometry. Furthermore, based on the results of selected area diffraction (SAD) analysis in 

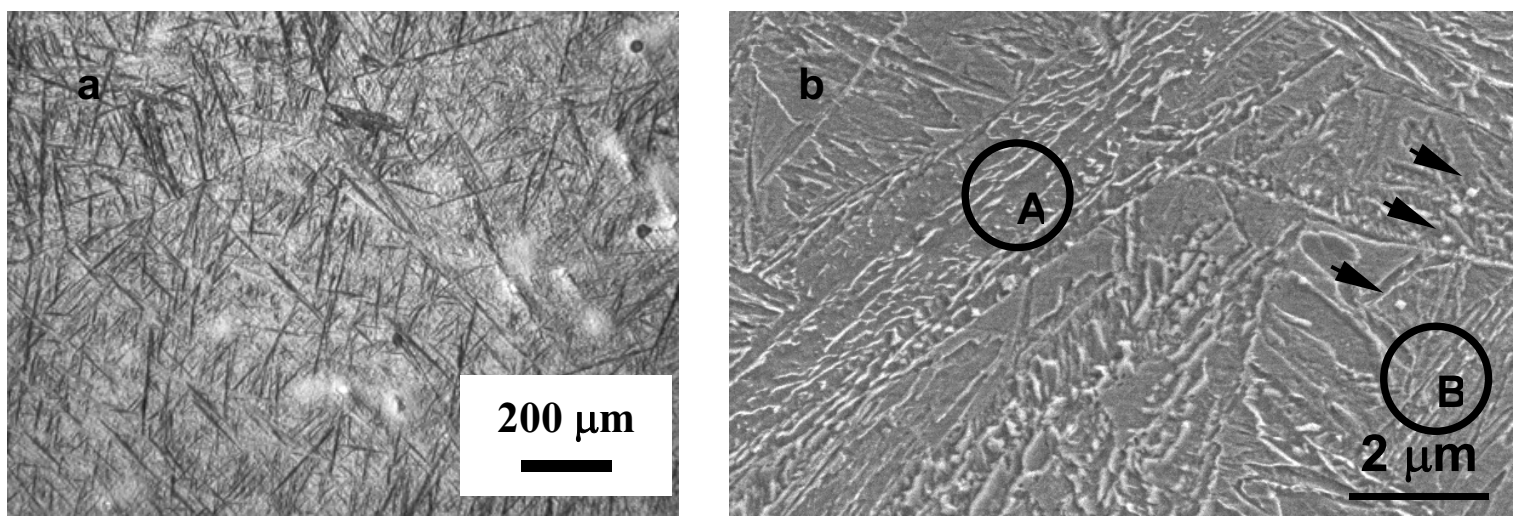

Figure 15. Microstructures of as-deposited H13. (a) OM. (b) SEM.
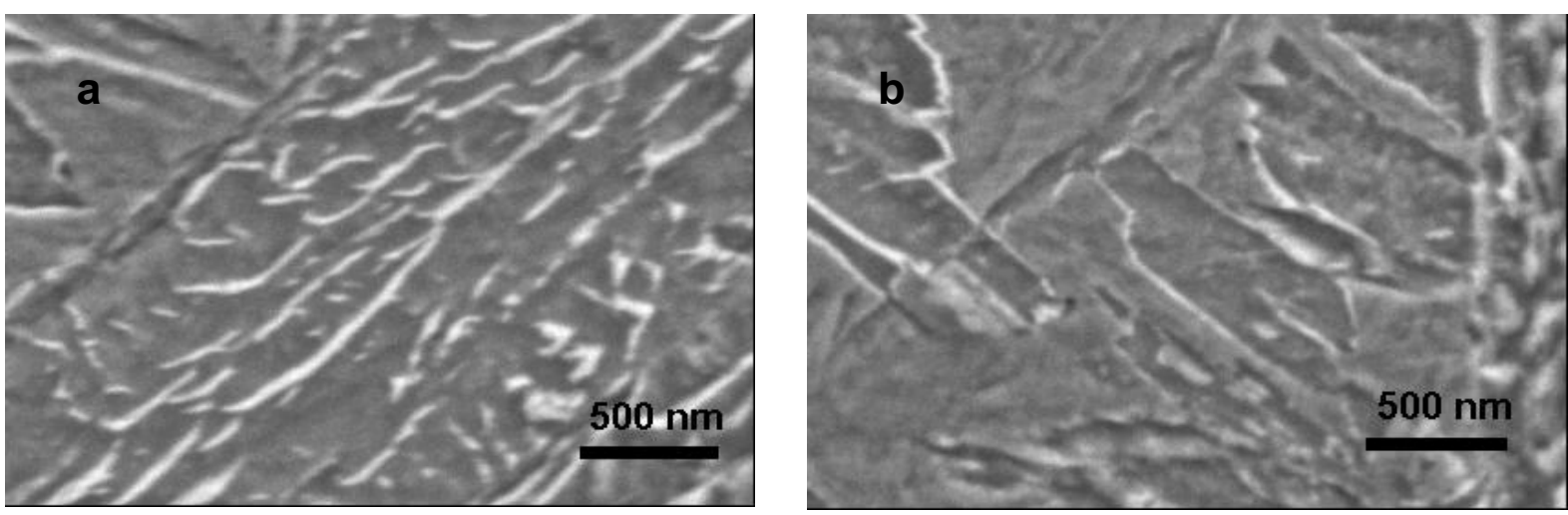

Figure 16. High magnification SEM micrographs of (a) lower bainite and (b) martensite.

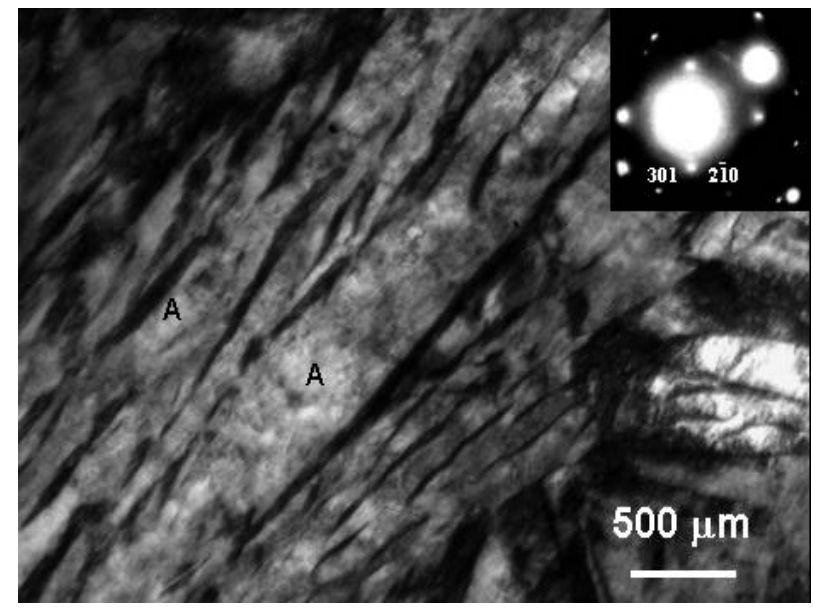

Figure 17. TEM micrograph of lower bainite. Bright field image and diffraction pattern of $(\mathrm{Fe}, \mathrm{M})_{3} \mathrm{C}$. 


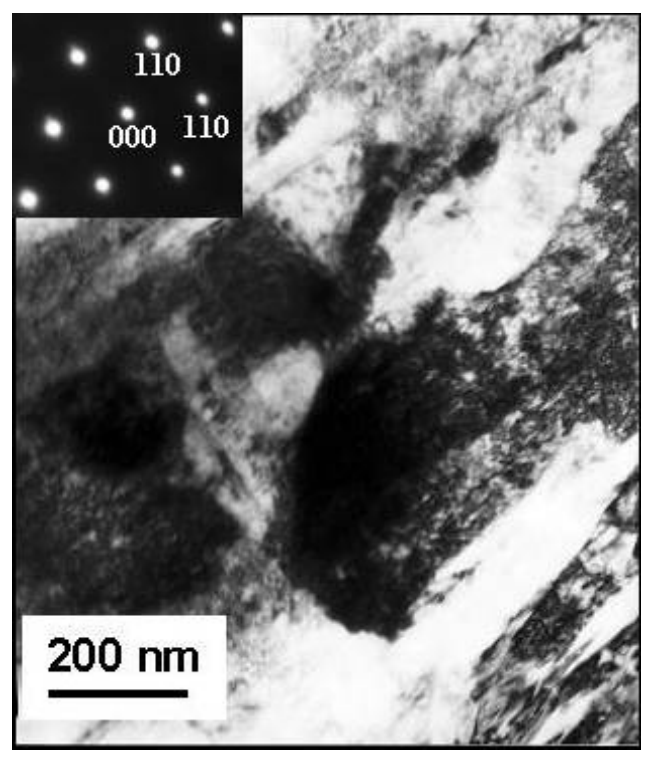

Figure 18. TEM micrograph of martensite. Bright field image and diffraction pattern.
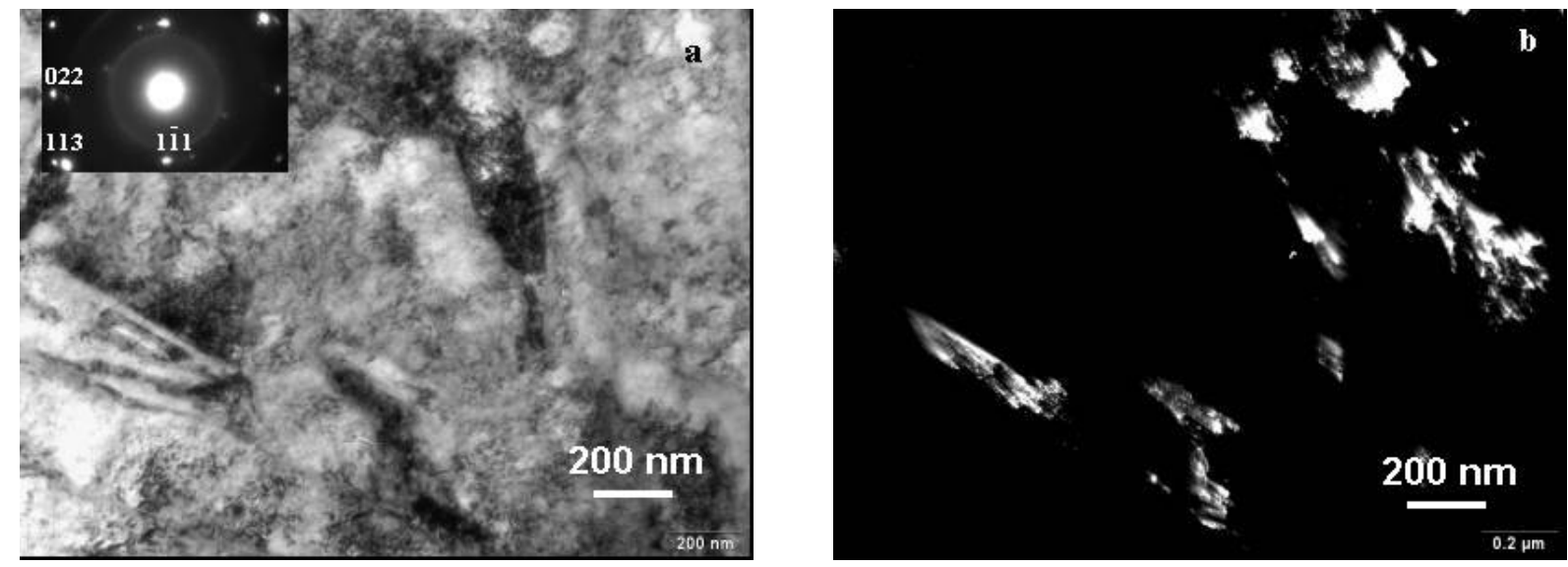

Figure 19. TEM micrograph showing retained austenite. (a) Bright field image and diffraction pattern. (b) ark field image from the diffraction spot $1 \overline{1} 1$ 


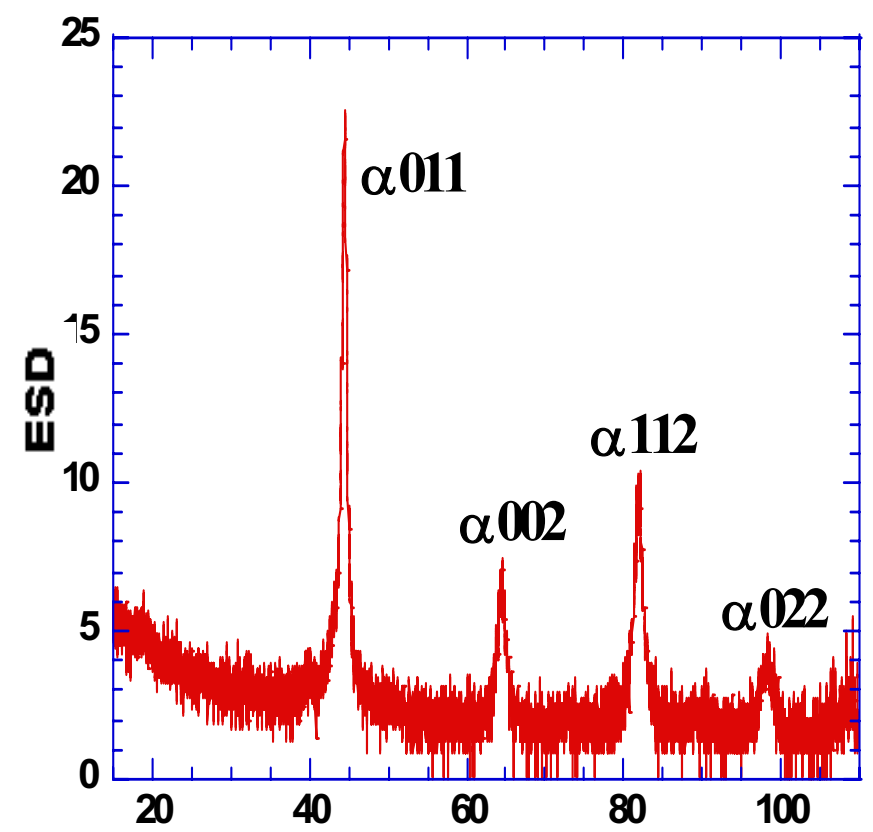

Figure 20. X-ray diffraction pattern of as-spray formed H13.
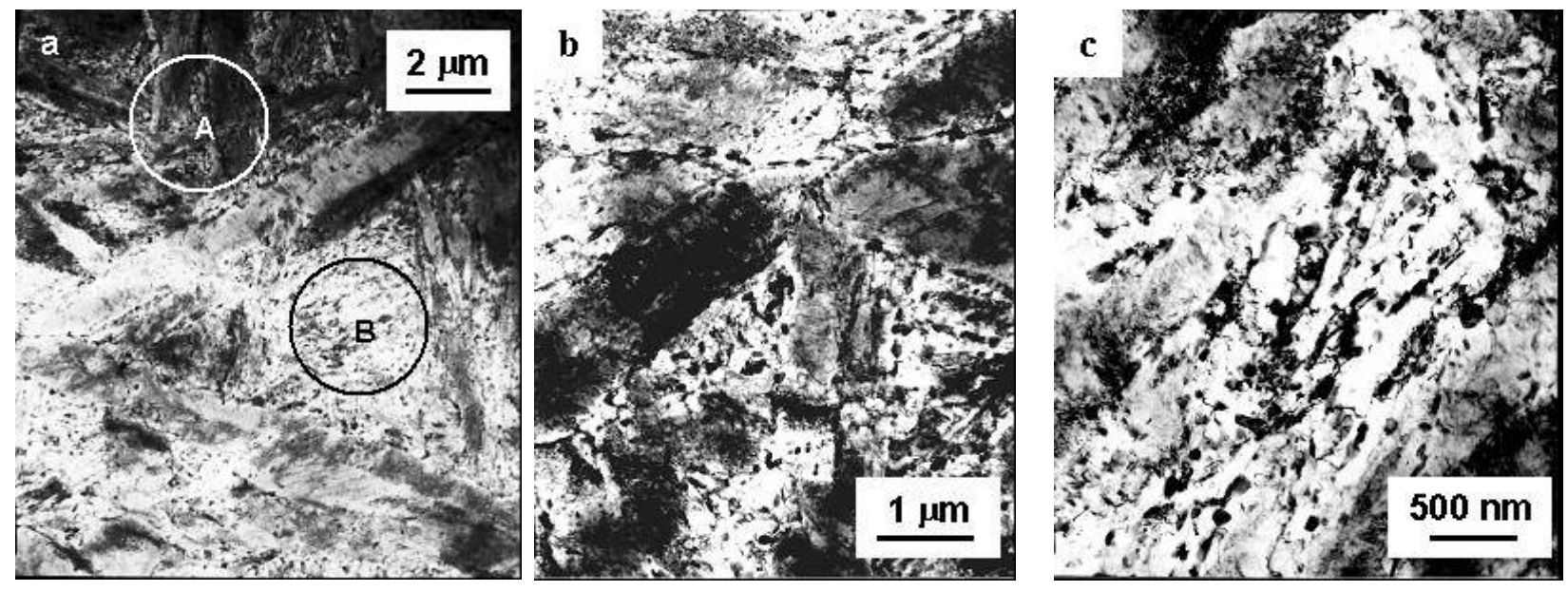

Figure 21. TEM micrographs of spray-formed and aged H13. (a) Overall morphology (Region A: tempered lower bainite; Region B: tempered martensite and retained austenite). (b) Morphology of tempered lower bainite. (c) Tempered martensite and retained austenite. 

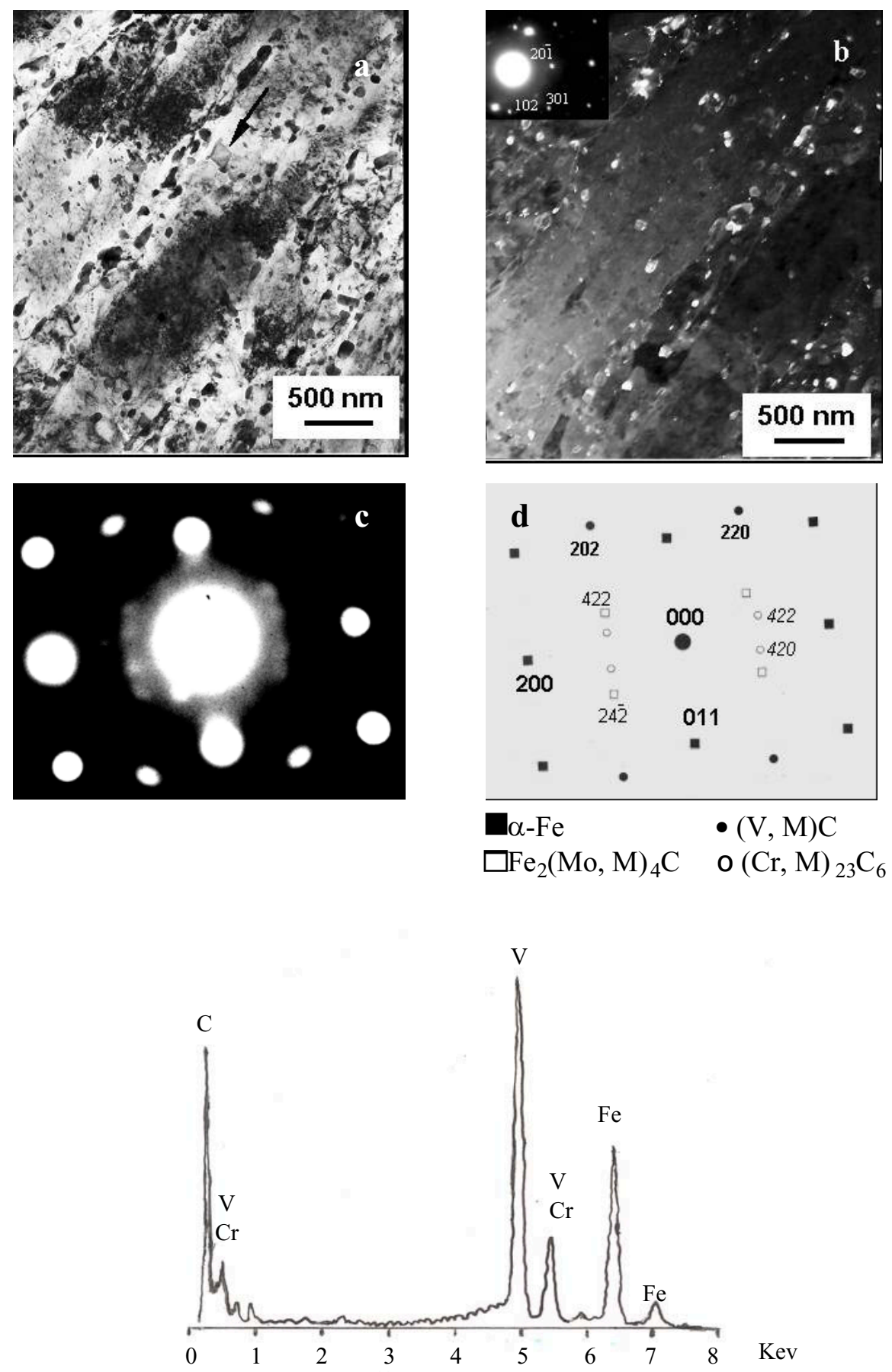

(e)

Figure 22. Analysis of spray-formed and aged H13. (a) TEM bright field image showing microstructure in tempered lower bainite. (b) Diffraction pattern of $(\mathrm{Fe}, \mathrm{M})_{3} \mathrm{C}$ and TEM dark field image from the diffraction spot $20 \overline{1}$. (c) Diffraction patterns of martensite and various alloying carbides in tempered lower bainite. (d) Indexed diffraction patterns that are reproduced from the diffraction patterns in (c). (e) EDS spectrum of proeutectoid carbide indicated by the arrow in (a). 
Figures $22 \mathrm{c}$ and $22 \mathrm{~d}$, three types of alloying carbides precipitate from the bainitic ferrite: $(\mathrm{V}, \mathrm{M}) \mathrm{C},(\mathrm{Cr}$, $\mathrm{M})_{23} \mathrm{C}_{6}$, and $\mathrm{Fe}_{2}(\mathrm{Mo}, \mathrm{M})_{4} \mathrm{C}$, where $\mathrm{M}$ represents $\mathrm{Fe}$ and other alloying elements substituting $\mathrm{V}$, $\mathrm{Cr}$, and Mo in the lattice of $\mathrm{VC}, \mathrm{Cr}_{23} \mathrm{C}_{6}$, and $\mathrm{Fe}_{2} \mathrm{Mo}_{4} \mathrm{C}$ carbides, respectively. These three types of alloying carbides are also found in the tempered martensite and the tempered retained austenite. (The SAD results corresponding to the tempered martensite and the tempered retained austenite are not shown here.) By comparing the proeutectoid carbide particles indicated by arrows in Figures 15b and 22a, it is seen that the morphology and size of the proeutectoid carbide remain unchanged during aging. Figure $22 \mathrm{e}$ shows the EDS spectrum of the proeutectoid carbide particle in Figure 22a, indicating that the proeutectoid carbide is V-rich. Since the morphology and size remain unchanged during aging, the proeutectoid carbide should be of $(\mathrm{V}, \mathrm{M}) \mathrm{C}$ type (i.e., a type of equilibrium $\mathrm{V}$-rich carbide).

3.4.1.6 Porosity. High levels of porosity in tool steels are detrimental because porosity can significantly reduce strength, toughness, hardness, and other properties. Porosity was studied using OM in conjunction with image analysis using Analysis ${ }^{\mathrm{TM}}$ software on the polished and unetched surface of an $\mathrm{H} 13$ tool steel deposit spray formed at $3.0 \mathrm{~kg} / \mathrm{min}$. Samples were sectioned from three locations: the deposit/substrate interface, central region, and exposed surface. Results are summarized in Table 5. In all of the samples, porosity is less than $1 \%$. Similar results were obtained for material spray formed at other rates. For example, the density of the sections shown in Figure 10 (spray formed at $2.2 \mathrm{~kg} / \mathrm{min}$ ) was $7.69 \mathrm{~g} / \mathrm{cm}^{3}$, i.e., $99.2 \%$ of theoretical density, while at the exposed surface the density was $7.71 \mathrm{~g} / \mathrm{cm}^{3}$ (99.5\% of theoretical density). Density measurements made by water displacement using Archimedes' Principle agreed with results from image analysis.

3.4.1.7 Tensile Properties. Insufficient strength can result in catastrophic die failure. While not normally a concern, poor processing can result in reduced strength due to inclusions or segregate coring. Table 6 gives the ultimate tensile strength and yield strength of spray-formed $(3 \mathrm{~kg} / \mathrm{min})$, cast, and forged/heat treated $\mathrm{H} 13$ tool steel measured at test temperatures of 22 and $550^{\circ} \mathrm{C}$. Values for sprayformed $\mathrm{H} 13$ are given in the as-deposited condition and following artificial aging and conventional heat treatments. The strength of the spray-formed material compares favorably with forged material and is considerably higher than that of cast tool steel. Spray-formed H13 is shown to retain its strength somewhat better than forged/heat treated H13 at higher temperatures.

3.4.1.8 Impact Energy. Impact energy is the energy absorbed during fracture, and is a measure of a steel's toughness or its ability to resist fracture. Impact energy correlates with a steel's carbon content, heat treatment, hardness, strength, and surface quality. Impact energy analysis was conducted at room temperature on spray-formed $\mathrm{H} 13$ tool steel in the as-deposited condition, following artificial aging, and following conventional heat treatment. Various deposition rates and quenching media were used in an effort to modify carbide formation and growth and the nature of the matrix phase, both of which strongly influence toughness. Spray-formed samples were produced at a deposition rate of (1) $3 \mathrm{~kg} / \mathrm{min}$ followed by cooling in still nitrogen, (2) at $3 \mathrm{~kg} / \mathrm{min}$ followed by oil quenching, and (3) at $1.7 \mathrm{~kg} / \mathrm{min}$ with still nitrogen cooling. The impact energy data for spray-formed samples reflect bulk rather than surface microstructural features and were strongly influenced by the amount of free carbide and the phases present in the surrounding matrix (martensite and bainite). $\mathrm{H} 13$ tool steel spray formed at $1.7 \mathrm{~kg} / \mathrm{min}$ had higher impact energy than material produced at $3 \mathrm{~kg} / \mathrm{min}$. Oil quenched and still-nitrogen cooled $\mathrm{H} 13$ tool steel spray formed at $3 \mathrm{~kg} / \mathrm{min}$ had similar impact energy values for a given heat treatment, suggesting that the cooling rate of the deposits during their formation more strongly influenced carbide coarsening and growth than did the post-deposition cooling rate. Both commercial forged $\mathrm{H} 13$ and spray-formed material produced at $1.7 \mathrm{~kg} / \mathrm{min}$ that were conventionally heat treated had similar impact energy values of 11-20 J. As-deposited and peak age hardened spray-formed H13 had similar impact energy values of 3$5 \mathrm{~J}$, while the value for overaged spray-formed material was somewhat higher $(5-8 \mathrm{~J})$. 
Table 5. Porosity in spray-formed H13 steel samples.

\begin{tabular}{|l|c|l|c|}
\hline \multirow{2}{*}{ Sample location } & Sample No. & \multicolumn{1}{|c|}{ Heat Treatment } & $\begin{array}{c}\text { Porosity } \\
\text { (vol.\%) }\end{array}$ \\
\hline \multirow{2}{*}{ Deposit/Substrate Interface } & 1 & As-deposited & 0.10 \\
\cline { 2 - 4 } & 2 & $500^{\circ} \mathrm{C} \times 2 \mathrm{~h}$ & 0.12 \\
\cline { 2 - 4 } & 3 & $630^{\circ} \mathrm{C} \times(2 \mathrm{~h}+2 \mathrm{~h})$ & 0.71 \\
\hline Exposed Surface & 4 & As-deposited & 0.05 \\
\hline Middle & 5 & $1052^{\circ} \mathrm{C}$ (air quenching) \& $593^{\circ} \mathrm{C} \times(2 \mathrm{~h}+2 \mathrm{~h})$ & 0.55 \\
\hline
\end{tabular}

Table 6. H13 tool steel mechanical properties.

\begin{tabular}{|c|c|c|c|}
\hline Sample/Heat Treatment & $\begin{array}{c}\text { Ultimate Tensile } \\
\text { Strength } \\
(\mathrm{ksi})\end{array}$ & $\begin{array}{c}\text { Yield Strength } \\
(\mathrm{ksi})\end{array}$ & $\begin{array}{c}\text { Test } \\
\text { Temperature } \\
\left({ }^{\circ} \mathrm{C}\right) \\
\end{array}$ \\
\hline Spray-formed/as-deposited & 154 & 138 & 22 \\
\hline Spray-formed/aged at $540^{\circ} \mathrm{C}$ & 285 & 273 & 22 \\
\hline Spray-formed/aged at $540^{\circ} \mathrm{C}$ & 239 & 214 & 550 \\
\hline Spray-formed/conventional heat treatment ${ }^{\mathrm{a}}$ & 197 & 168 & 22 \\
\hline Cast & 87 & $\square^{\mathrm{b}}$ & 22 \\
\hline Cast/conventional heat treatment ${ }^{\mathrm{a}}$ & 128 & ${ }^{\mathrm{b}}$ & 22 \\
\hline Commercial forged/heat treated ${ }^{\mathrm{a}}$ & 261 & 244 & 22 \\
\hline Commercial forged/heat treated ${ }^{\mathrm{a}}$ & 192 & 181 & 550 \\
\hline
\end{tabular}

3.4.1.9 Hardness. Hardness is one of the most commonly quoted properties of tool steels, and high hardness following heat treatment is a common objective-provided it does not detrimentally affect toughness. As a measure of the localized strength of a particular microstructure, hardness is related to the chemistry, crystal structure, phases, and phase distribution of the steel. With spray-formed H13 tool steel, it was found that hardness (as well as other properties) could be tailored using a relatively low temperature aging heat treatment as well as the conventional heat treatment.

A typical aging curve for spray-formed H13 tool steel is shown in Figure 23. The shape is similar to a Class 4 tempering curve of a medium-alloyed hot-work die steel but with a pronounced secondary hardening peak. Aging was performed by soaking samples for $1 \mathrm{~h}$ at temperatures ranging from 300 to $700^{\circ} \mathrm{C}$. As-deposited hardness, measured using a microindentation (Vickers) approach, was $59 \mathrm{HRC}$ for this sample. This is significantly higher than the hardness of commercial material following a conventional heat treatment (see Figure 23), even at high austenitization temperatures. As the soak temperature increased, there was an initial decrease in hardness due to stress relieving. This was followed by a rise in hardness to a peak age hardness of $62 \mathrm{HRC}$. SEM/EDS analysis indicated that this rise in hardness was accompanied by precipitation of very fine VC carbides, and to a lesser extent, Mo- and Cr-rich carbides. These carbides coarsened as the soak temperature increased. 
As-deposited H13 tool steel was also hardened following the conventional heat treatment cycle used with commercial material. Samples of forged/mill annealed commercial and spray-formed materials were austenitized at $1010^{\circ} \mathrm{C}$, air quenched, and double tempered $(2 \mathrm{~h}+2 \mathrm{~h})$ at $538^{\circ} \mathrm{C}$. The microstructure in both cases was found to be tempered martensite with a few spheroidal particles of alloy carbide. Hardness values for both materials were very nearly identical.

The bar plot in Figure 24 summarizes mid-sample hardness values for as-deposited H13 tool steel, spray-formed/aged H13 following 2-h soaks at temperature, and spray-formed and commercial forged H13 following a conventional heat treatment. Following deposition, spray-formed material was cooled in still nitrogen or oil. Results indicated that as-deposited H13 had a hardness of about $56 \mathrm{HRC}$, regardless of post-deposition quench rate. Soaking the material at $500^{\circ} \mathrm{C}$ for $2 \mathrm{~h}$ increased the hardness by several units on the Rockwell C scale. As discussed previously, SEM/EDS analysis indicated that this rise in hardness corresponded primarily to the precipitation of very small MC-type vanadium carbides. Increasing the soak temperature resulted in a decrease in hardness, which was accompanied by the precipitation and coarsening of chromium and molybdenum carbides. The post-deposition cooling rate of the spray-formed steel did not seem to greatly influence hardness response to aging.

Microindentation (Vickers) hardness measurements were made along the cross section of an asdeposited H13 die that was cooled in still nitrogen. Hardness values, shown in Figure 25, were found to be graded over about two Rockwell $\mathrm{C}$ units from the somewhat higher values at the deposit/pattern interface to the exposed surface. The somewhat higher hardness at the die's deposit/pattern interface is attributable to shrinkage stresses and supersaturation due to a higher quench rate, while slight carbide coarsening near the exposed surface accounts for the somewhat lower hardness shown at the top of Figure 25 .

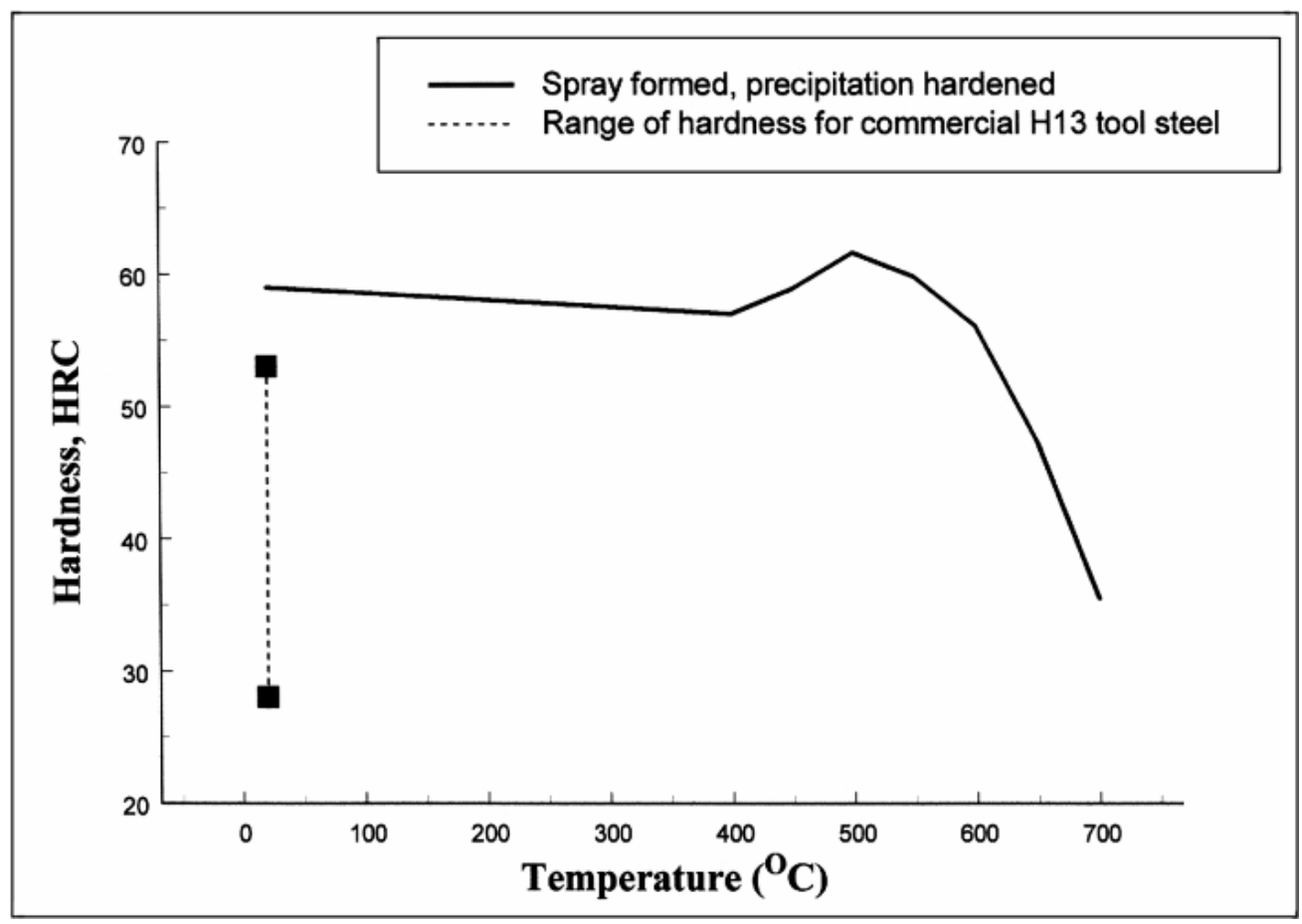

Figure 23. Hardness of artificially-aged spray-formed H13 tool steel following 1-h soaks at temperature. The hardness range of conventionally heat treated H13 is included for comparison. 


\section{H13 Tool Steel}

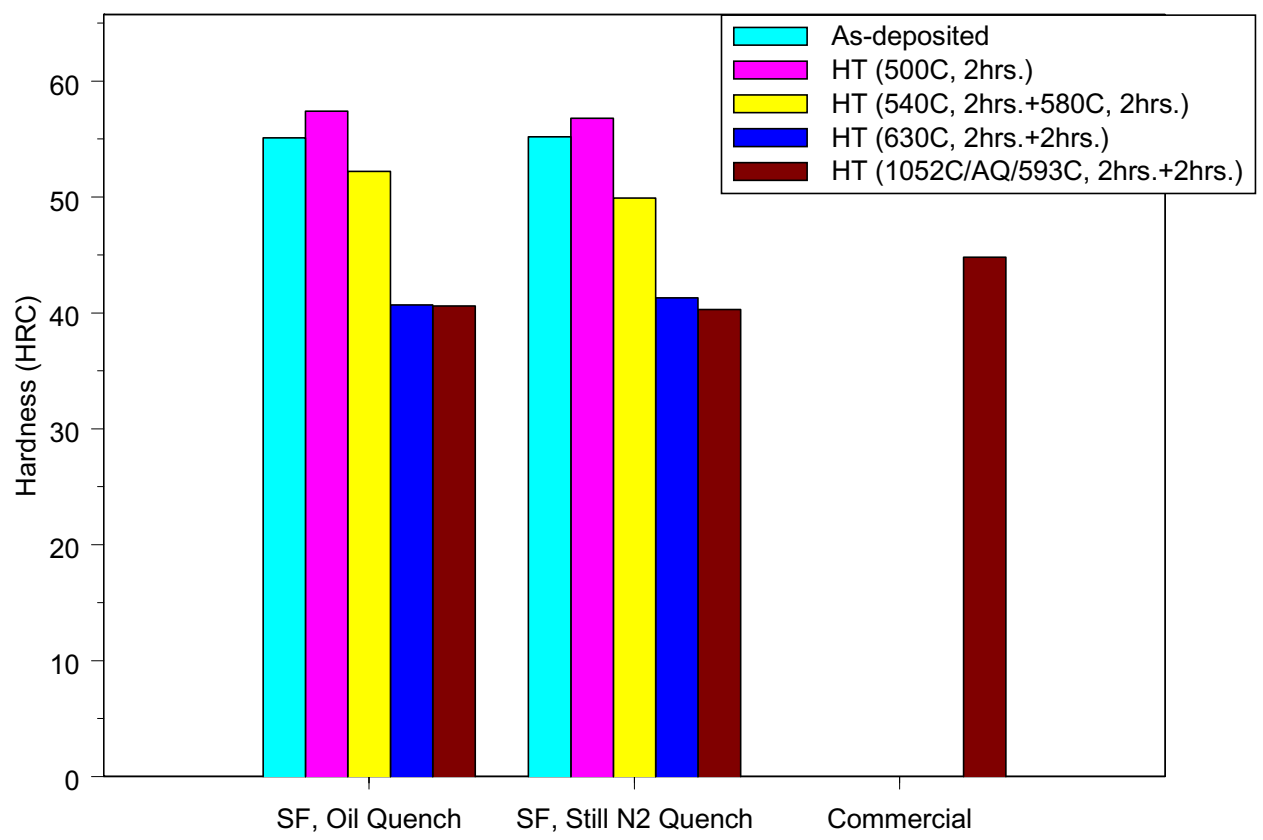

Figure 24. Rockwell C hardness of H13 tool steel.

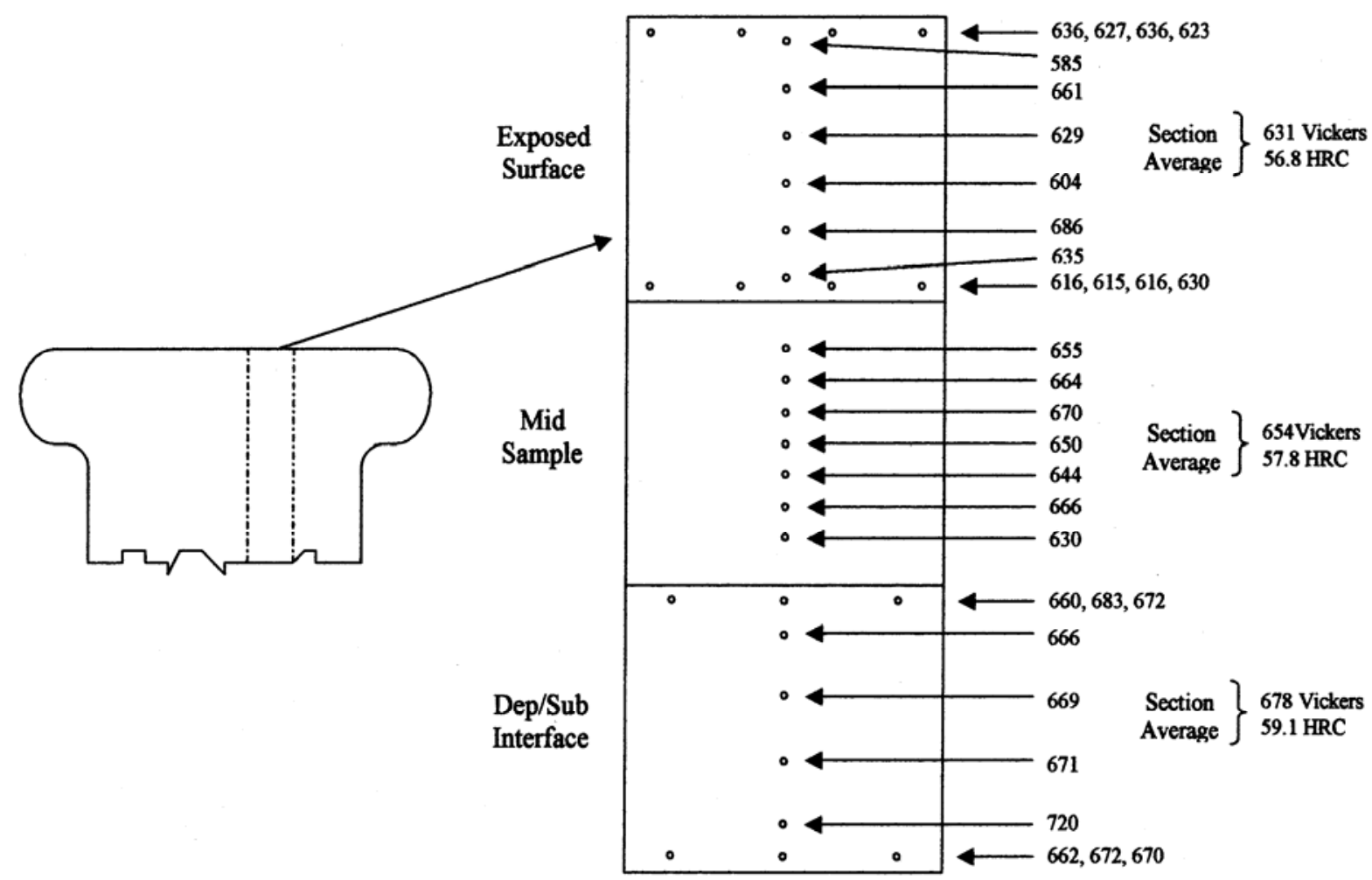

Figure 25. Vickers hardness profile through a spray-formed, free-convection-cooled, H13 tool steel die. 
Figure 26 compares the hardness of commercial forged $\mathrm{H} 13$ tool steel and spray-formed $\mathrm{H} 13$ tool steel following prolonged soaks at $500^{\circ} \mathrm{C}$. Spray-formed samples were free-convection cooled or forcedconvection cooled following deposition. The spray-formed samples retained high hardness at elevated temperature.

3.4.1.10 Temper Response. Following austenitization and quenching, hot-work tool steels such as $\mathrm{H} 13$ are tempered to bring about several desirable microstructural changes to the as-quenched martensite. These include stress relief, carbon diffusion, carbide precipitation, and decomposition of retained austenite. The temper responses of spray-formed H13 and spray-formed/annealed H13 were compared with those of commercial forged/annealed material by evaluating the hardness of samples that were heat treated side-by-side. The samples were austenitized at $1015^{\circ} \mathrm{C}$, air quenched, and tempered $2 \mathrm{~h}$ at temperatures ranging from 425 to $700^{\circ} \mathrm{C}$. As shown in Figure 27, which encompasses the secondary hardening peak and beyond, spray-formed H13 and commercial forged H13 responded in a similar way to conventional heat treatment. Microstructural analysis of spray-formed H13 and commercial forged H13 tool steel also indicated that their microstructures are similar following conventional heat treatment.

3.4.1.11 Differential Thermal Analysis. Differential thermal analysis (DTA) is useful for analyzing the heat absorption or evolution that accompanies phase transformations, precipitation of new phases, re-solution of phases, etc. DTA was performed on samples of spray-formed H13, sprayformed/annealed $\mathrm{H} 13$, and commercial forged/annealed $\mathrm{H} 13$. The samples were austenitized at $1010^{\circ} \mathrm{C}$ and air quenched. Scan data and peak assignments are summarized in Figure 28. Similar peaks corresponding to the exothermic precipitation and growth of carbides, curie transformation, ferrite-toaustenite transformation, gamma-to-delta iron transformation, and melting were observed for all samples.

3.4.1.12 Residual Stress Analysis. An understanding of the residual stresses that develop in a die during spray forming and heat treatment is important because stresses can affect die life and dimensional accuracy. Surface stresses are particularly important. For example, large tensile residual stress at the surface can cause gross cracking and premature heat checking during thermal cycling of a die in aluminum die casting. In general, compressive stresses at the surface are beneficial and can help prevent cracking. Large stresses can also lead to die distortion, which can result in components being formed that are out of tolerance. While a high cooling rate in tool steels can reduce segregation and improve microstructural features, it can also lead to residual stresses. Knowledge of the factors that lead to development of residual stresses during spray forming and heat treatment is useful for controlling stress and improving the service life and accuracy of spray-formed dies.

Neutron diffraction is an ideal technique for mapping the bulk residual stress because it is nondestructive and yet penetrates deep into the test samples. The bulk residual stress in a typical sprayformed tool steel die was measured at Chalk River Laboratories. ${ }^{a}$ These measurements included three components of residual stress at different positions for samples with different structural features. Figure 29 shows a spray-formed H13 sample and the measured residual stresses associated with different features of the sample. Some difficulties were encountered in obtaining reliable quantitative data. Qualitatively, however, surface residual stresses of the spray-formed H13 die were found to be compressive and to transition to tensile stresses away from the surface. Earlier neutron diffraction studies conducted on spray-formed $\mathrm{H} 13$ found that the stresses were compressive, ranging from about $100 \mathrm{MPa}$ to as high as about $600 \mathrm{MPa}{ }^{22}$ The latter is fairly large but is well below the yield stress of H13 (about $1700 \mathrm{MPa}$ ). However, a stress relieving heat treatment is prudent and is recommended prior to running dies in-service. Stress relieving will be accomplished during the normal aging or tempering heat treatment.

a. National Research Council of Canada, Chalk River, ON, Canada. 


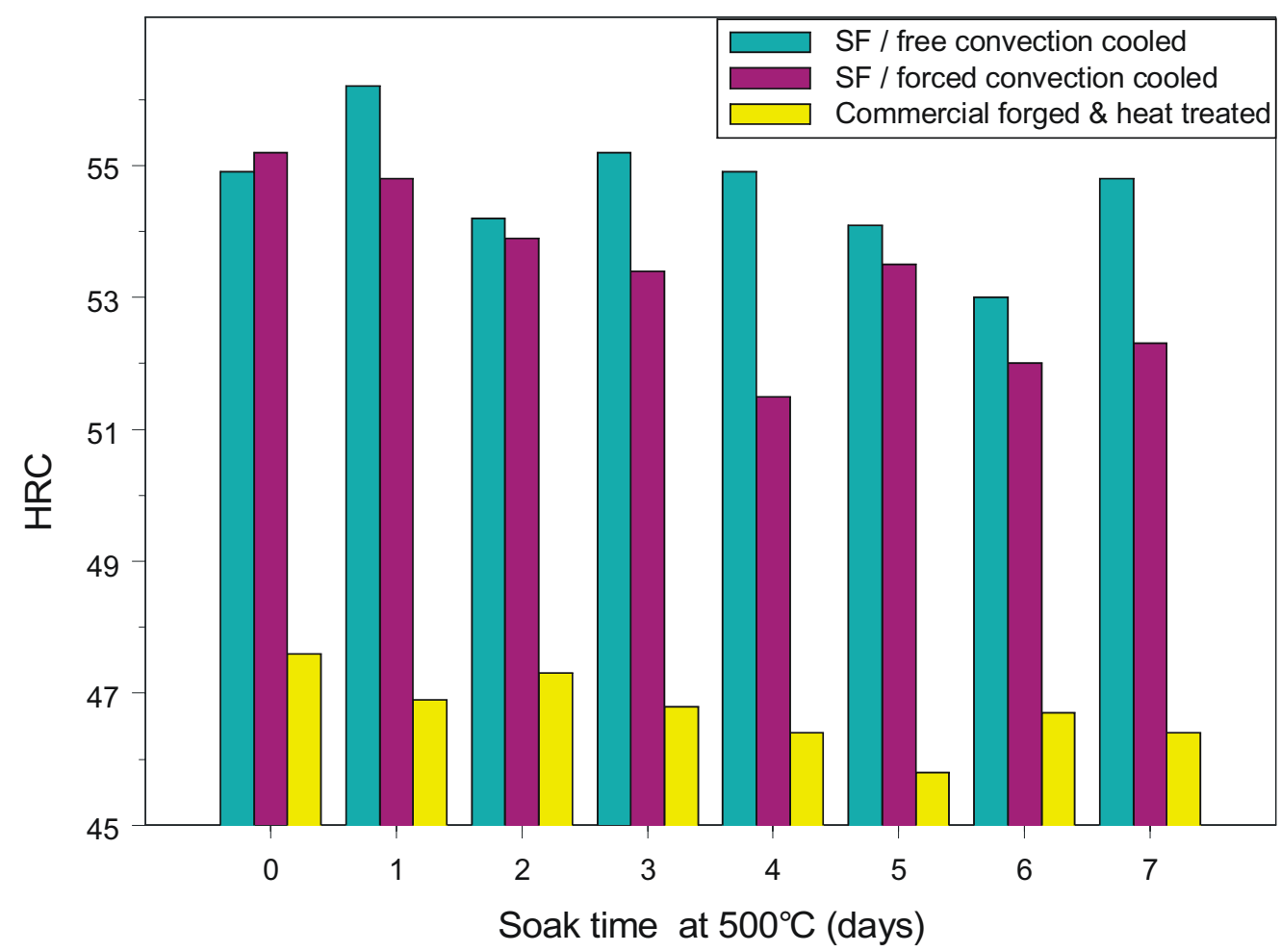

Figure 26. Hardness of spray-formed and commercial $\mathrm{H} 13$ tool steel following soaks at $500^{\circ} \mathrm{C}$.

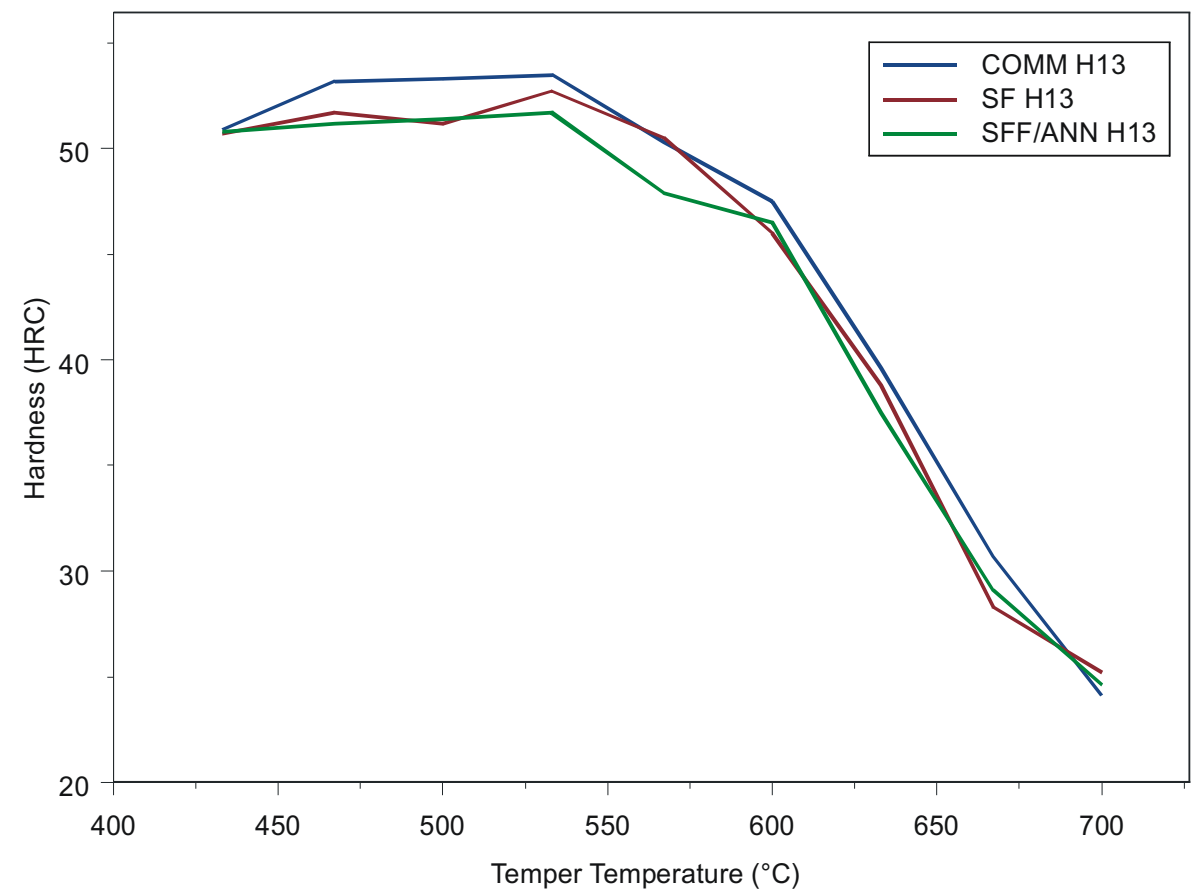

Figure 27. Temper response of heat treated $\mathrm{H} 13$ tool steel. Samples were austenitized at $1015^{\circ} \mathrm{C}$, air quenched, and tempered $2 \mathrm{~h}$ at the indicated temperatures. 


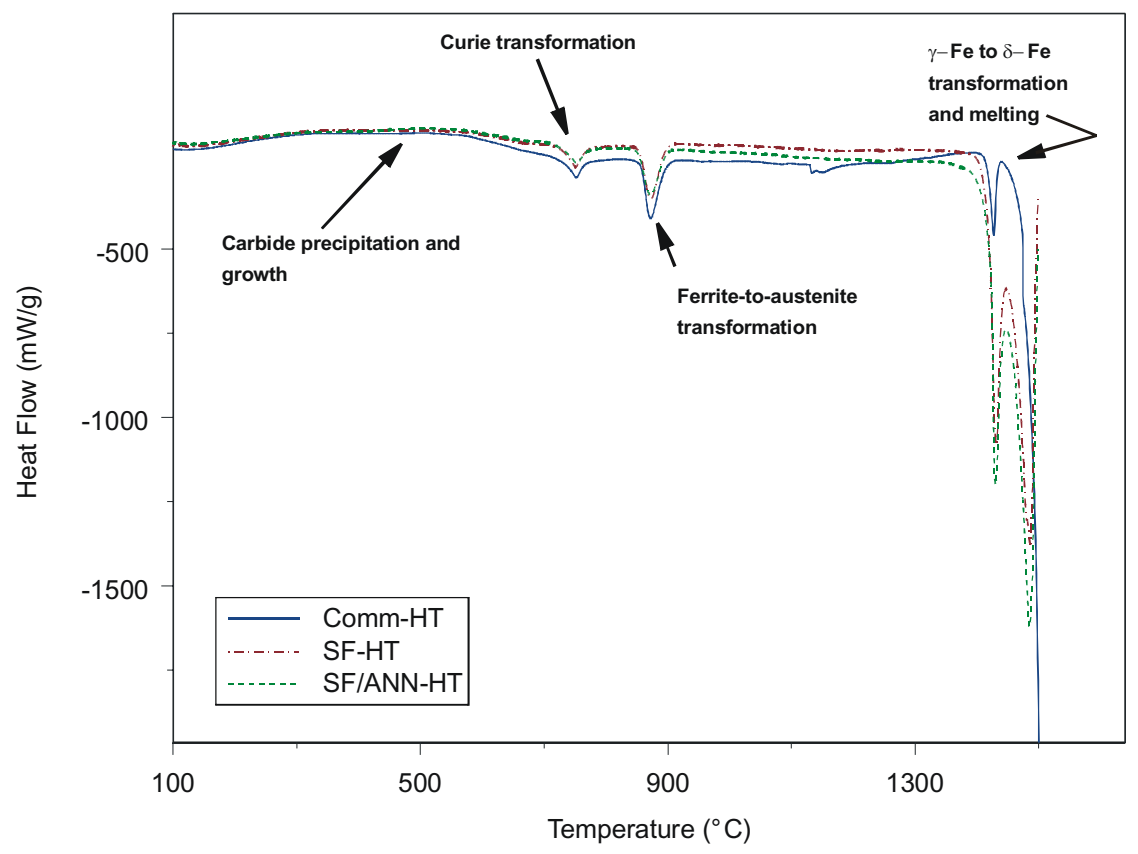

Figure 28. DTA scans on austenitized $\left(1015^{\circ} \mathrm{C}\right)$ and air-quenched $\mathrm{H} 13$ tool steel samples.

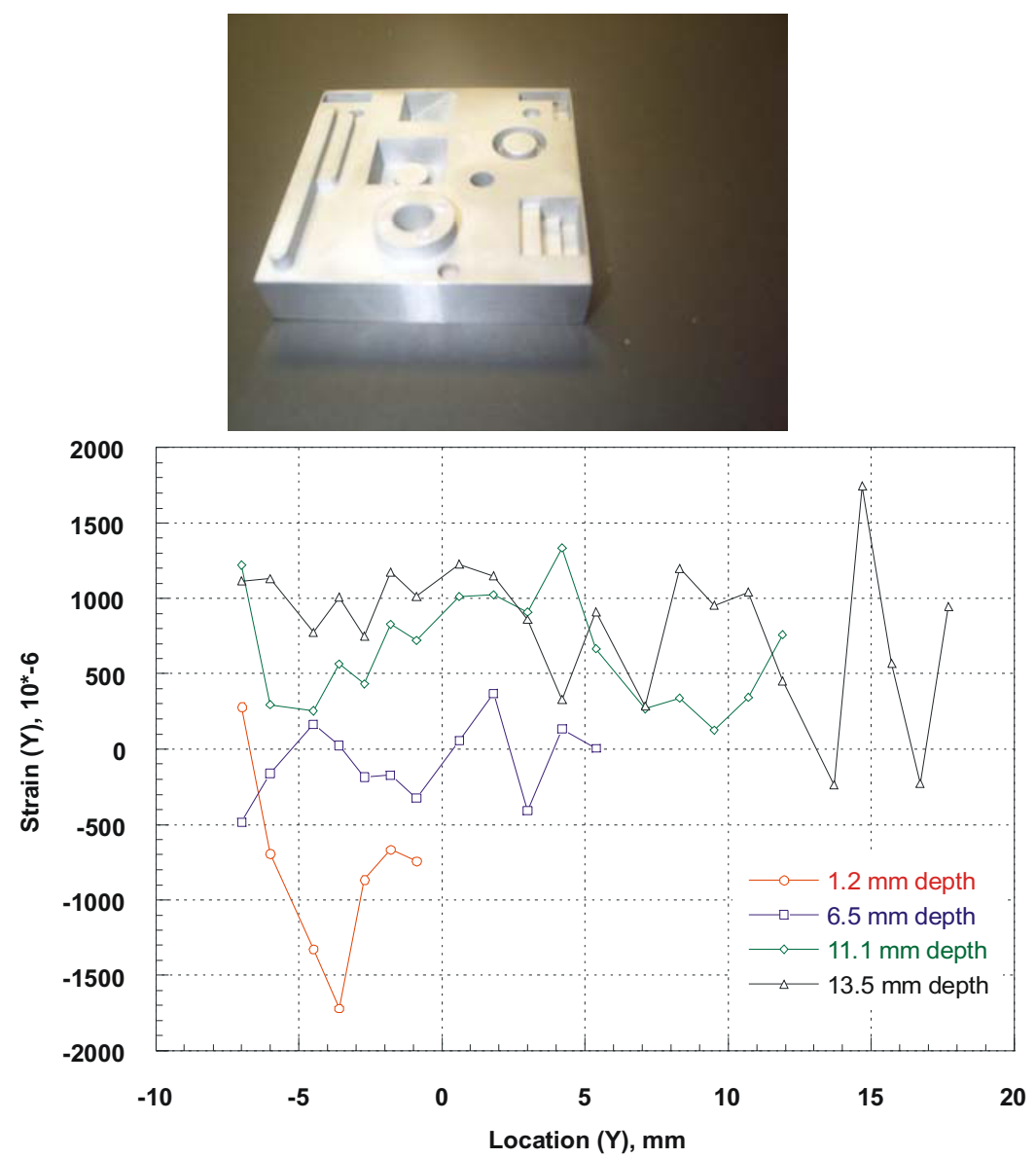

Figure 29. H13 tool steel sample fabricated by spray forming (top) and residual stresses (bottom) of the step feature in the bottom right corner of the sample. 
3.4.1.13 Results of Production Runs with Spray-Formed H13 Dies. Evaluation of the performance of spray-formed dies during production runs was the single most important test conducted on the dies. To date, many dies have been used in short runs making prototype parts and in long production runs. Dies have been evaluated in plastic injection molding, die casting, forging, glass manufacture, and extrusion. All runs were conducted by various manufacturing companies in cooperation with industry participants.

Figure 30 provides an example of dies for an aluminum die casting production run with $380 \mathrm{Al}$ alloy. A spray-formed/aged H13 tool steel die was run side-by-side with conventional machined dies of the same geometry. The industry partner had routinely run similar dies in the past and knew the expected die life and failure modes. The spray-formed dies (Figure 30a) were aged $\left(540^{\circ} \mathrm{C}, 2 \mathrm{~h}+580^{\circ} \mathrm{C}, 1.5 \mathrm{~h}\right.$ ) while the machined dies were conventionally heat treated (austenitized/quenched/tempered) following the company's normal practice for production dies. All dies were mounted in a holding block (Figure 30b). The machined dies were premium-grade $\mathrm{H} 13$ tool steel while the spray-formed dies were commercial grade. Despite this, the spray-formed dies outlasted their conventional counterparts by about $20 \%$. The life of a standard die is about 85,000 die cast parts while the spray-formed and aged die produced about 102,000 parts. Eventual die failure was attributed to a combination of erosive wear and soldering for all dies. Analysis indicated that the spray-formed die showed less wear and heat checking, and significantly less soldering, than the conventional dies.

In various die-life case studies, spray-formed dies were found to meet or exceed the production volume of conventional dies. The performance of dies depends on the manufacturing process, material that is formed, heat treatment of the die, and other factors. An exhaustive study of spray-formed die performance was not possible in this study. However, preliminary results are encouraging. Table 7 summarizes results from production runs in forging, die casting, and extrusion for spray-formed and conventional H13 dies. As mentioned previously, spray-formed/aged $\mathrm{H} 13$ dies exhibited 20\% die life extension over conventional machined dies when casting Al alloy 380 parts. In a hot forging run of steel gears, spray-formed/aged dies were found to exhibit about $7 \%$ die life extension. In forging steel files, the spray-formed/aged dies had double the output of a conventional machined die. Finally, in a cold-extrusion study of $\mathrm{H} 13$ bar, as-spray-formed dies outlasted conventional $\mathrm{H} 13$ dies by $50 \%$. Aluminum die casting, forging, and extrusion are three of the most demanding applications of commercial dies. In addition to these studies, numerous studies in other forming operations are ongoing.

\subsubsection{Modeling Results for Spray-Formed H13 Tool Steel.}

3.4.1.14.1. Modeling Heat Transfer and Solidification. Modeling analysis of heat transfer and solidification during spray forming of H13 (and A2) tooling was used to assist our understanding of microstructure evolution during spray forming and heat treatment. A description of the model is given in the Appendix to this report. Modeling is beneficial because it helps correlate processing conditions with the mechanical properties of spray-formed dies. Predictive insight gained through modeling allows the size of the experimental matrix to be reduced, saving time and money.

The temperature and liquid fraction of spray-formed H13 steel deposits were calculated. Figure 31 shows the calculated temperature as a function of time at the deposit/substrate interface, half thickness of the deposit, and at the exposed surface. According to Figure 31, liquid phase is present throughout the entire thickness of the deposited material during spray forming. By assuming equilibrium for the simulation in Figure 31, an estimate of liquid fraction is obtained (Figure 32). According to Figure 32, the calculated maximum liquid fraction at the deposit/substrate interface, half thickness, and the exposed surface are approximately $0.202,0.238$, and 0.209 , respectively. The liquid phase exists at these locations for the time intervals of 460,320, and $30 \mathrm{~s}$, respectively. Since the calculated maximum liquid fraction is above $20 \%$ throughout the entire thickness, it is predicted that there should be very low porosity in the asdeposited materials. This prediction is in good agreement with experimental measurements of porosity summarized in Table 5. 

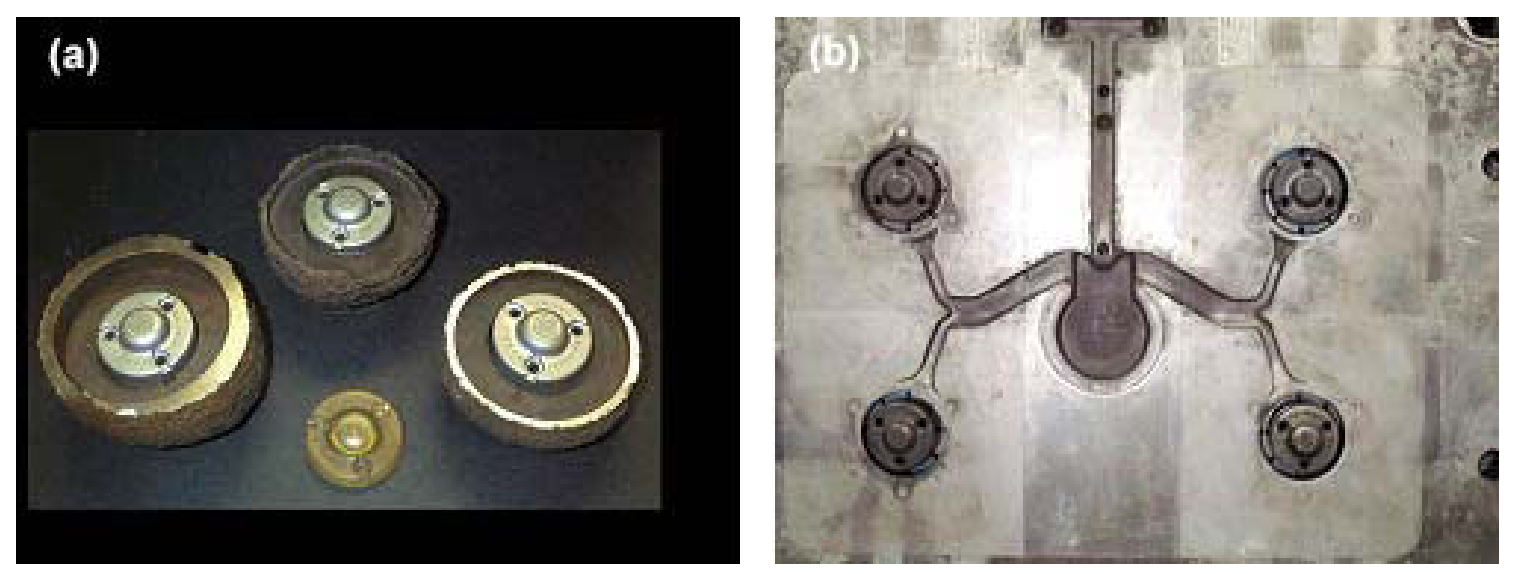

Figure 30. Spray-formed H13 tool steel die casting dies. (a) As-deposited dies and stereolithography master. (b) Spray-formed and commercial dies mounted in a holding block.

Table 7. Summary of die life studies in forging, extrusion and die casting H13 tool steel dies.
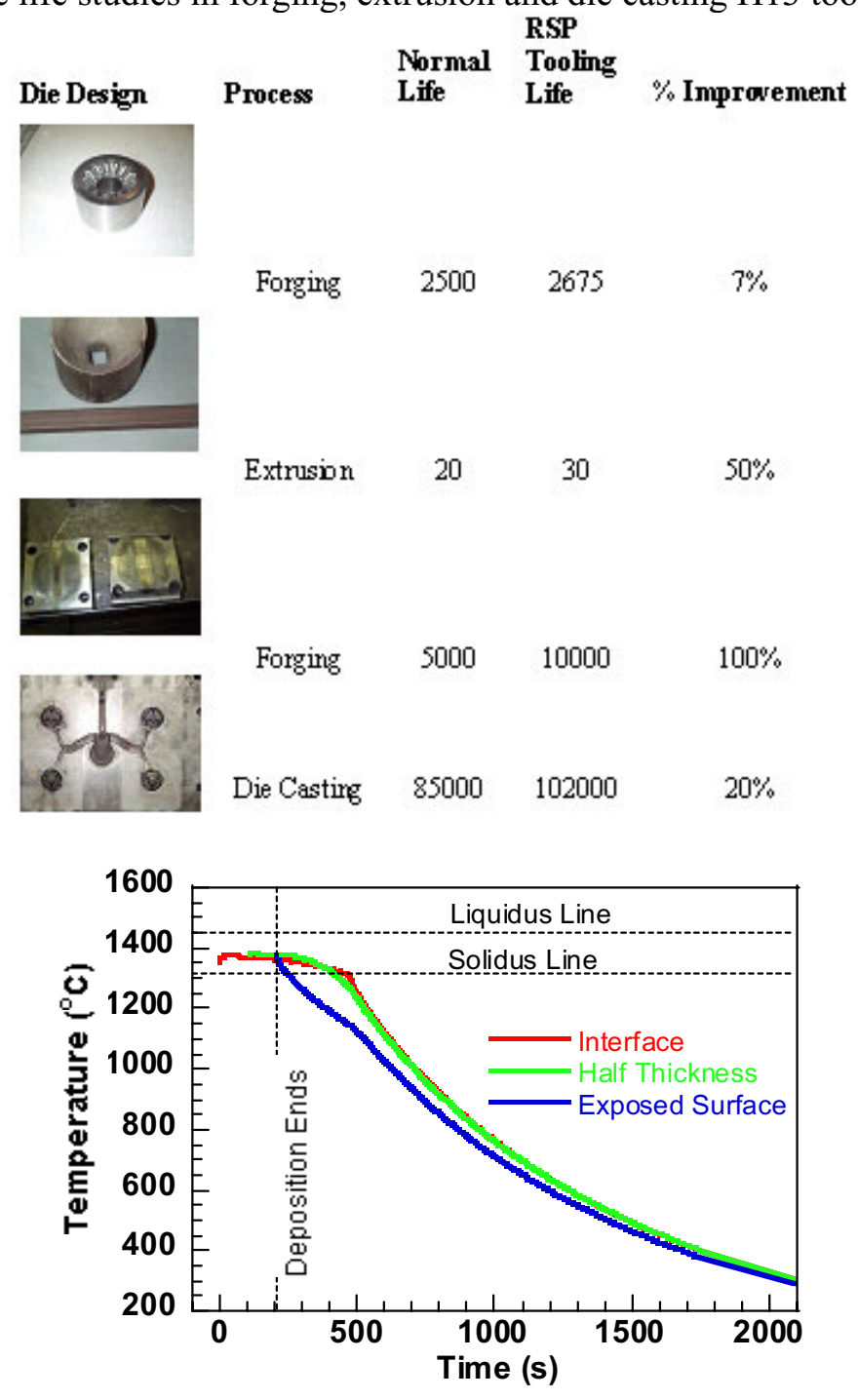

Figure 31. Calculated temperature as a function of time in spray-formed H13 tooling. 


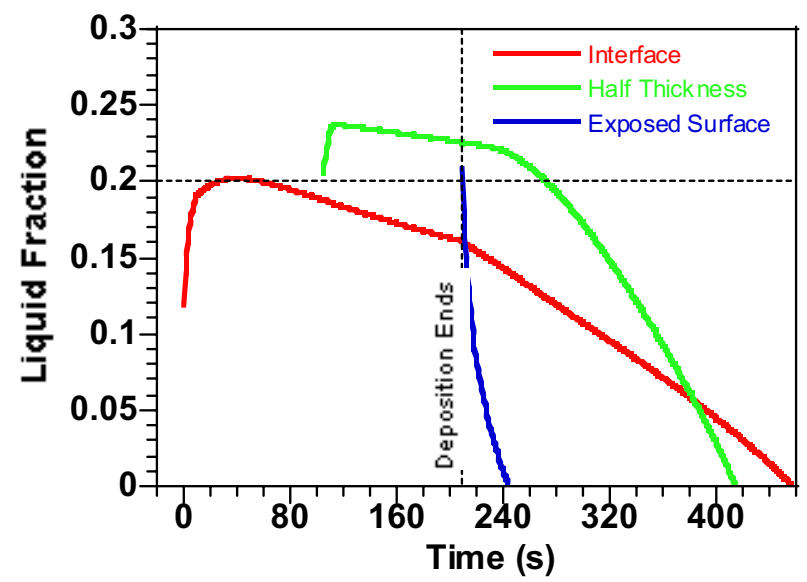

Figure 32. Calculated liquid fraction as a function of time in spray-formed H13 tooling derived from Figure 31 .

In Figure 33, the calculated curves of temperature vs. time for temperatures below $1100^{\circ} \mathrm{C}$ are mapped to the transformation diagram of $\mathrm{H} 13$ steel in order to predict the phases in the as-deposited material. It is noted that austenite decomposition occurs only when the temperature decreases to a value that is lower than the temperature corresponding to the austenite single-phase region in the equilibrium phase diagram. The lowest temperature corresponding to the austenite single-phase region is estimated to be $1100^{\circ} \mathrm{C}$. On the basis of the prediction in Figure 33, as-deposited $\mathrm{H} 13$ consists of proeutectoid carbides, bainite, martensite, and retained austenite, consistent with SEM and TEM analysis results of asdeposited H13 in Figures 15 to 19.

Using the model described above, the temperature and liquid fraction of $\mathrm{H} 13$ during spray forming were calculated. Figure 34 shows the calculated temperature as a function of time at the deposit/substrate interface, half thickness of the deposited material, and the exposed surface of the deposited material. According to Figure 34, liquid phase is present throughout the entire thickness of the deposited material during spray forming. The deposited material remains mushy for 94, 76, and $35 \mathrm{~s}$ at the deposit/substrate surface, $10 \mathrm{~mm}$ thickness, and top surface (i.e., $20 \mathrm{~mm}$ thickness), respectively.

\subsection{Influence of the Substrate Preheat Temperature on Solidification and}

Cooling. Figure $35 \mathrm{a}$ compares the calculated temperature in the range between solidus and liquidus temperatures as a function of time for a preheated substrate and one that is not preheated. The temperatures for the preheated substrate are higher than those for the substrate that is not preheated. Figure $35 \mathrm{~b}$ compares the calculated temperatures below $1100^{\circ} \mathrm{C}$, where austenite decomposition occurs. Below $1100^{\circ} \mathrm{C}$, the cooling rate is similar for the two cases. In other words, the substrate preheat temperature has a negligible influence on cooling rate below $1100^{\circ} \mathrm{C}$.

\subsection{Influence of the Deposit Growth Rate on Solidification and Cooling.}

Figure 36 shows the influence of the growth rate of the deposited material on the calculated liquid fraction at the deposit/substrate interface without substrate preheating. The higher growth rate in Figure $36 \mathrm{~b}$ is achieved by raising the metal flow rate to $187.6 \mathrm{~g} / \mathrm{s}$ and the gas flow rate to $24.0 \mathrm{~g} / \mathrm{s}$ (to maintain a droplet liquid fraction identical to that used in Figure 36a). Increasing the growth rate from 0.242 to $1.0 \mathrm{~mm} / \mathrm{s}$ increases the maximum liquid fraction from approximately 0.036 to approximately 0.155 and the duration of the liquid phase from approximately $280 \mathrm{~s}$ to approximately $365 \mathrm{~s}$. Based on these results, it is possible to generate sufficient liquid fraction in the as-deposited material to eliminate porosity without preheating the substrate by choosing a high metal flow rate, and thus achieving a high 
growth rate of the deposited material. Figure 37 compares the calculated temperatures below $1100^{\circ} \mathrm{C}$, where austenite decomposition occurs, under the two cases corresponding to Figures $36 \mathrm{a}$ and $36 \mathrm{~b}$. The growth rate of the deposited material has almost no influence on the cooling rate in the temperature region below $1100^{\circ} \mathrm{C}$.

\subsubsection{H13 Mod 1}

H13 tool steel has low carbon content to promote toughness, medium $\mathrm{Cr}$ content to resist softening at elevated temperatures, Si to resist oxidation at high temperatures, and Mo and $\mathrm{V}$ to form stable carbides that increase wear resistance. In spray-formed H13, vanadium carbides appear to be most responsive to secondary hardening during aging. As a result, a new alloy, designated H13 Mod 1, containing increased levels of carbon and vanadium, was developed and tested. Blocks of tool steel were spray formed at $2.7 \mathrm{~kg} / \mathrm{min}$ and sectioned for microstructural analysis. Samples were placed in a furnace and aged for $2 \mathrm{~h}$ at temperatures up to $700^{\circ} \mathrm{C}$. Hardness was measured. Results are summarized in Figure $38 \mathrm{c}$ and Figure 39. The shape of the aging curve is similar to standard H13, exhibiting a secondary aging peak at $500^{\circ} \mathrm{C}$ to a peak hardness of $58 \mathrm{HRC}$. This is followed by a rapid decline in hardness as the soak temperature was increased.

Figure 40 presents representative photomicrographs of spray-formed H13 Mod 1 following 2-h soaks at $350-700^{\circ} \mathrm{C}$. Optically, the microstructure appears to consist of a combination of martensite with bainite and some retained austenite. Primary carbides are prominent due to the relatively low solubility of VC. As the aging temperature increases, the austenite converts to martensite, which ultimately converts to bainite at high temperatures.

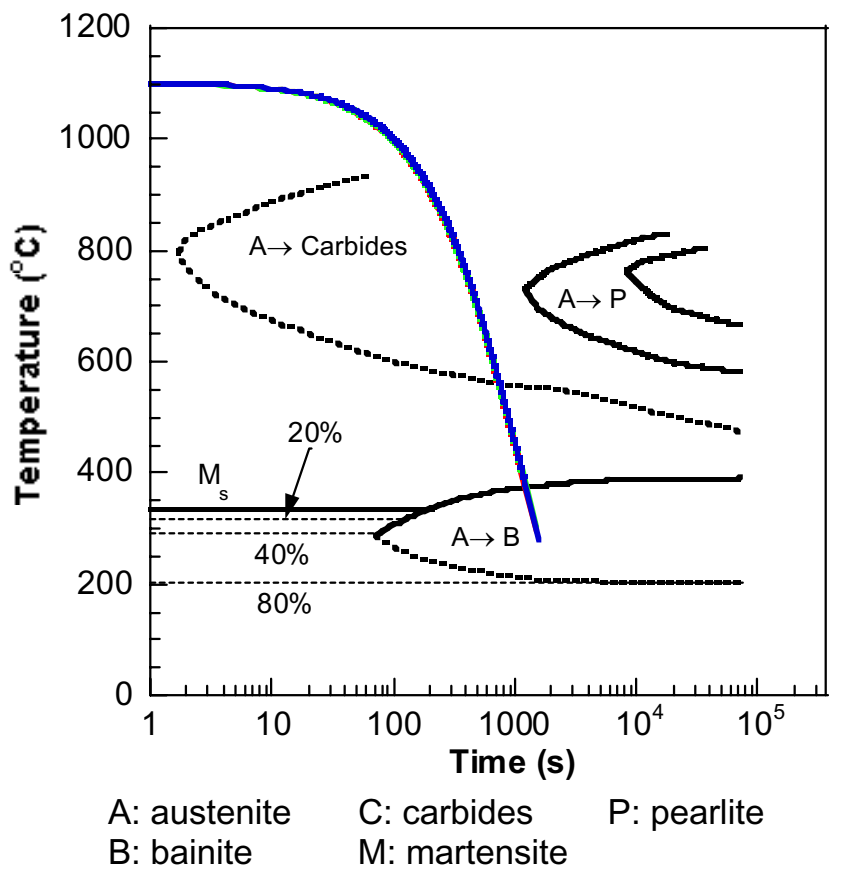

Figure 33. Calculated temperature as a function of time in the temperature region of austenite decomposition. 


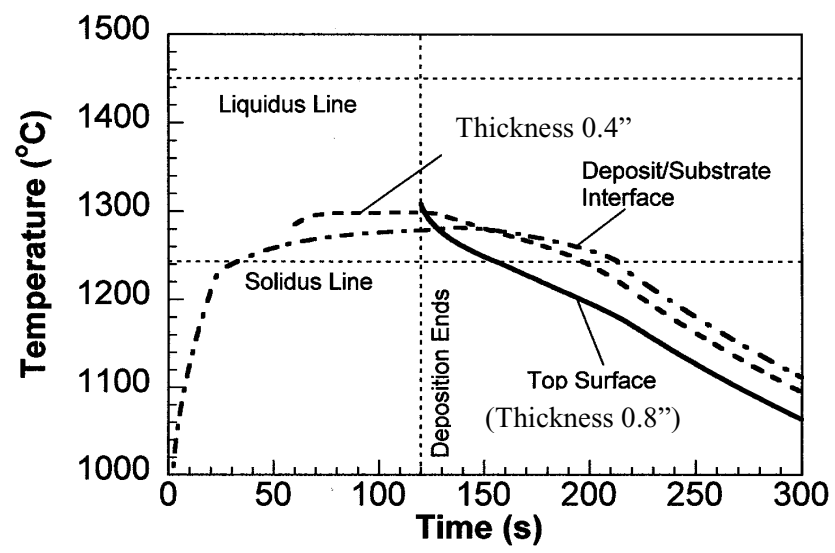

Figure 34. Calculated temperature as a function of time in spray-formed H13 tooling.

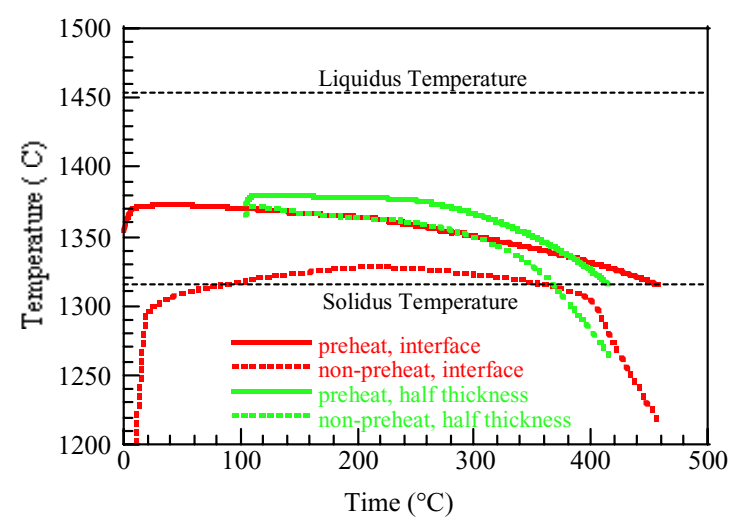

(a)

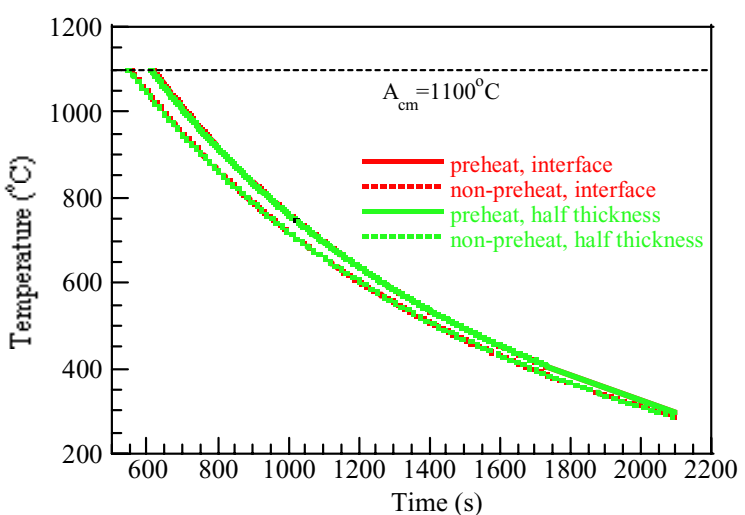

(b)

Figure 35. Calculated temperature as a function of time in spray-formed H13 tooling with and without substrate preheating. (a) Between solidus and liquidus temperature. (b) Temperatures corresponding to austenite decomposition (below $\mathrm{A}_{\mathrm{cm}}=1100^{\circ} \mathrm{C}$ ).

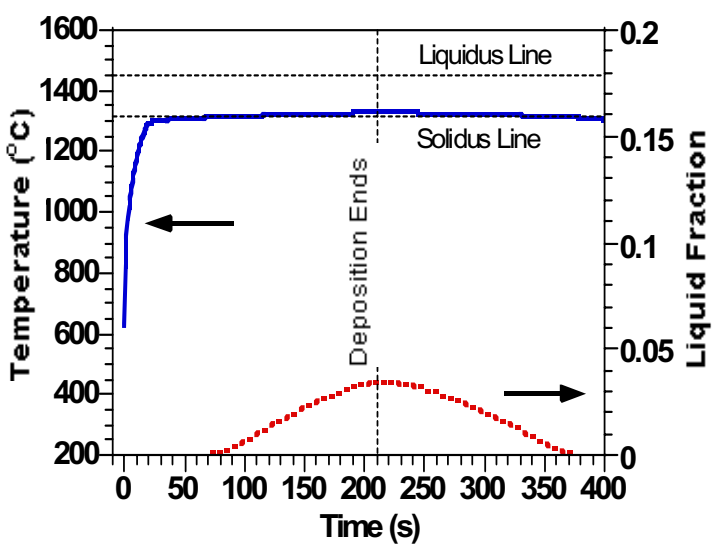

(a)

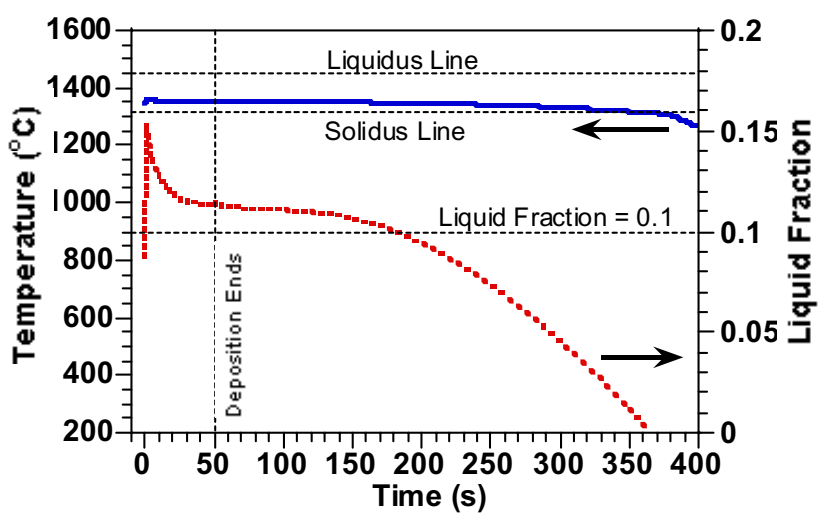

(b)

Figure 36. Liquid fraction at the deposit/substrate interface under two deposit growth rates.

(a) $0.242 \mathrm{~mm} / \mathrm{s}$. (b) $1.0 \mathrm{~mm} / \mathrm{s}$. 


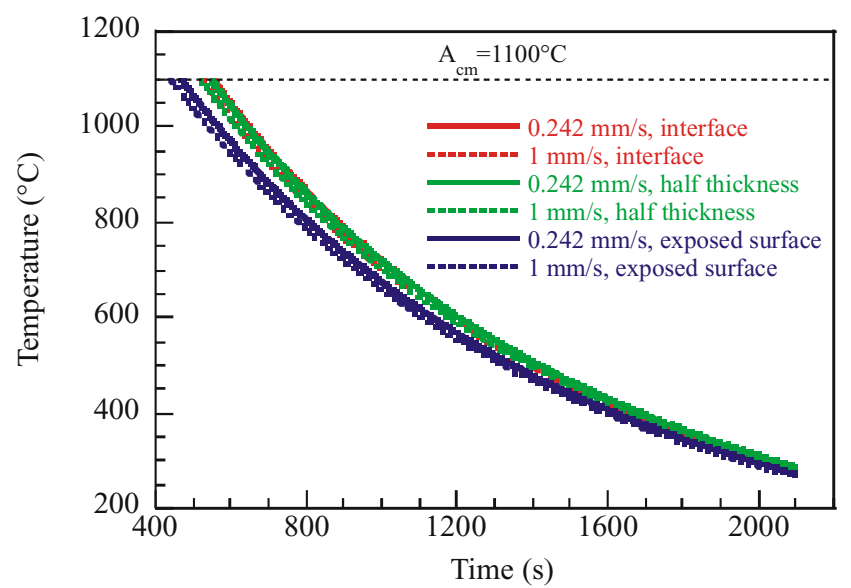

Figure 37. The temperature history, below $1100^{\circ} \mathrm{C}$, of materials deposited at 0.242 and $1.0 \mathrm{~mm} / \mathrm{s}$.
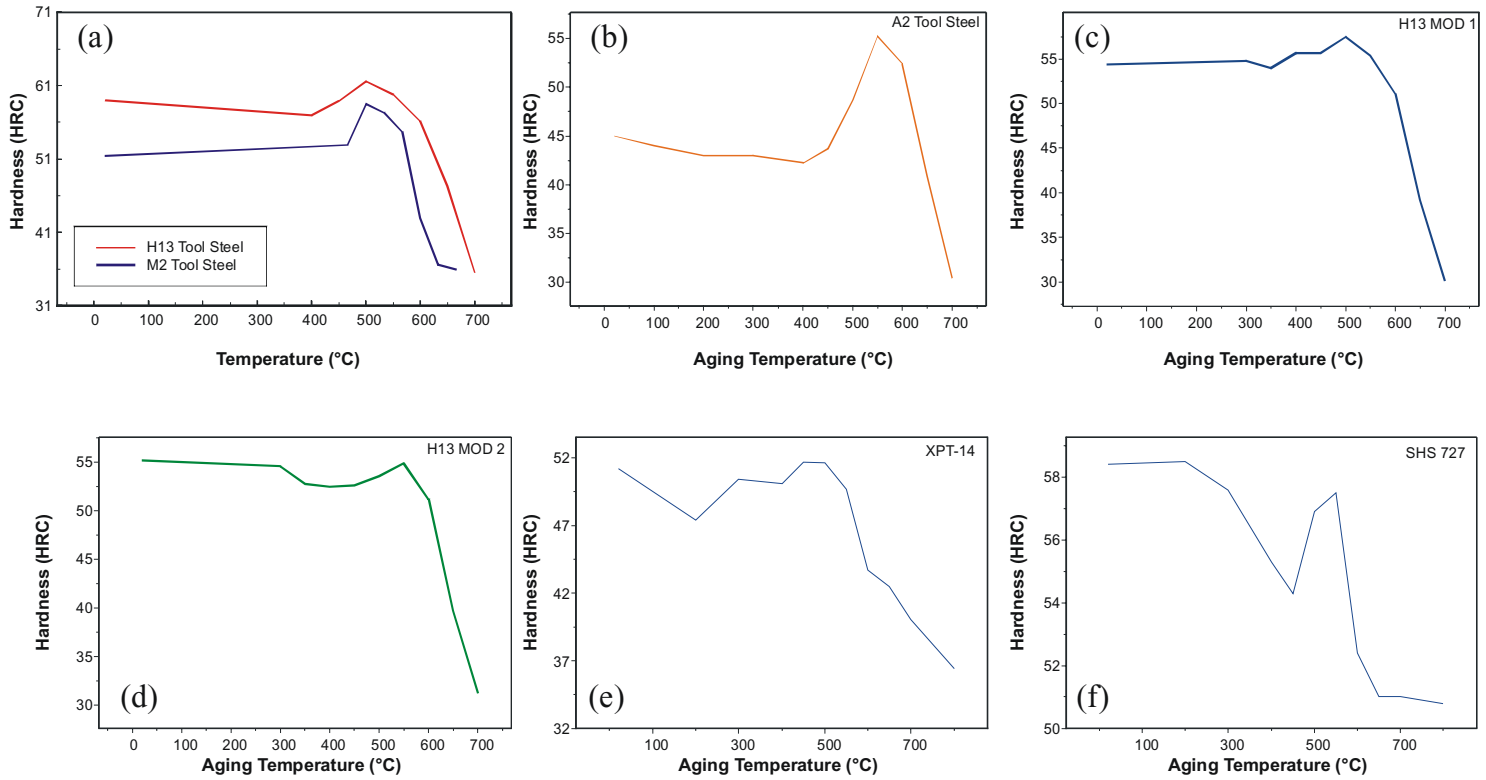

Figure 38. Comparison of aging curves of alloys processed in this project. (a) H13 and M2 tool steels. (b) A2 tool steel. (c) H13 Mod 1. (d) H13 Mod 2. (e) XPT-14. (f) SHS 727.

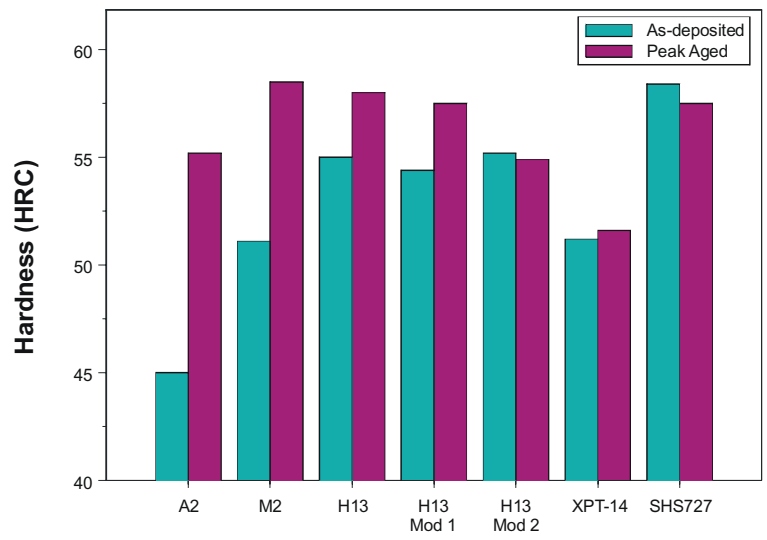

Figure 39. Comparison of as-deposited hardness and peak-aged hardness of spray-formed tool steels. 


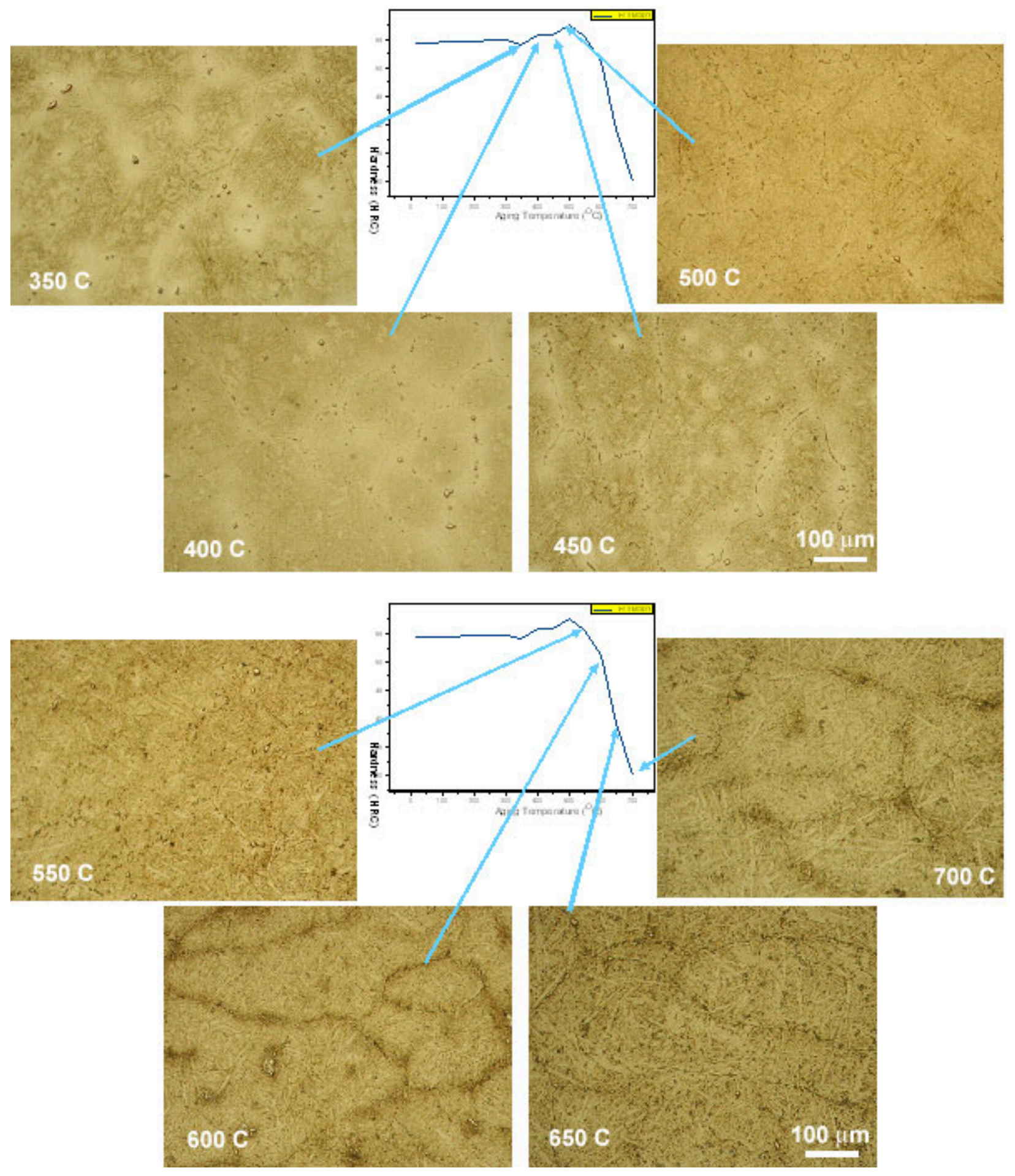

Figure 40. Microstructure transformation in spray-formed H13 Mod 1 during aging. 


\subsubsection{H13 Mod 2}

A second modification to H13 tool steel (H13 Mod 2) was alloyed having higher Mo content and lower $\mathrm{V}$ and $\mathrm{Si}$. The alloy was processed by spray forming, sectioned, and heat treated by aging and conventional austenitization/quench/temper. Figures 38d and 39 summarize the hardness response of spray-formed H13 Mod 2 to aging. The aging curve shows an initial drop in hardness due to stress relieving as was observed with $\mathrm{H} 13$ tool steel. Similarly, this was followed by a rise in hardness to a peak-age hardness of about $55 \mathrm{HRC}$ following a 2-h soak at $550^{\circ} \mathrm{C}$. Unlike $\mathrm{H} 13$, however, the peak-aged $\mathrm{H} 13 \mathrm{Mod} 2$ was only slightly harder than the as-deposited material, indicating that Mo-rich $\mathrm{M}_{2} \mathrm{C}$ and $\mathrm{M}_{6} \mathrm{C}$ carbides play a smaller role in secondary hardening during aging than do V-rich MC carbides.

Microstructure transformations that occur during aging of spray-formed H13 Mod 2 are summarized in Figure 41. In general, the microstructures of the as-deposited material and the alloy aged at low temperatures were very uniform throughout and contained few primary carbides due to higher solubility of Mo-rich carbides.

Additional material was conventionally heat treated by austenitizing at $1015^{\circ} \mathrm{C}$ for $30 \mathrm{~min}$, quenching in air, and double tempering at 400 to $650^{\circ} \mathrm{C}$ for $2 \mathrm{~h}$. Rockwell $\mathrm{C}$ hardness was evaluated; these results are summarized in Figure 42. As with $\mathrm{H} 13$ tool steel, the highest hardness was obtained for spray-formed and aged material with peak age hardness following a 2-h soak at $550^{\circ} \mathrm{C}$. In general, when compared to commercial H13, conventionally heat treated H13 Mod 2 alloy appears to exhibit high temper resistance, somewhat lower hardness, somewhat lower strength, higher toughness, and higher resistance to gross cracking.

\subsubsection{M2 Tool Steel}

M2 tool steel is a tungsten-molybdenum high speed steel. The composition (wt $\%$ ) is $0.85 \mathrm{C}$ 0.30 Mn-0.30 Si-4.15 Cr-1.95 V-6.40 W-5.0 Mo. Applications include broaches, end mills, forming tools, punches, taps, and tool bits.

A form punch die used to manufacture steel gears was supplied by an industry partner. $\mathrm{Al}_{2} \mathrm{O}_{3}$ ceramic tool patterns were freeze cast using the die, fired, and sent to industry partners for dimensional analysis. One of the tool patterns was used to spray form a replica M2 die of the original form punch; it is shown in Figure 43. The die was returned to the industry partner for conventional heat treatment, dimensional analysis, and in-service testing.

The dimensional accuracy of the die was within specifications. A production run yielded good results. The service life and failure mode of the spray-formed die were similar to those of a conventional machined die. Die life extension was not observed for spray-formed M2 following a conventional heat treatment.

Microstructure analysis was conducted; results are summarized in Figure 44. The cast alloy (Figure 44a) shows gross segregation of solute-rich phases. To eliminate this, it is extensively hot worked at the steel mill to redistribute the solute-rich phases. This results in pronounced carbide stringers in the forging direction (Figure 44b). In contrast, the as-deposited alloy exhibits a more uniform carbide particle distribution but with localization of carbide along grain boundaries (Figure 44c). An interconnected network of grain boundary carbide can be problematic, particularly with regard to tool toughness. Preliminary tests were conducted that quenched the steel at a higher rate and disturbed the formation of a carbide network by applying a directional force to the steel immediately after deposition. This approach appears to have merit (Figure 44d). 

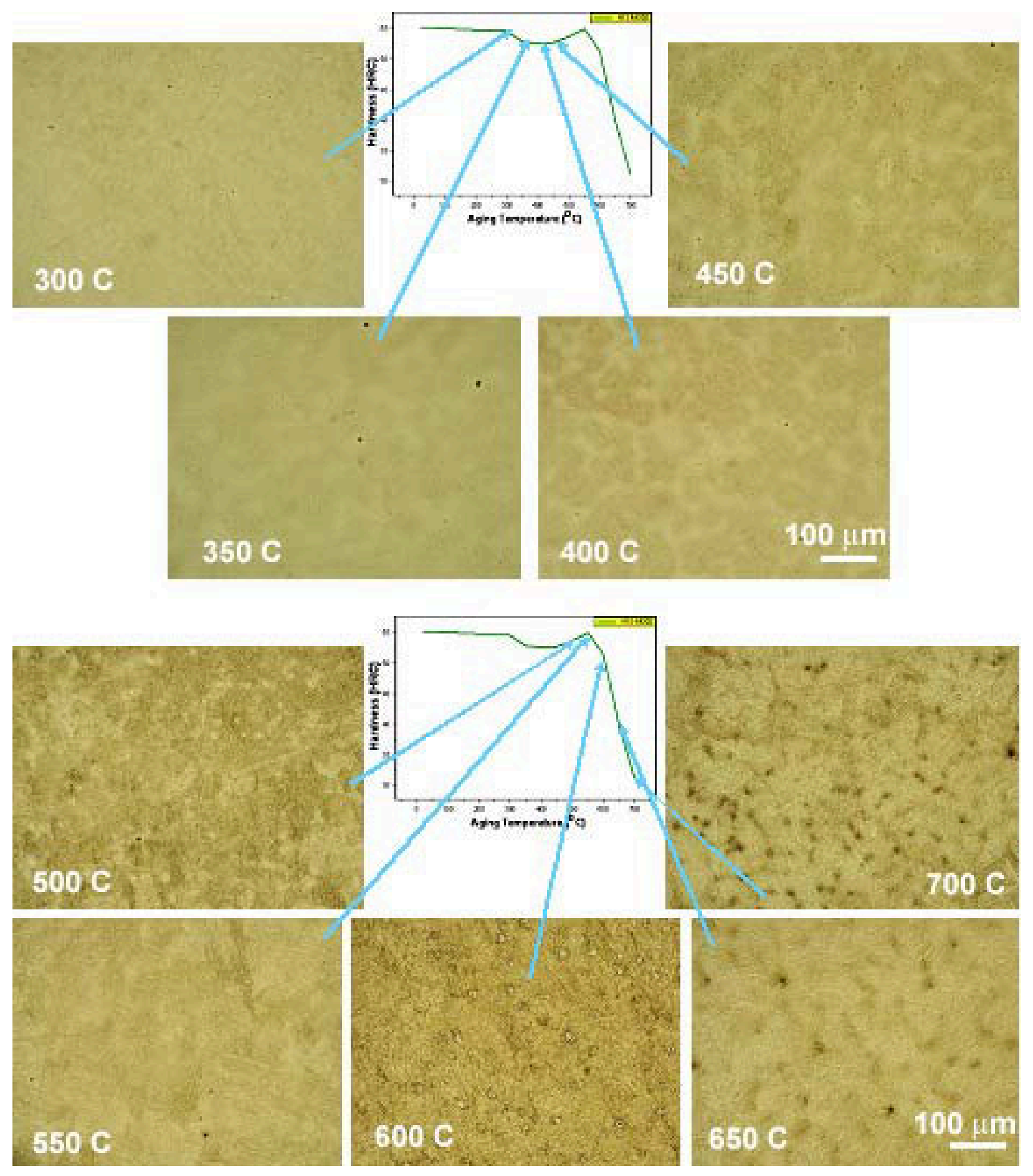

Figure 41. Microstructure transformation in spray-formed H13 Mod 2 during aging. 


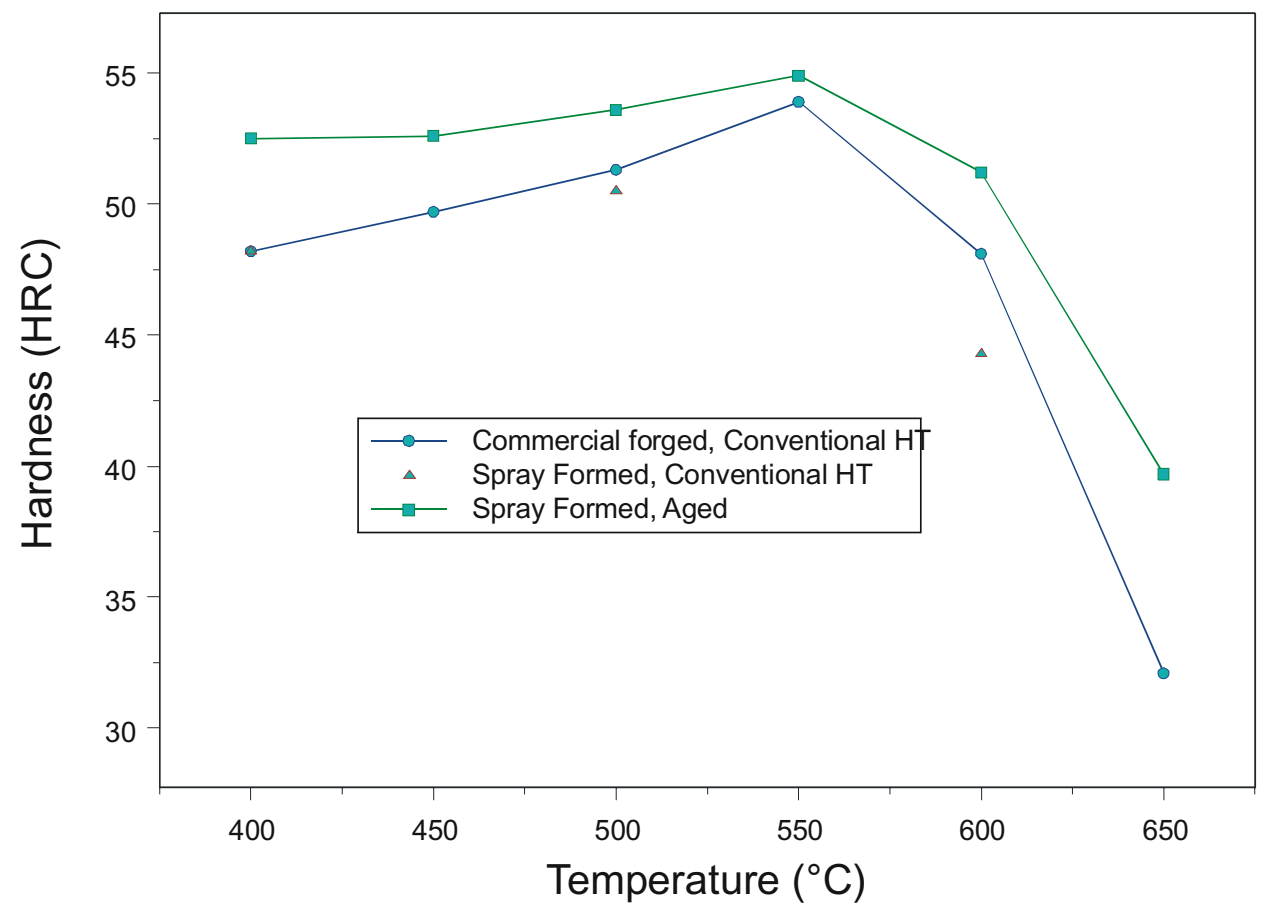

Figure 42. Temper and aging response of spray-formed H13 Mod 2.

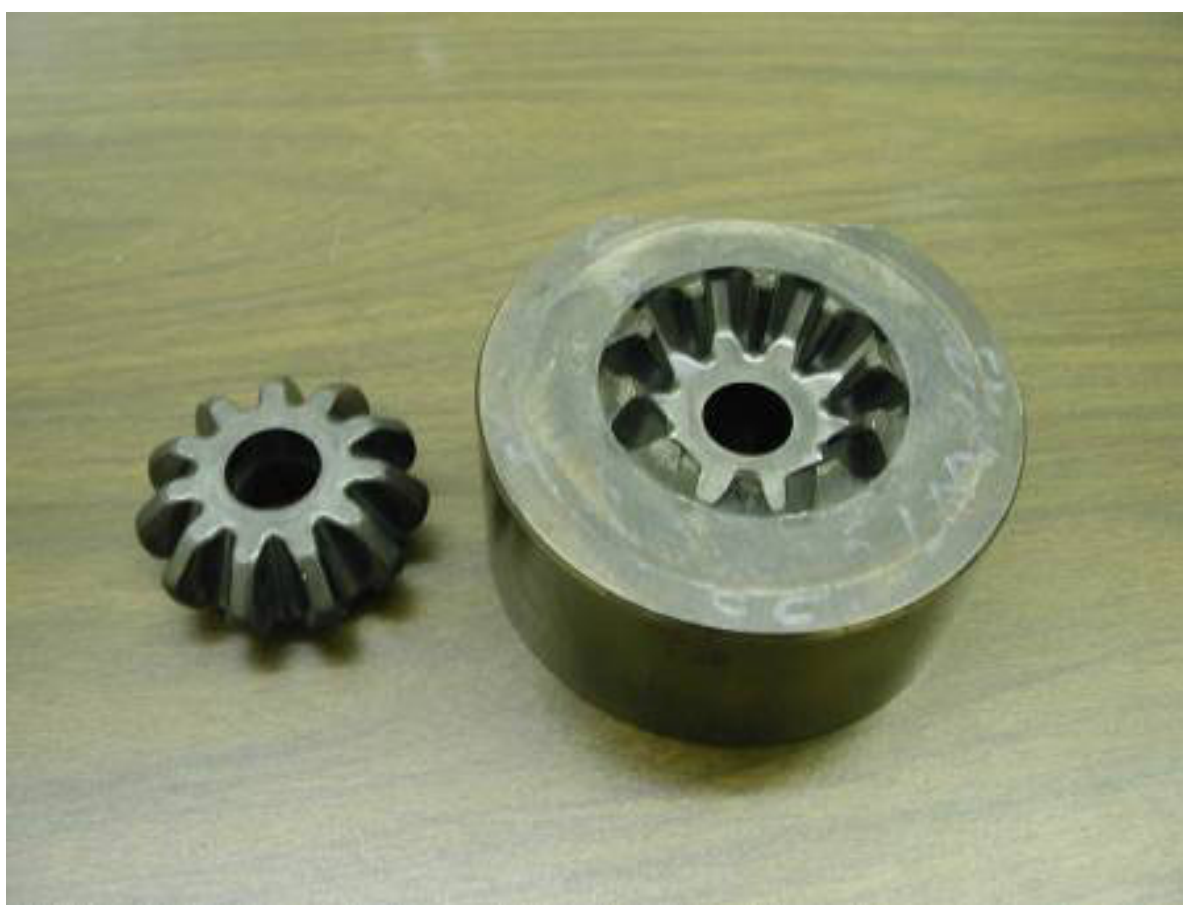

Figure 43. Spray-formed M2 tool steel forging die with forged steel gear. 

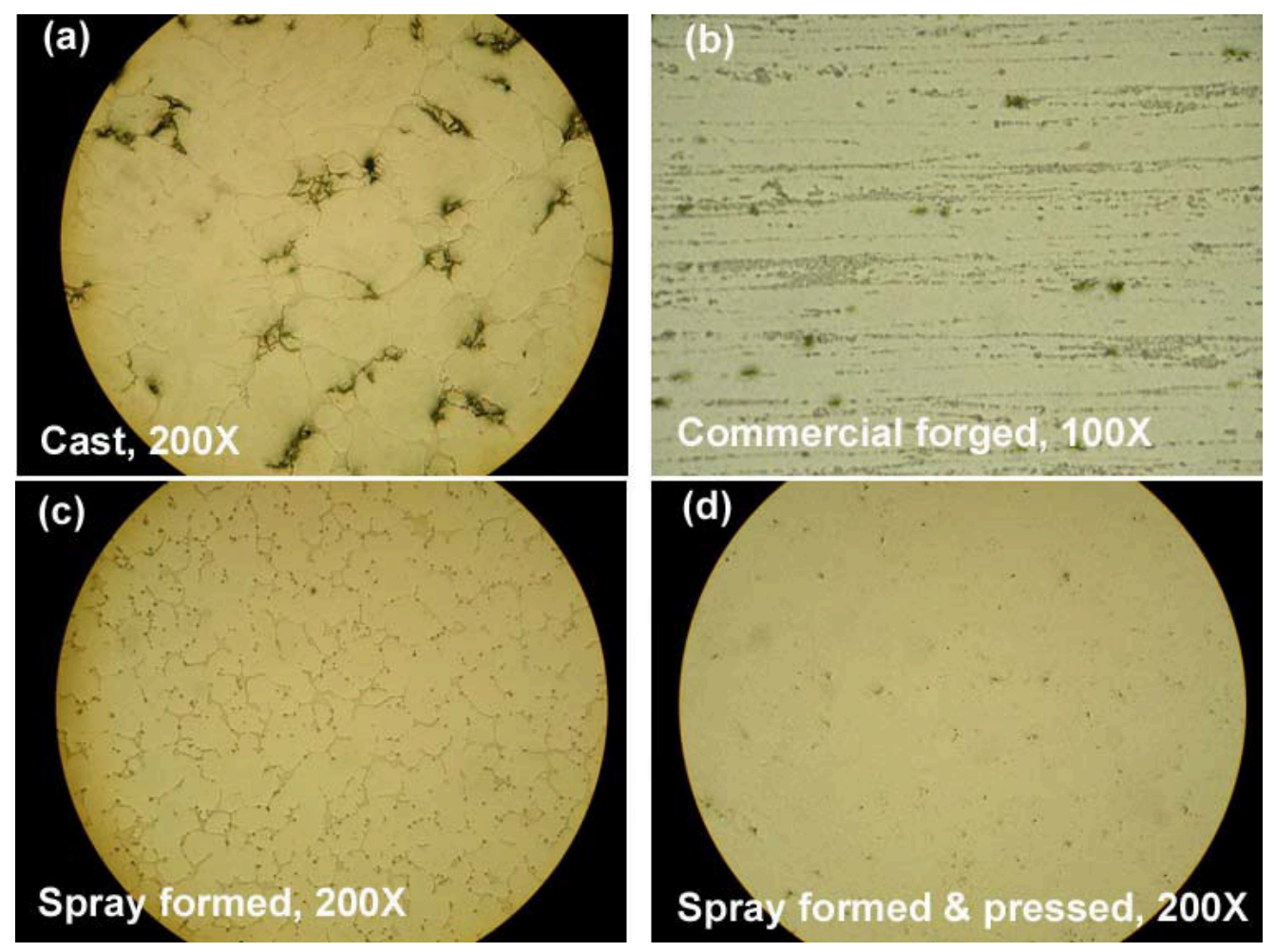

Figure 44. Photomicrographs of (a) cast, (b) commercial forged, (c) spray formed, and (d) sprayformed/pressed M2 tool steel.

\subsubsection{A2 Tool Steel}

A2 tool steel is an air hardening tool steel with high wear resistance and good toughness. Its properties make it well suited for a wide variety of tooling applications, particularly molding and processing of abrasive materials. The chemistry of A2 (wt\%) is $1.0 \mathrm{C}-0.85 \mathrm{Mn}-0.35 \mathrm{Si}-5.25 \mathrm{Cr}-$ $1.1 \mathrm{Mo}-0.25 \mathrm{~V}$.

3.4.5.1 Hardness and Microstructure. Industry partners supplied a stereolithography master of the glass-forming mold shown in Figure 45. The master was used to cast ceramic tool patterns from which two dies, also shown in Figure 45, were spray formed. One of these was provided to the industry partner for in-service analysis while the other was sectioned for heat treatment, hardness testing, and microstructure analysis (Figure 46).

Prior-austenite grain boundaries are clearly resolved in Figure 46. The grain structure is equiaxed with an average grain size of about $80 \mu \mathrm{m}$ and was uniform along the cross section. Average hardness of the as-deposited dies was 45 HRC.

As shown in Figure 47, application of a uniaxial force, using a room temperature metal plate, to a spray-formed A2/4340 steel clad immediately following deposition significantly decreased the grain size due to the enhanced cooling rate. The average grain size was reduced from about $80 \mu \mathrm{m}$ in the unpressed region to about $35 \mu \mathrm{m}$ in the pressed region.

Figure 48 compares the microstructures of cast A2, forged/annealed commercial material, asdeposited A2, and spray-formed A2 that was aged at $500^{\circ} \mathrm{C}$ for $2 \mathrm{~h}$. The cast material had a coarse dendritic structure with carbide segregation between dendrite arms. Extensive hot working at the steel 
mill broke up the segregate and formed carbide stringers in the forging direction. In contrast, the sprayformed and free-convection-cooled alloy had a refined structure with a uniform distribution of small carbide particles.

The microstructure of as-deposited A2 was analyzed using OM and XRD. Figure 49 is an OM micrograph of as-deposited A2, showing needle-like martensite and a large amount of retained austenite. The XRD pattern in Figure 50 confirms the existence of martensite and retained austenite. The high carbon (and other alloying element) content of A2 lowers the martensite start temperature, $\mathrm{M}_{\mathrm{S}}$, resulting in an increase in retained austenite. Retained austenite in spray-formed A2 is high because the metal rapidly transitions from the molten state through a high austenitizing temperature, allowing the austenite composition to be enriched in carbon and other alloying elements, which lowers $\mathrm{M}_{\mathrm{S}}$. High austenitizing temperatures reduce as-deposited hardness, increase the amount of retained austenite, and increase the prior-austenite grain size.

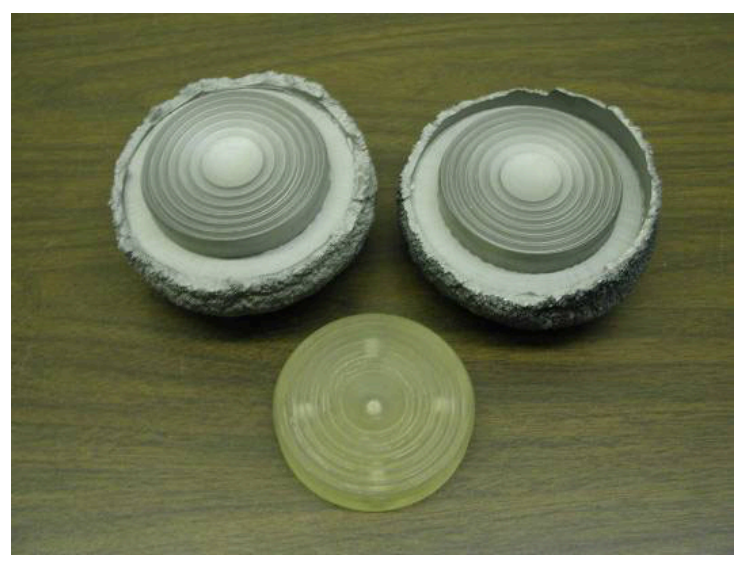

Figure 45. As-deposited A2 tool steel glass-forming dies and stereolithography master.
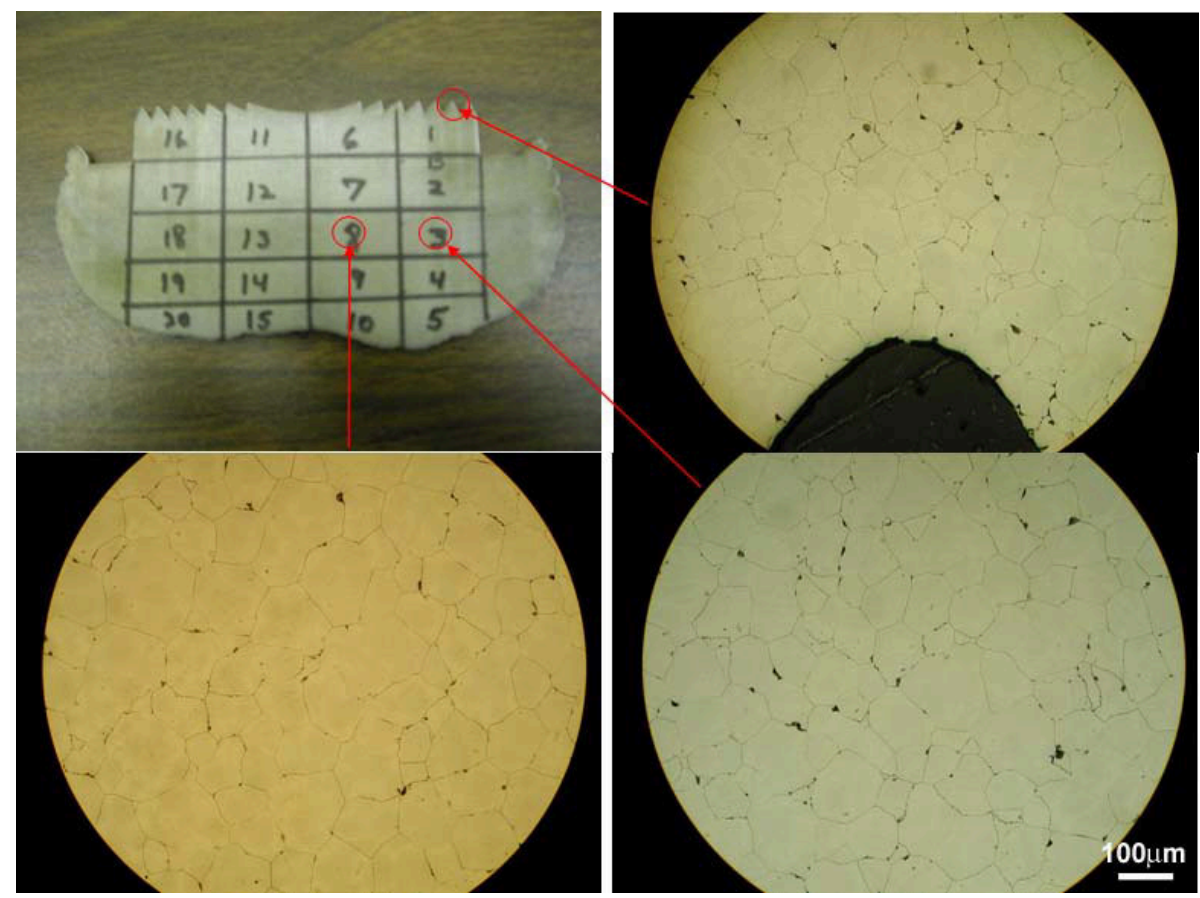

Figure 46. Microstructure at the surface and interior of an as-deposited A2 tool steel mold. 200X. 


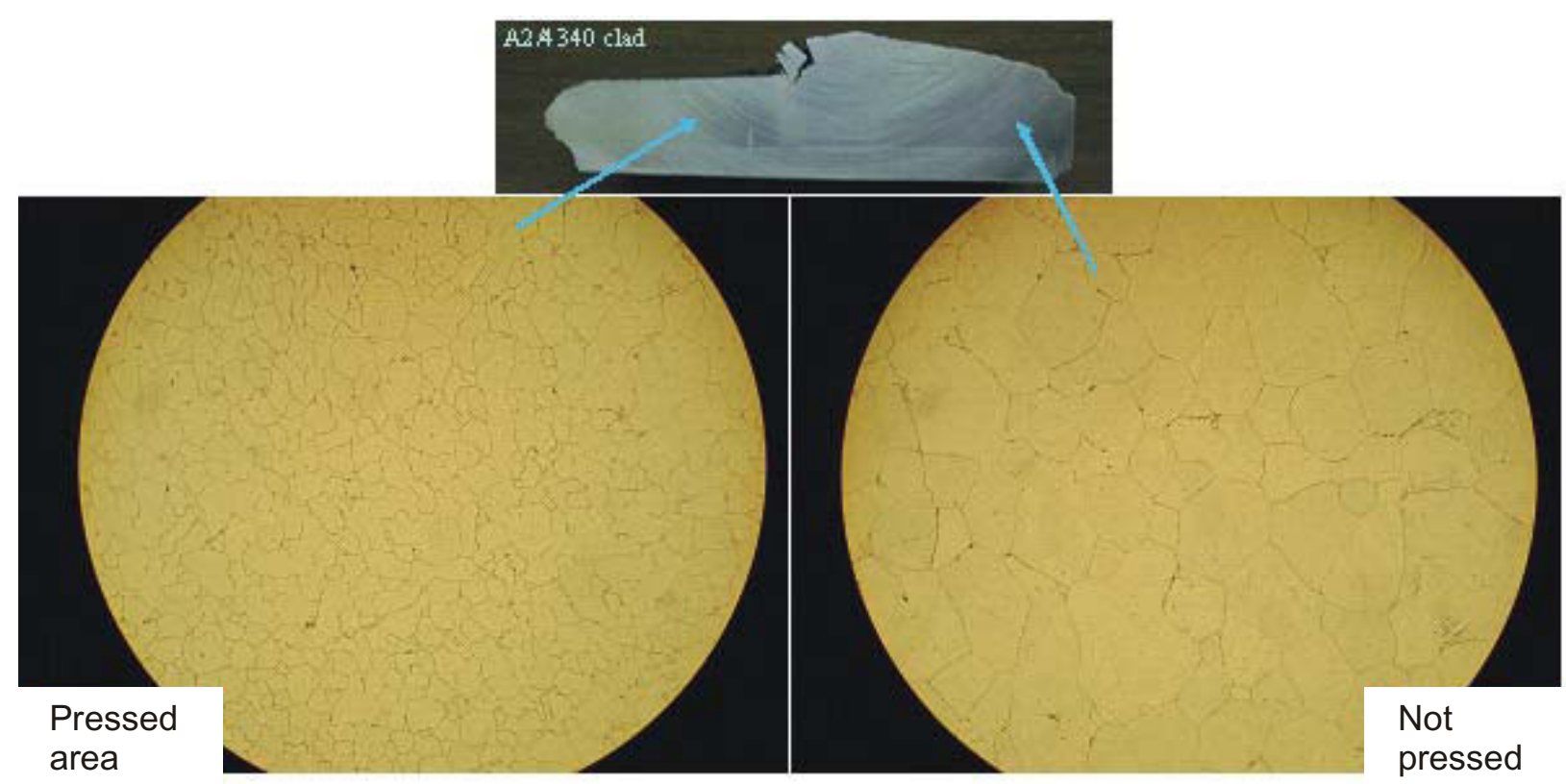

Figure 47. Photomicrographs of A2/4340 steel clad. 200X.
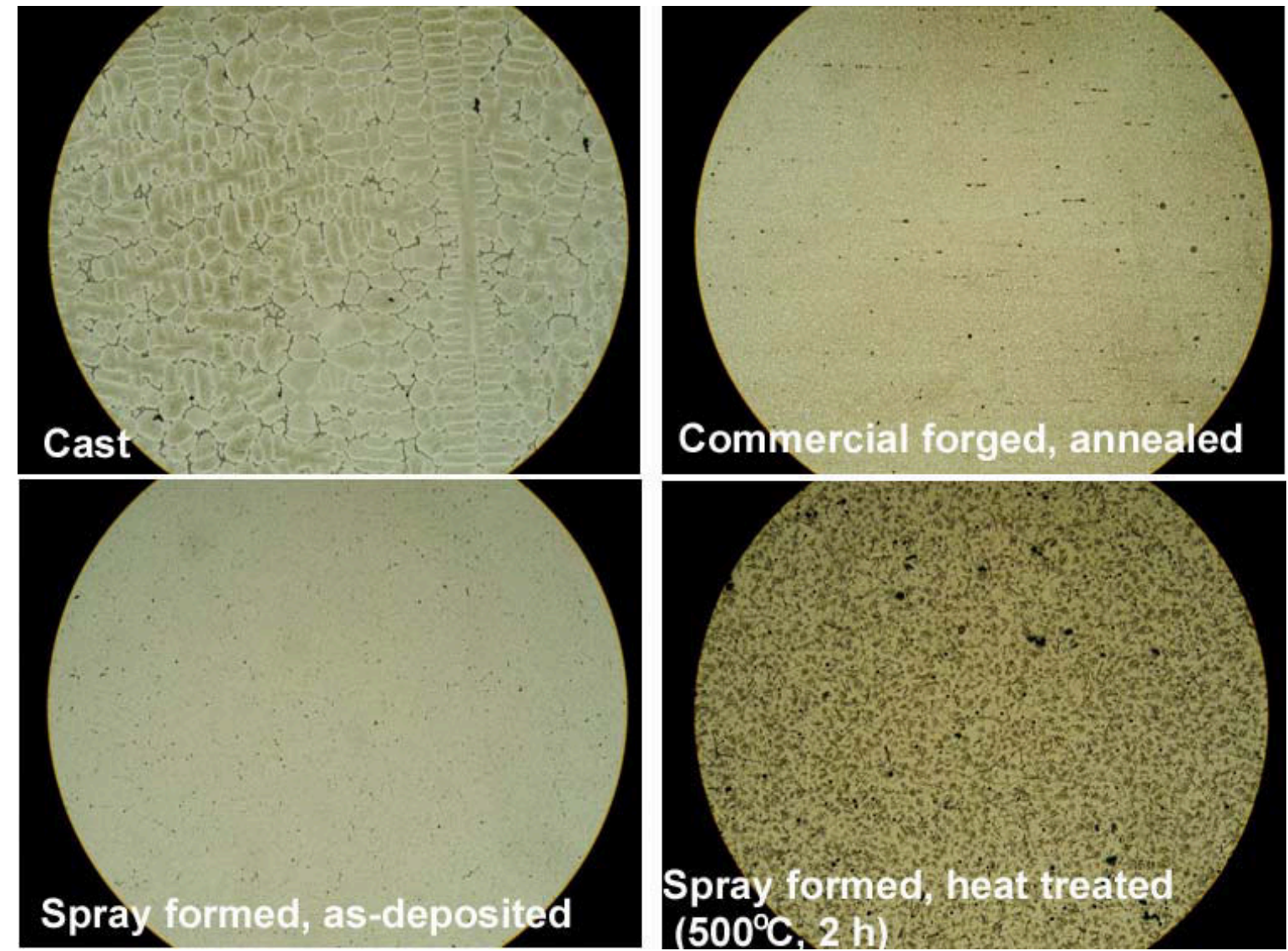

Figure 48. 50X photomicrographs of A2 tool steel.

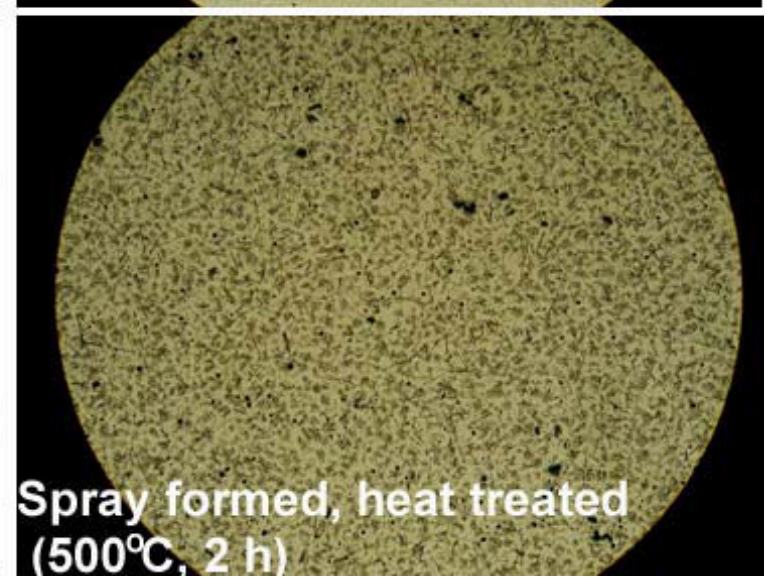




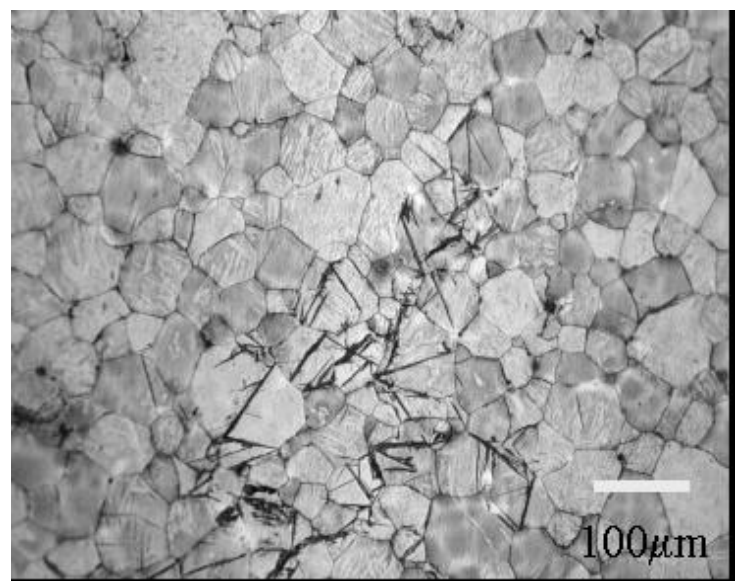

Figure 49. OM microstructure of as-deposited $\mathrm{A} 2$.

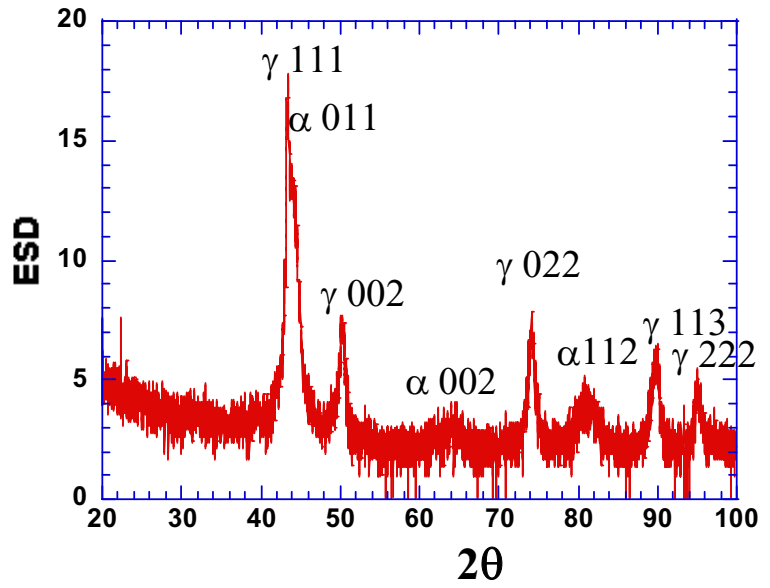

Figure 50. XRD pattern of as-deposited A2.

Figure 51 illustrates the microstructure transformations that occur in spray-formed A2 during artificial aging. Retained austenite in as-deposited A2 begins to decompose and form patches of martensite needles (plates) following a 2-h soak between 100 and $200^{\circ} \mathrm{C}$. This is a diffusionless transformation and is not accompanied by a change in chemical composition. The rise in hardness that results from the formation of martensite appears initially to be offset by strain relieving, and the hardness drops slightly until about $400^{\circ} \mathrm{C}$. As the soak temperature increases, a large secondary hardening peak is observed with a rise in hardness from about $42 \mathrm{HRC}$ at $400^{\circ} \mathrm{C}$ to a peak-age hardness of $55 \mathrm{HRC}$ at $550^{\circ} \mathrm{C}$. As the soak temperature increases to about $700^{\circ} \mathrm{C}$, the matrix phase transforms to bainite with a large drop in hardness.

Figure 52 compares 1000X photomicrographs of commercial forged and spray-formed A2 samples that were conventionally heat treated. Samples were austenitized at $950^{\circ} \mathrm{C}(40 \mathrm{~min}$.), air cooled,and double tempered $(2 \mathrm{~h}+2 \mathrm{~h})$ at $550^{\circ} \mathrm{C}$. The microstructures are very similar, consisting of a few spheroidal particles of carbide in tempered martensite. The hardness of both samples was about 51 HRC.

Figure 53 provides results of SEM/EDS analysis of features observed in as-deposited A2, while Figure 54 provides results for peak-age hardened A2.

Spray-formed and commercial forged A2 were conventionally heat treated by austenitizing at $950^{\circ} \mathrm{C}$ for $40 \mathrm{~min}$ followed by quenching in air and double tempering at $567^{\circ} \mathrm{C}$. In both cases, this heat treatment resulted in the formation of tempered martensite with spheroidal carbide particles. SEM/EDS analysis is provided in Figure 55 (commercial forged) and Figure 56 (spray formed). Similar microstructures are observed except that carbide particles in the spray-formed material are smaller and more uniformly distributed.

The temper response of spray-formed and commercial forged A2 tool steel was compared by evaluating the hardness of samples that were austenitized at $950^{\circ} \mathrm{C}$ for $40 \mathrm{~min}$, air cooled, and double tempered $(2 \mathrm{~h}+2 \mathrm{~h})$ at various temperatures. Results, summarized in Figure 57, indicated that the two materials responded in a similar way to conventional heat treatment. The as-quenched hardness of sprayformed A2, $65 \mathrm{HRC}$, was slightly higher than that of the commercial forged material (63 HRC). The high hardness is attributable to $\mathrm{C}$ atoms trapped in the octahedral interstitial sites of the martensite crystal structure. As tempering temperature is increased, carbides precipitate. At higher temperatures the microstructure of the steel is transformed to bainitic mixtures of carbides and ferrite. 


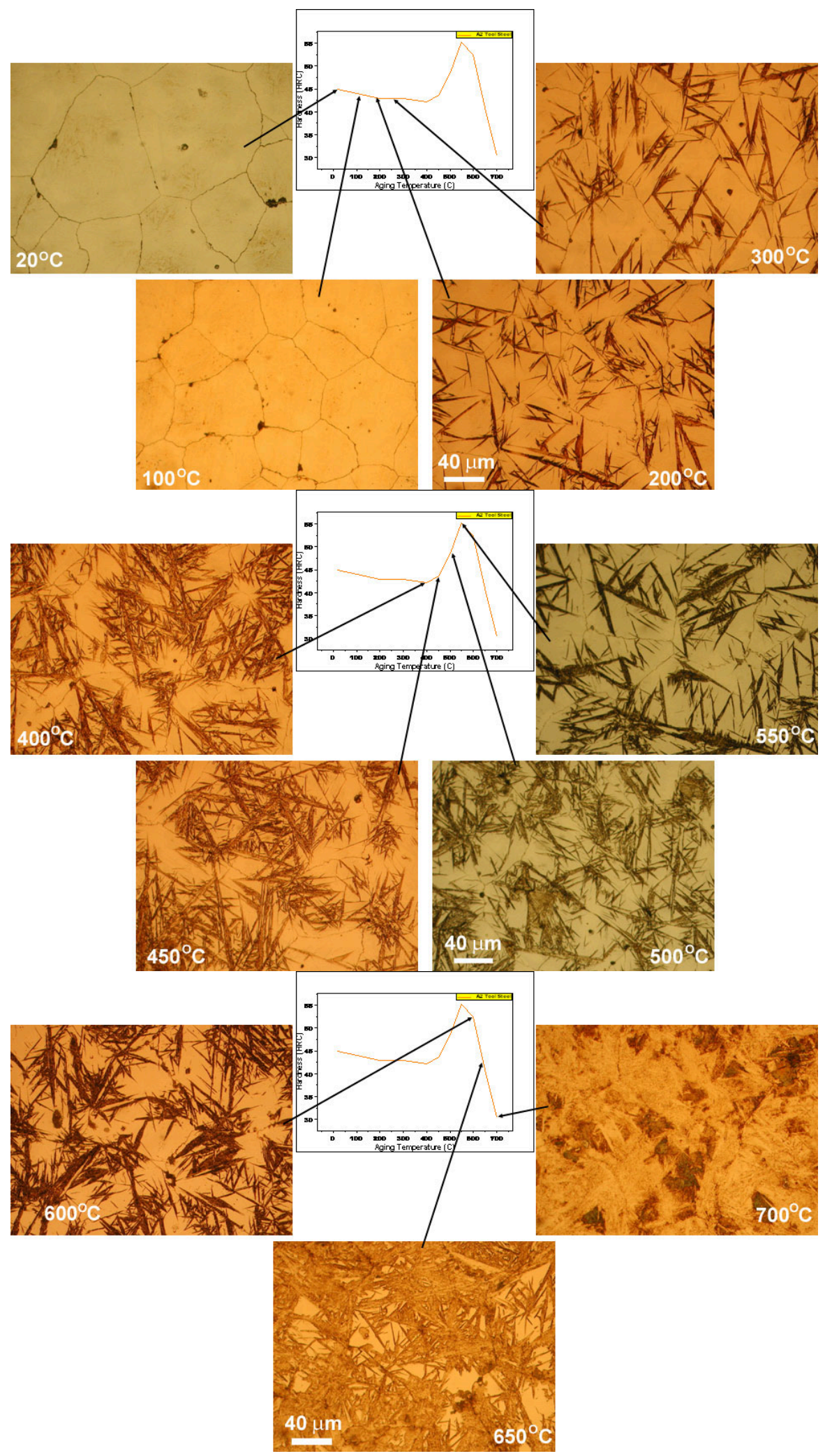

Figure 51. Microstructure transformation of spray-formed A2 during aging. 500X photomicrographs. $3 \%$ nital etch. 

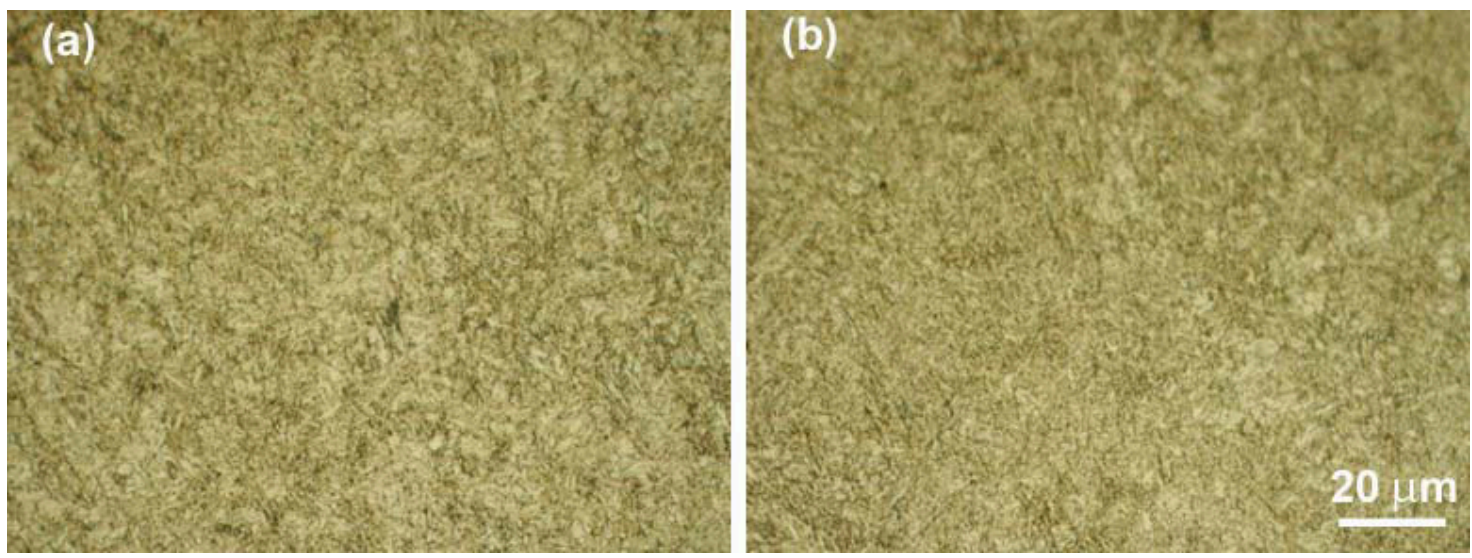

Figure 52. Photomicrographs of conventionally heat treated (austenitized/quenched/tempered) A2 . (a) Commercial forged. (b) Spray formed.
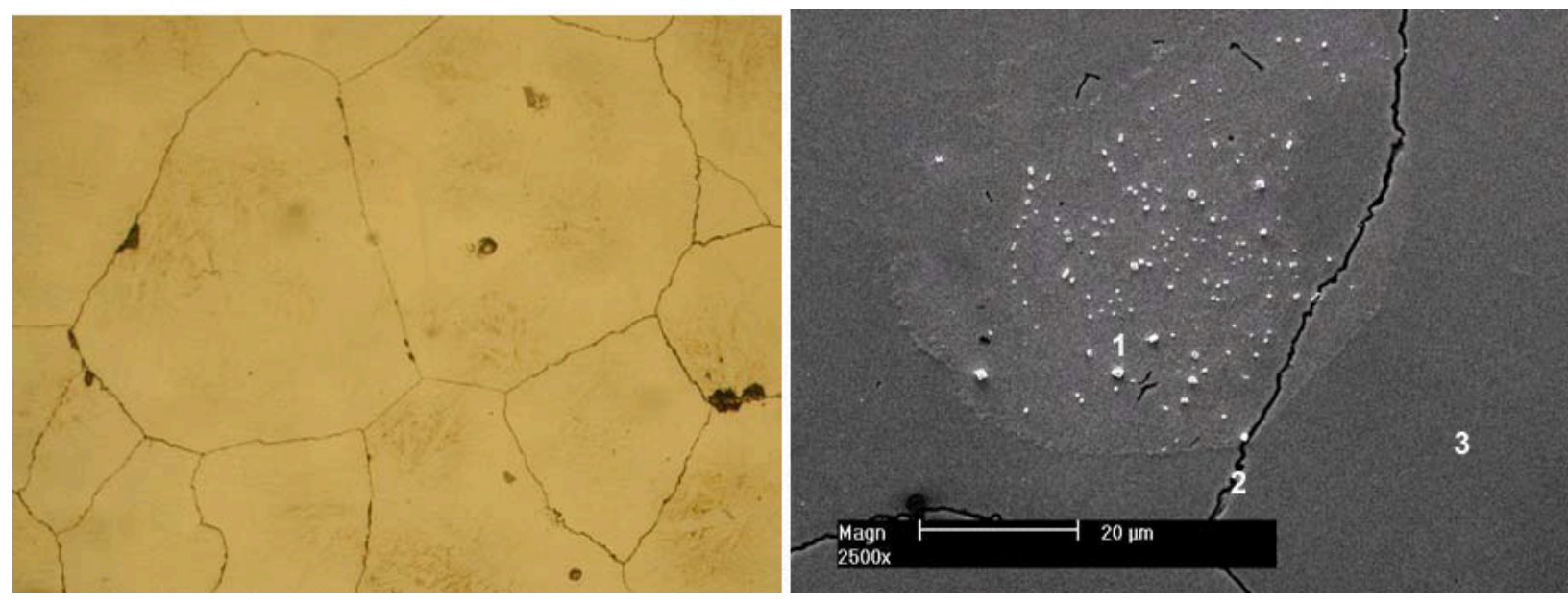

\begin{tabular}{|c|c|c|c|}
\hline Element & $\begin{array}{c}\text { Spot 1 } \\
(\text { wt\%) }\end{array}$ & $\begin{array}{c}\text { Spot 2 } \\
(\text { wt } \%)\end{array}$ & $\begin{array}{c}\text { Spot 3 } \\
(\text { wt\%) }\end{array}$ \\
\hline $\mathrm{Fe}$ & 95.1 & 95.1 & 93.1 \\
\hline $\mathrm{Cr}$ & 4.4 & 4.5 & 6.3 \\
\hline $\mathrm{C}$ & 0.4 & 0.3 & 0.7 \\
\hline $\mathrm{V}$ & 0.1 & 0.1 & 0.2 \\
\hline
\end{tabular}

Figure 53. Optical and SEM photomicrographs of as-deposited A2. EDS analysis results of features shown in the SEM photomicrograph are summarized in the table. 

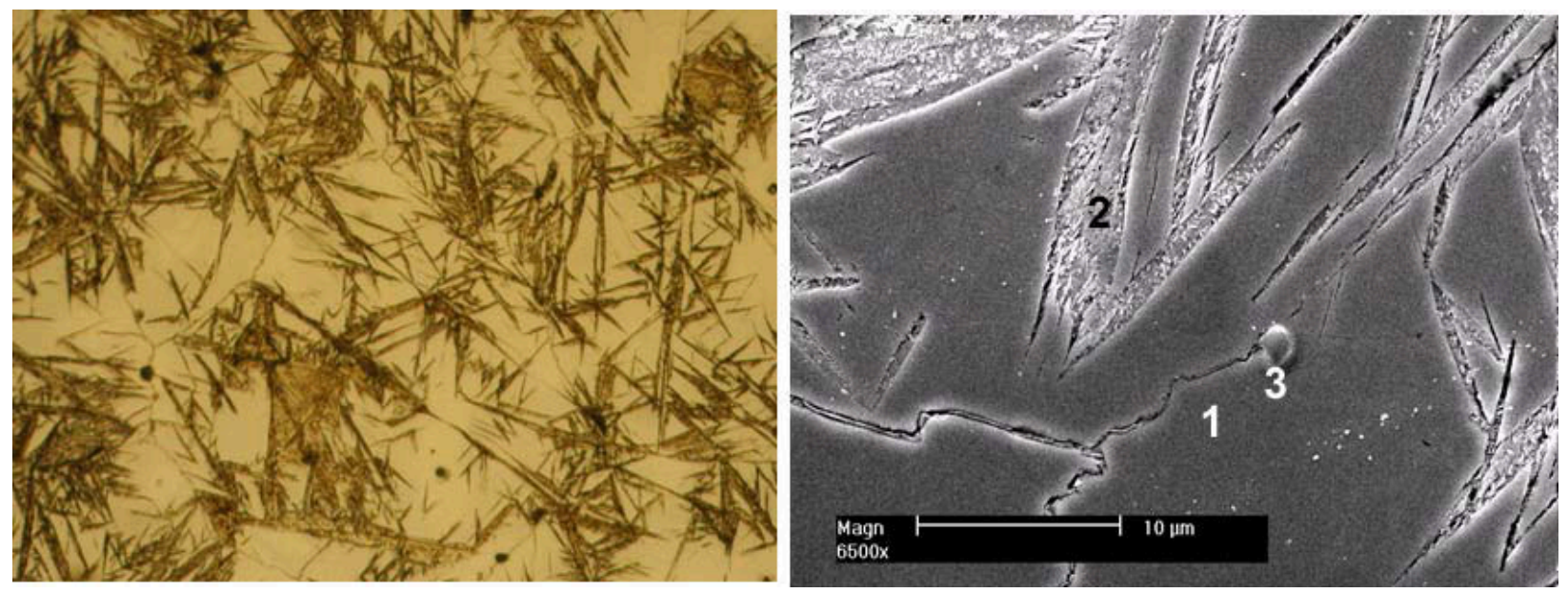

\begin{tabular}{|c|c|c|c|}
\hline Element & $\begin{array}{c}\text { Spot 1 } \\
(\mathrm{wt} \%)\end{array}$ & $\begin{array}{c}\text { Spot 2 } \\
(\mathrm{wt} \%)\end{array}$ & $\begin{array}{c}\text { Spot 3 } \\
(\mathrm{wt} \%)\end{array}$ \\
\hline $\mathrm{Fe}$ & 94.5 & 94.6 & 47.5 \\
\hline $\mathrm{Cr}$ & 4.9 & 4.9 & 6.7 \\
\hline $\mathrm{C}$ & 0.4 & 0.3 & 0.4 \\
\hline $\mathrm{V}$ & 0.2 & 0.2 & 11.8 \\
\hline $\mathrm{Ti}$ & 0 & 0 & 33.7 \\
\hline
\end{tabular}

Figure 54. Optical and SEM photomicrographs of spray-formed A2 following an aging heat treatment $\left(500^{\circ} \mathrm{C}, 2 \mathrm{~h}\right)$. EDS analysis results of features shown in the SEM photomicrograph are summarized in the table.
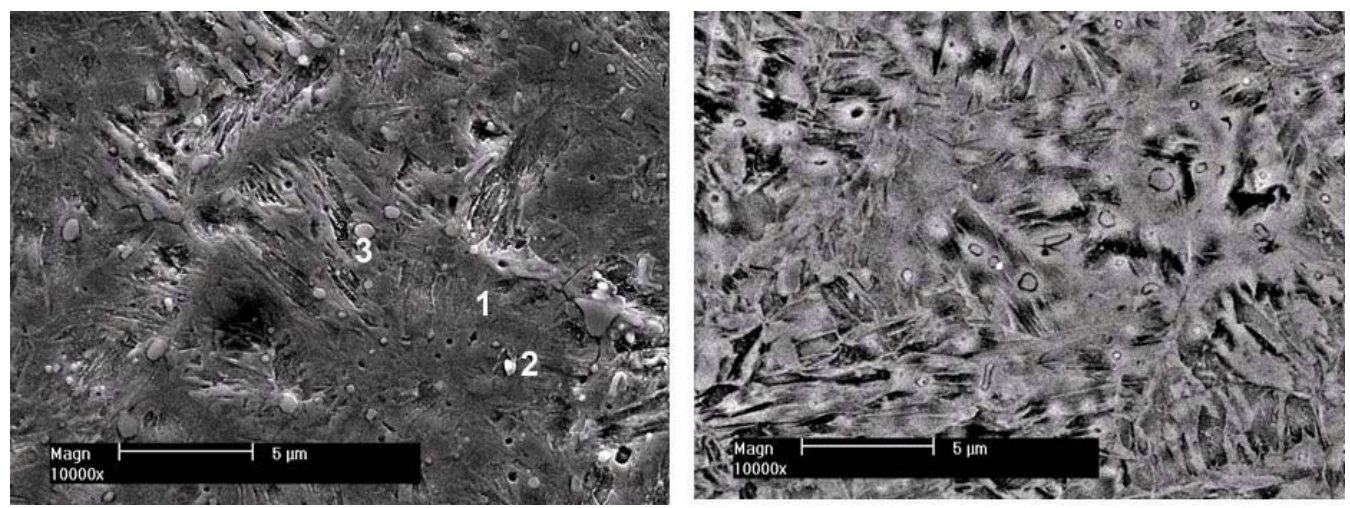

\begin{tabular}{|c|c|c|c|}
\hline Element & $\begin{array}{c}\text { Spot 1 } \\
(\mathrm{wt} \%)\end{array}$ & $\begin{array}{c}\text { Spot 2 } \\
(\mathrm{wt} \%)\end{array}$ & $\begin{array}{c}\text { Spot 3 } \\
(\mathrm{wt} \%)\end{array}$ \\
\hline $\mathrm{Fe}$ & 92.8 & 73.8 & 94.4 \\
\hline $\mathrm{Cr}$ & 6.3 & 22.2 & 5.0 \\
\hline $\mathrm{Mo}$ & 0 & 1.0 & 0 \\
\hline $\mathrm{C}$ & 0.7 & 0.9 & 0.3 \\
\hline $\mathrm{V}$ & 0.2 & 2.1 & 0.4 \\
\hline
\end{tabular}

Figure 55. SEM photomicrographs of commercial A2 following a conventional heat treatment $\left(950^{\circ} \mathrm{C}\right.$ $\left.[40 \mathrm{~min}]+567^{\circ} \mathrm{C}[2 \mathrm{~h}+2 \mathrm{~h}]\right)$. 

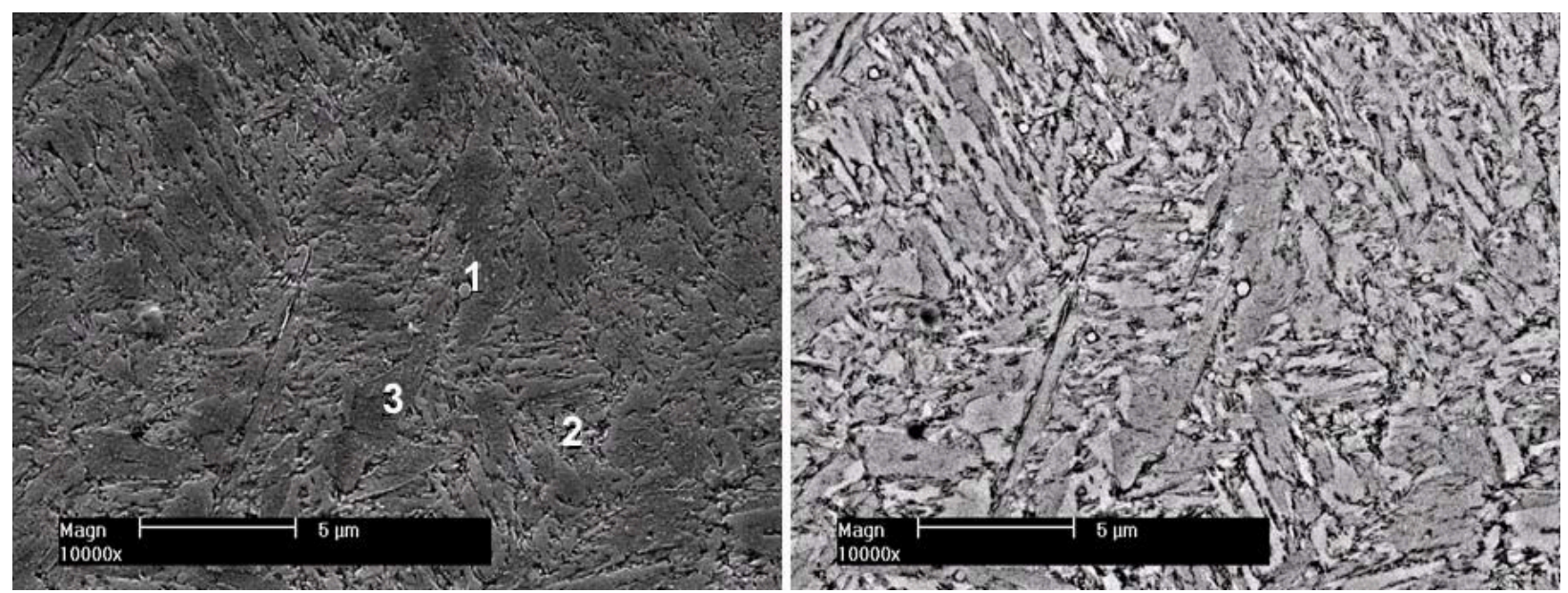

\begin{tabular}{|c|c|c|c|}
\hline Element & $\begin{array}{c}\text { Spot 1 } \\
(\text { wt\%) }\end{array}$ & $\begin{array}{c}\text { Spot 2 } \\
(\text { wt\%) }\end{array}$ & $\begin{array}{c}\text { Spot 3 } \\
(\text { wt\%) }\end{array}$ \\
\hline $\mathrm{Fe}$ & 86.4 & 94.2 & 94.2 \\
\hline $\mathrm{Cr}$ & 12.6 & 5.2 & 5.1 \\
\hline $\mathrm{Mo}$ & 0.5 & 0 & 0 \\
\hline $\mathrm{C}$ & 2.5 & 0.4 & 0.3 \\
\hline $\mathrm{V}$ & 0.4 & 0.2 & 0.3 \\
\hline
\end{tabular}

Figure 56. SEM photomicrographs of spray-formed A2 following a conventional heat treatment $\left(950^{\circ} \mathrm{C}\right.$ $\left.[40 \mathrm{~min}]+567^{\circ} \mathrm{C}[2 \mathrm{~h}+2 \mathrm{~h}]\right)$.

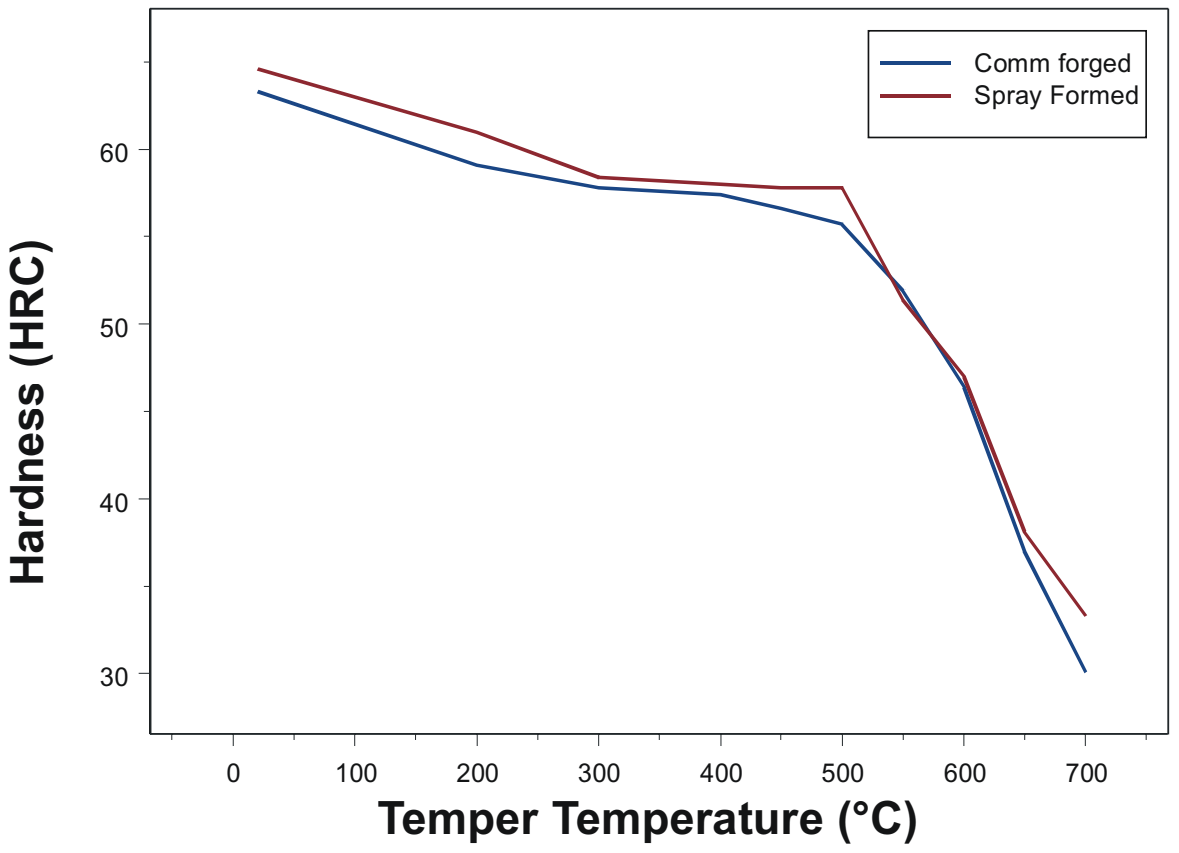

Figure 57. Temper curves for commercial forged and spray-formed A2 tool steel. 


\subsubsection{Numerical Analysis of Residual Stresses in A2 Tool Steel.}

The residual stresses were analyzed using a finite element method. The residual stress state was determined by coupled thermoelastic equations. To solve the nonlinear coupled temperature-displacement equations, the equations need to be integrated over time repeatedly. In the present study, a commercial finite element code, ABAQUS, ${ }^{\text {b }}$ was employed to solve the thermoelastic equations. The backward difference algorithm is used as a time integration operator in ABAQUS. The geometric model was meshed by four-node elements because of the symmetry of geometry. The mesh was refined in the regions where large temperature gradients or large geometric gradients exist. The calculation was carried out from coarse meshes to finer meshes to obtain accurate convergent numerical data. The results shown below arise from the model with 2229 nodes and 1952 elements (see Figure 58).

The residual stresses are related to the initial temperature field, thermal expansion coefficient, thermal conductivity, elastic modulus, and other material parameters. To compare with the experimental results, some data, e.g. elastic modulus, specific heat, and Poisson ratio are chosen from the experimental measurements. It should be pointed out that the thermophysical properties are dependent on the temperature. The residual stresses are then influenced by these temperature-dependent factors. In this study, the properties are assumed to be independent of temperature.

Figure 59 shows the von Mises stress distribution in spray-formed A2 tool steel. During spray forming, high stress only exists in the small region where the molten particles impact. Large temperature gradients occur in the top surface and decrease sharply toward the underlying layers. So the quenching stresses mainly exist in the exposed surface band. This point was confirmed by the numerical results. It is seen that the von Mises equivalent stress decreases from the surface zone to the bottom band and peripheral zone. The maximum von Mises stress occurs at the point in the top surface, which means that the transient thermal gradient stress plays the main role in the residual stress. The highest value of von Mises stress calculated was $235 \mathrm{MPa}$. Although this is a large residual stress, A2 tool steel has a yield stress of $1600 \mathrm{MPa}$, so these stresses are still within the elastic regime of the material.

The radial stress distribution is shown in Figure 60. The spray-forming process usually introduces compressive stresses to the materials. The radial stress is compressive in the upper zone of the deposited material and tensile in the bottom and peripheral zones. The radial stress in the upper region is higher than that in the lower region. Also, the tensile radial stress is at least one order of magnitude less than the compressive radial stress. The interior and surface band have different cooling histories. The surface band has a higher cooling rate and, therefore, higher cooling stress than the interior. For this reason, the interior has a tensile radial stress state. The highest value of tensile radial stress is about 27.8 MPa.

As shown in Figure 61, the axial stress is compressed in most of the spray-formed part and is tensile only in peripheral zone. In the top layer, the axial stress varies from compressive to tensile from the top point toward the periphery. The value of axial stress decreases from the surface band to the bottom band and peripheral zone. The highest values of axial stress and radial stress are on the same order, $231 \mathrm{MPa}$.

The shear stress (Figure 62) is at least one order of magnitude less than the radial stress and axial stress. Thus, shear stress can be neglected in the residual stresses consideration. The shear stress results from geometric constraints and microstructure deflection while, in general, the radial stress and axial stress are due to thermal deformation. These results show that geometric constraints have some effect on the residual stress, but the thermal gradient plays the main role.

b. Hibbitt, Karlsson, and Sorensen, Inc., Pawtucket, Rhode Island. 

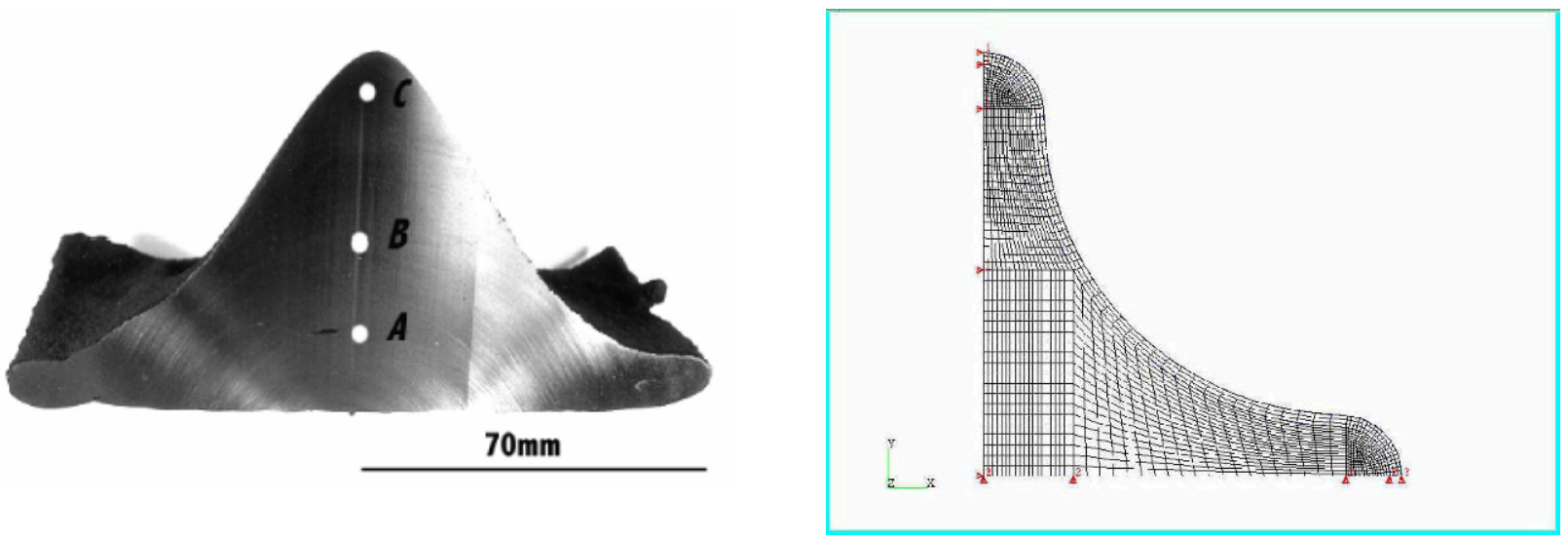

Figure 58. Spray-formed A2 tool steel (left) and axisymmetric finite element mesh for this part (right).

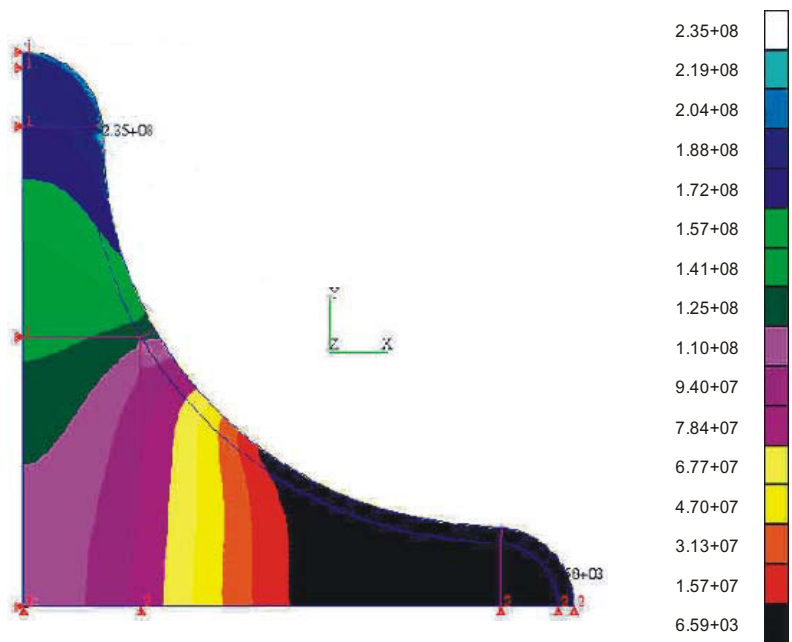

Figure 59. Von Mises stress distribution of spray-formed A2 tool steel.
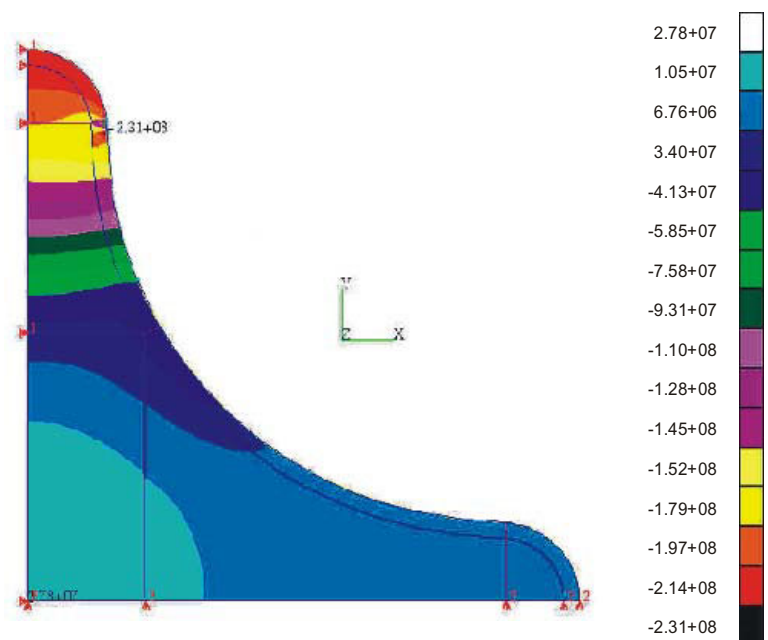

Figure 60. Radial stress distribution of spray-formed A2 tool steel. 


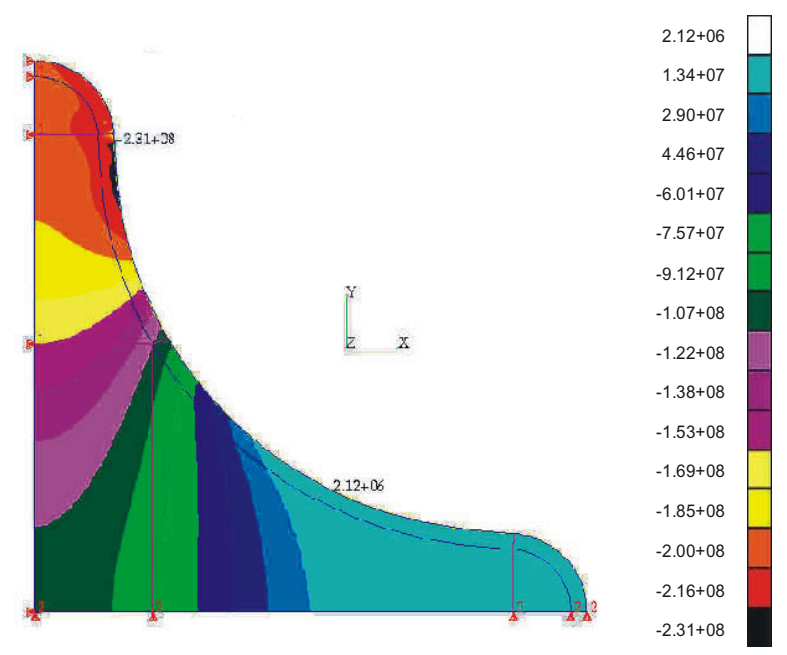

Figure 61. Axial stress distribution of spray-formed A2 tool steel.

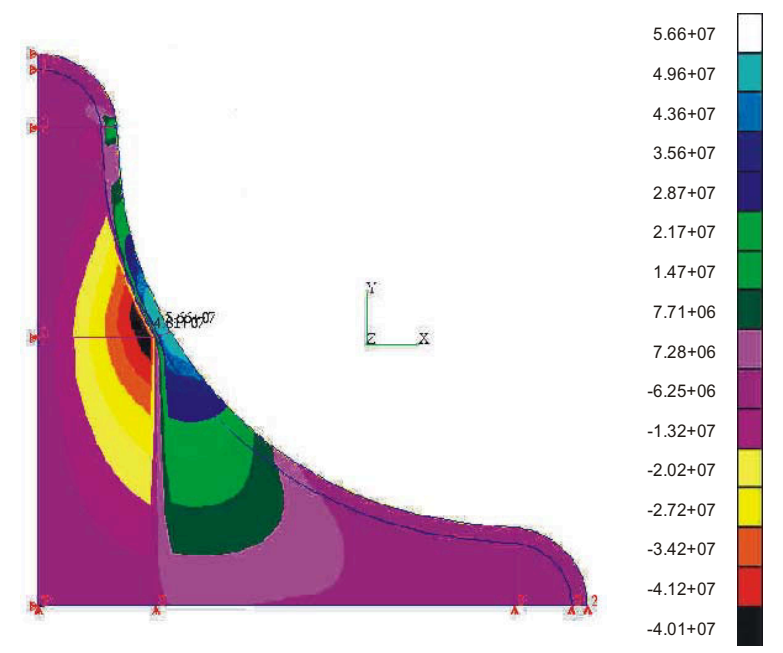

Figure 62. Shear stress distribution of spray-formed A2 tool steel.

The residual stress distribution along the centerline is shown in Figure 63. From previous X-ray experimental measurements, the radial stresses at 31 and $48 \mathrm{~mm}$ from the bottom along the centerline are -121 and $-192 \mathrm{MPa}$, respectively. The numerical data coincide with the experimental results very well at the measurement points. This shows that the numerical method, with appropriate assumptions and initial boundary conditions, can reveal the entire residual stress state and predict the thermal stress very well. Figure 63 also shows the axial stress distribution along the centerline. The axial stresses change from tensile to compressive as the distance from the bottom increases. This is because the symmetric geometry imposes constraints on heat conduction in the region along centerline. Otherwise, the heat at the bottom can quickly transfer to the substrate. Then, the heat transfer rate in the bottom zone is higher than that of the upper zone. The different contraction rates cause the axial stresses at the lower part along the centerline to be tensile.

The stress states along the bottom line and surface band are shown in Figure 64. The radial stresses are greater at the top surface than at the bottom line. This shows that the quenching stresses generated by deposition are larger than the cooling stresses. This point has been confirmed by the work of Kuroda. ${ }^{23}$ 
The magnitude of axial stress increases gradually from the center toward the peripheral zone until it reaches its maximum value at about $10 \mathrm{~mm}$ from the centerline; then it drops. Two conclusions can be drawn from these results. First, the quenching stress only exists in a small region, the top layer where droplets impinge. Second, the maximum stress occurs at the junction where the depositing layer binds with the previously deposited layer. The axial stress is greater at the top surface than in the bottom line. Figure 65 shows the effect of geometric constraints on the residual stress field: stress values increase as deposit height increases. While geometric constraints have some effect on the residual stress, the thermal gradient plays the main role because the temperature gradient is very large close to top surface. The temperature gradient leads to large residual stress.

Based on these results, we conclude that:

1. The quenching process controls the residual stress field in the interfacial zone between the depositing layer and previously deposited material. A large temperature gradient leads to "sharp" heat conduction, generating large compressive stresses as identified by the numerical results. The temperature profile of the previously deposited material leads to heat conduction in this zone that is stable and gentle. This is verified by the stress distribution at inner layers and the bottom.

2. Reheating occurs in the region below the top surface. Heat transfers from the top to the bottom and peripheral region, leading to a more uniform temperature distribution and residual stress field.

3. The geometric constraints affect the residual stress. Because the geometry is symmetric, the region near the centerline has more constraints. The radial stress is higher at the bottom near the centerline than far from the centerline, showing the effect of constraint.

\subsubsection{Metallic Glass-Forming Alloys}

Recently, near-eutectic steels have been developed that form an amorphous, metallic glass structure if the cooling rate exceeds about $10^{5} \mathrm{~K} / \mathrm{s}$. These alloys have the potential to form very hard and strong tools. One such alloy, SHS 727, is a nine-element steel containing Fe, Cr, Mo, W, C, Mn, Si, Zr, and B. The alloy was melted at about $1250^{\circ} \mathrm{C}$, superheated, and spray deposited onto ceramic tool patterns to form two forging dies. An example is shown in Figure 66. One of these dies was sectioned for hardness and microstructure analysis.

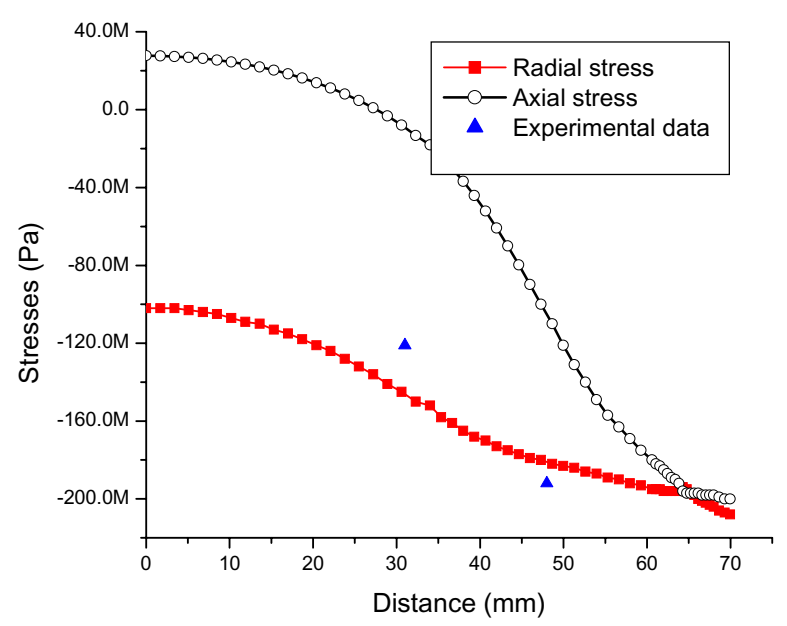

Figure 63. Stresses along the centerline vs. distance from bottom. 


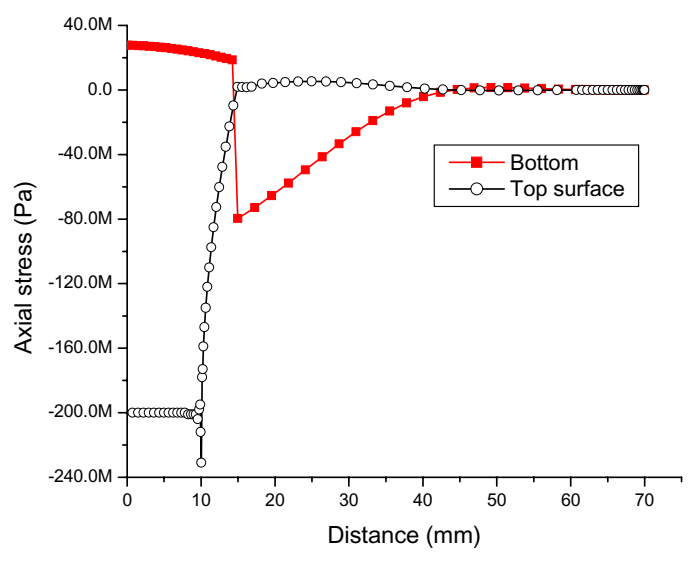

(a)

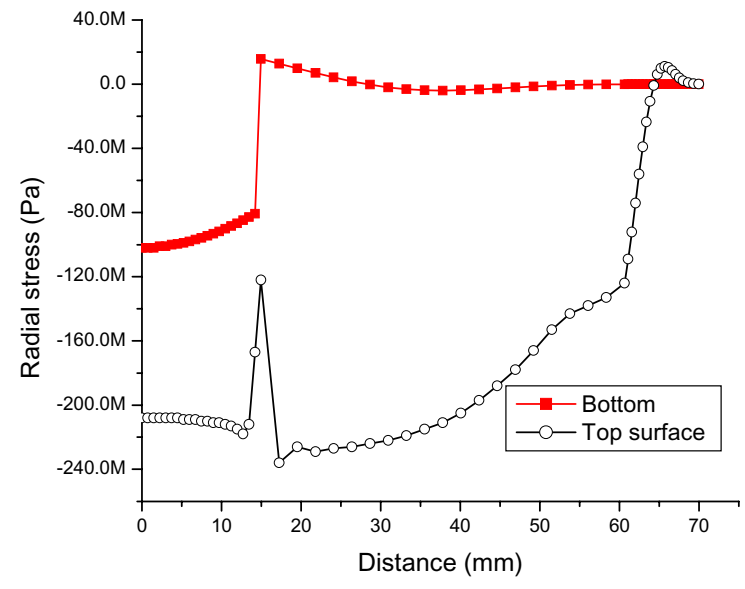

(b)

Figure 64. Stress distribution along the bottom line and top surface (distance from centerline to peripheral zone). (a) Axial stress. (b) Radial stress.

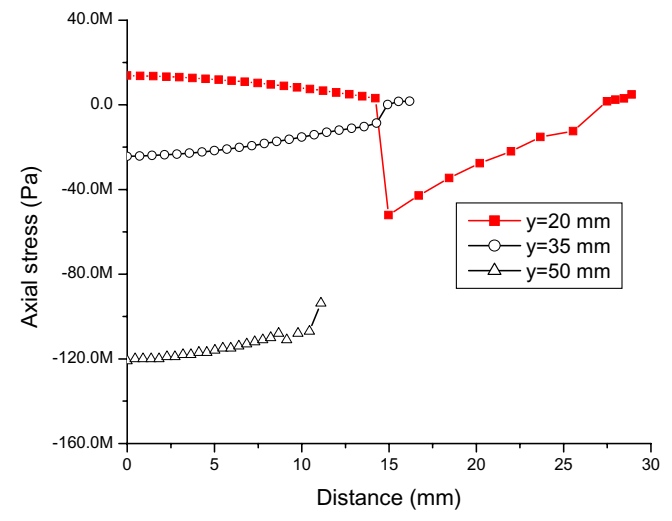

(a)

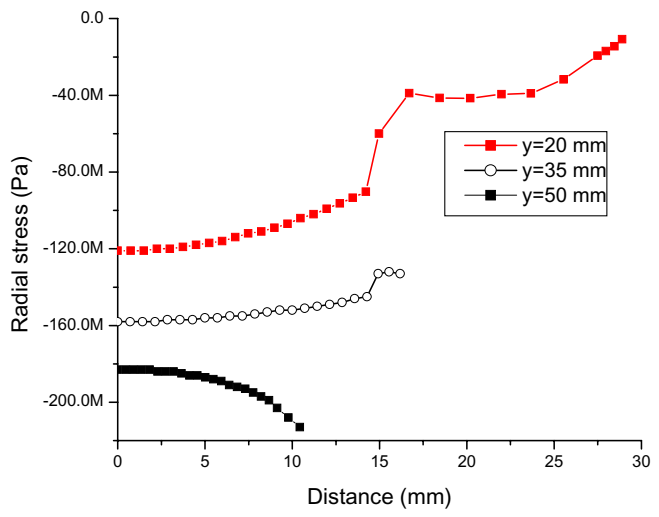

(b)

Figure 65. Stress distribution at height distances of 20, 35, and $50 \mathrm{~mm}$ (axis distance valued from centerline to peripheral zone). (a) Axial stress. (b) Radial stress.

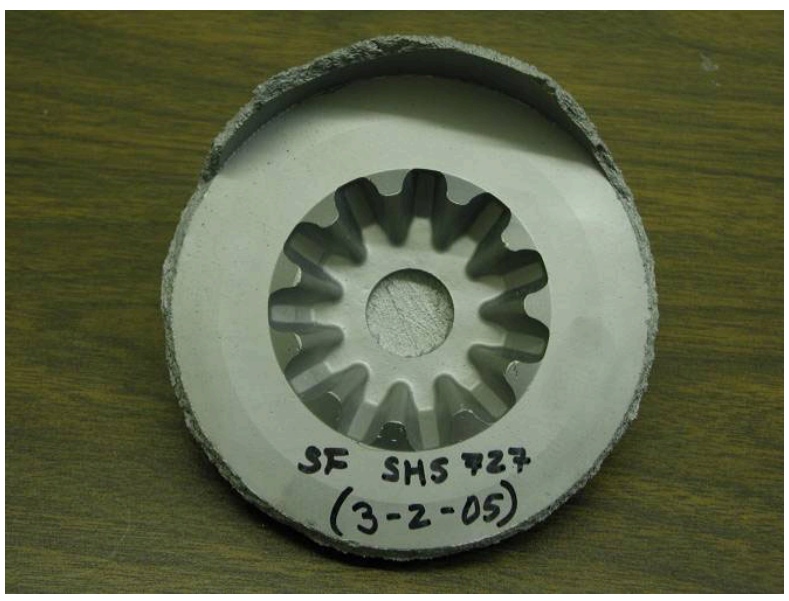

Figure 66. Spray-formed SHS 727 forging die. 
As-deposited hardness was about 58 HRC. Representative photomicrographs of the spray-formed and the cast alloy are shown in Figure 67. Spray forming resulted in a narrow band of deposit with an amorphous structure at the deposit/tool pattern interface. The bulk of the deposit was microcrystalline. The distribution of secondary phases in the spray-formed metal was significantly more uniform than in the cast metal, as shown in Figure 67.

Energy-dispersive spectroscopic analysis of the primary phases indicated that the light phase in both samples was rich in $\mathrm{W}$ and Mo while the surrounding matrix was rich in $\mathrm{Fe}$ and $\mathrm{Mn}$.

The hardness response of spray-formed material to artificial aging is summarized in Figure $38 \mathrm{f}$. The drop in hardness from $58 \mathrm{HRC}$ in the as-deposited material to $54 \mathrm{HRC}$ following a 2-h soak at $450^{\circ} \mathrm{C}$ indicated that there is significant relief of stresses that form due to volume change during solidification. Secondary hardening was observed, presumably due to precipitation of carbides, and resulted in a rise in hardness of about $3 \mathrm{HRC}$. The peak-age hardness $(57.5 \mathrm{HRC})$ occurred following a 2 -h soak at $550^{\circ} \mathrm{C}$, but was slightly less than the as-deposited hardness. The alloy exhibited significant resistance to softening in the overaged condition. Following a 2-h soak at $800^{\circ} \mathrm{C}$, SHS 727 still maintained significant hardness (about $51 \mathrm{HRC}$ ) in contrast to conventional tool steels such as H13.

A developmental glass-forming alloy, XPT-14, was also spray formed to generate forging dies (Figure 68). This alloy is reported to have higher toughness than SHS 727. It was developed for weld overlay hardfacing of metals such as carbon steel. As with SHS 727 , a cooling rate approaching $10^{5 \circ} \mathrm{C} / \mathrm{s}$ is required to form an amorphous or nanocrystalline steel. It also is a nine-element proprietary alloy containing Fe-Cr-Mo-Mn-W-B-C-Si-Ti; it melts at about $1250^{\circ} \mathrm{C}$.

A die was sectioned, aged, and evaluated for hardness and microstructure. As-deposited hardness was about $51 \mathrm{HRC}$, much lower than SHS 727. Hardness was evaluated following 2-h soaks at temperatures up to $800^{\circ} \mathrm{C}$ (Figure 38e). A $4 \mathrm{HRC}$ drop in hardness followed a soak at $200^{\circ} \mathrm{C}$. This was followed by a gradual rise in hardness as soak temperature increased to a peak-age hardness of $52 \mathrm{HRC}$ at $500^{\circ} \mathrm{C}$. At higher aging temperatures, there was a rapid drop in hardness to $36 \mathrm{HRC}$ at $800^{\circ} \mathrm{C}$.

Figure 69 presents photomicrographs of cast and spray-formed XPT-14. As with SHS 727, the spray-formed material exhibited a significantly higher degree of uniformity.

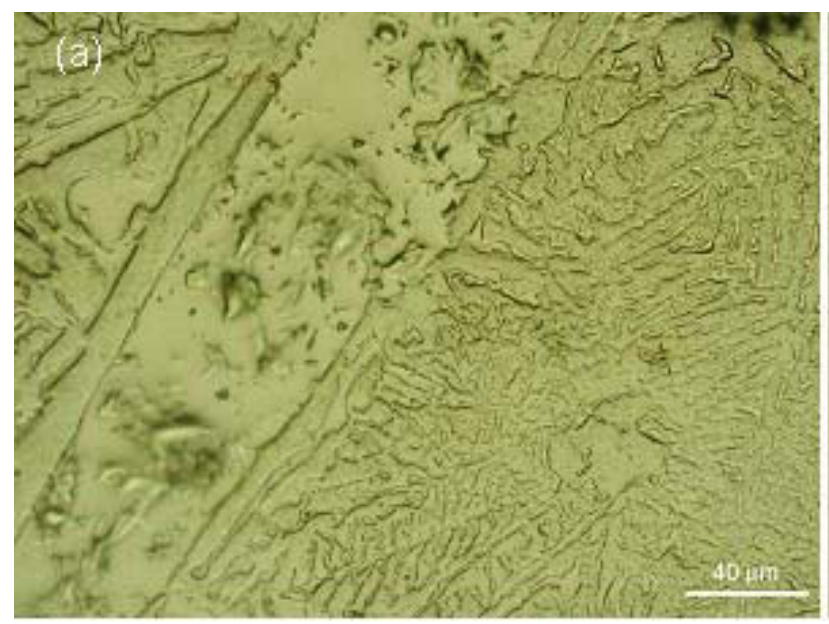

Figure 67. Photomicrographs of SHS 727. (a) Cast. (b) Spray formed. 


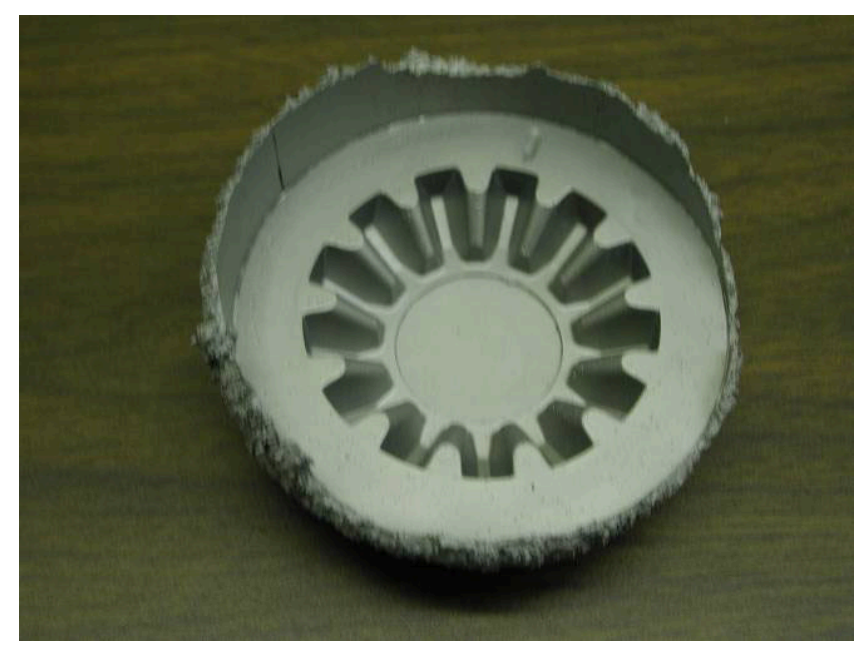

Figure 68. Spray-formed XPT-14 forging die.

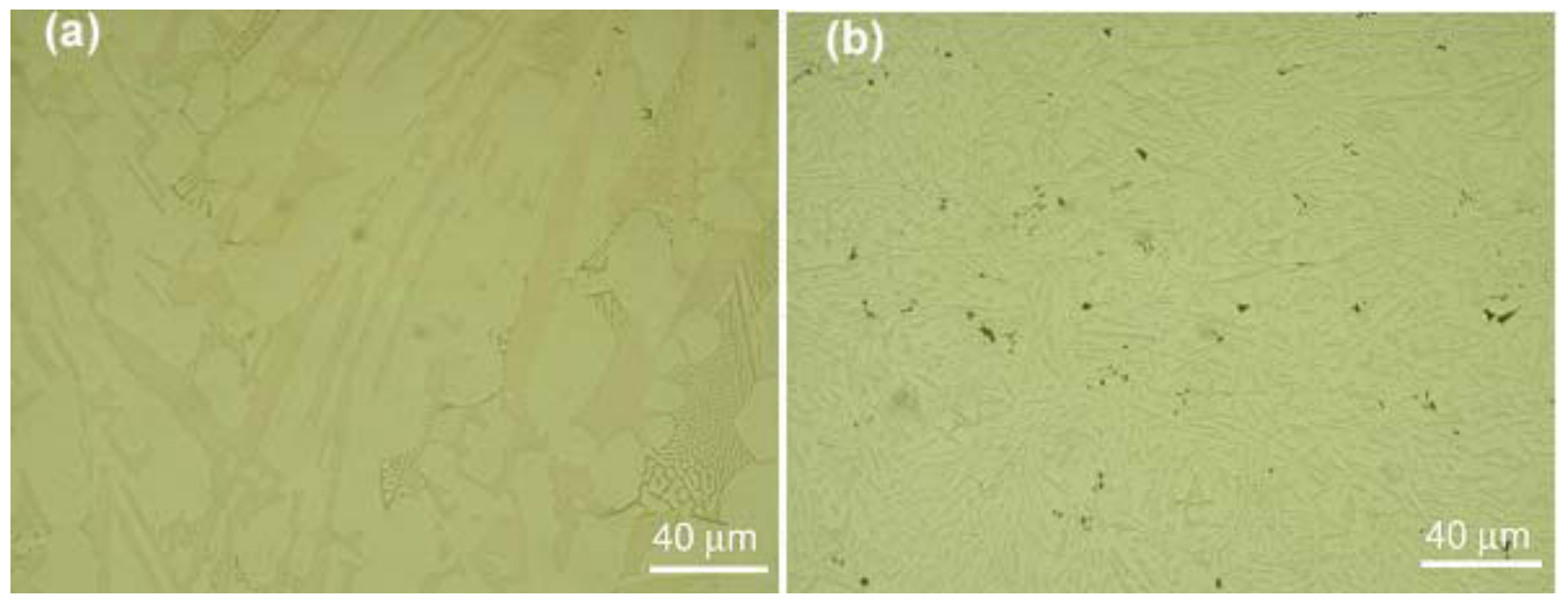

Figure 69. Photomicrographs of XPT-14. (a) Cast. (b) Spray formed. 


\section{ACCOMPLISHMENTS}

\subsection{Patents, Publications, and Presentations}

\subsubsection{Patents}

- $\quad$ "Rapid Solidification Processing System For Producing Molds, Dies, and Related Tooling." United States Patent Number 6,746,225 issued June 8, 2004.

\subsubsection{Publications}

- $\quad$ Yaojun Lin, Kevin M. McHugh, Young-Soo Park, Yizhang Zhou, and E. J. Lavernia, "Microstructure and Mechanical Properties of Spray-Formed H13 Steel Tooling," Materials Processing and Manufacturing Division. Sixth Global Innovations Proceedings: Trends in Materials and Manufacturing Technologies for the Transportation Industry and Powder Metallurgy Research and Development in the Transportation Industry. Edited by T. R. Bieler, J. E. Carsley, H. L. Fraser, J. W. Sears, and J. E. Smugersky, TMS, San Francisco, CA, February 13-17, 2005. pp. 45-50 (2005).

- $\quad$ Kevin McHugh, "Use of RSP Tooling to Manufacture Die Casting Dies,” Die Casting Engineer, p. 38, July 2004.

- $\quad$ Kevin M. McHugh and James E. Folkestad, "Production of Molds and Dies Using the RSP Tooling Approach," Proceedings of the International Conference on Spray Deposition and Melt Atomization 2003 and the International Conference of Spray Forming V, Bremen, Germany, p. 5-123, (2003).

- $\quad$ Kevin M. McHugh, "Rapid Solidification Process (RSP) Tooling For Moldmaking," Proceedings of Moldmaking 2003, Cleveland, OH, April 29-May 1, 2003, p. 23 (2003).

- $\quad$ Kevin M. McHugh and James R. Knirsch, "Producing Production Level Tooling in Prototype Timing-An Update," Moldmaking Technology 5 (10), October 2002, p. 42.

- J. R. Knirsch, K. M. McHugh, and J. E. Folkestad, "RSP Tooling-A Revolutionary New Process to Manufacture Die Cast Production Tooling in Prototype Timing," Die Casting Engineer 46 (3), May 2002, p. 56.

\subsubsection{Presentations}

- $\quad$ Kevin M. McHugh, “Advanced Alloys For Die Cast Tooling,” Ohio Technology Showcase, Crowne Plaza Cleveland City Centre, Cleveland, OH, September 28, 2005.

- James R. Knirsch, "Bi-Metallic Dies For Injection Molding Operations," Ohio Technology Showcase, Crowne Plaza Cleveland City Centre, Cleveland, OH, September 28, 2005.

- James R. Knirsch, "Prototype and Low Volume Forging Dies are Now a Reality," Ohio Technology Showcase, Crowne Plaza Cleveland City Centre, Cleveland, OH, September 28, 2005.

- Yaojun Lin, Kevin M. McHugh, Young-Soo Park, Yizhang Zhou, and E. J. Lavernia, "Microstructure and Mechanical Properties of Spray-Formed H13 Steel Tooling," Materials 
Processing and Manufacturing Division. Sixth Global Innovations Proceedings: Trends in Materials and Manufacturing Technologies for the Transportation Industry and Powder Metallurgy Research and Development in the Transportation Industry. TMS, San Francisco, CA, February 16, 2005.

- $\quad$ Kevin M. McHugh, Yizhang Zhou, Yaojun Lin, and Enrique Lavernia, "Processing Advantages and Energy Savings in the Manufacture of Tool Steel Molds and Dies by Spray Deposition," Materials for Energy Efficiency in Industrial Processes \& Manufacturing Symposium, ASM Materials Solutions 2004, October 20, 2004.

- Yaojun Lin, Young-Soo Park, Yizhang Zhou, Kevin M. McHugh, and Enrique J. Lavernia, "Modeling and Experimental Investigation of Spray-Formed H13 Steel Tooling," International Symposium on Modeling and Computer Applications in Metal Casting, Shaping and Forming Processes, Materials Science \& Technology 2004, New Orleans, Louisiana, September 27, 2004.

- $\quad$ An open house was conducted by RSP Tooling, LLC Feb. 4-7, 2003 in Solon, OH. Approximately 200 people attended. Presentations on RSP Tooling technology were given by INL and industry participants in this project.

- $\quad$ K. M. McHugh, "Rapid Solidification Process (RSP) Tooling for Moldmaking," presented at Moldmaking 2003 Conference and Expo, Cleveland, OH, April 29, 2003.

\subsection{Commercialization Activities}

Spray-forming technology developed at INL and used in this project to manufacture molds and dies (RSP Tooling) was licensed and commercialized with the formation of RSP Tooling, LLC in January 2002. The company is located in Solon, OH. The company's business strategy was to find partners familiar with the tooling industry who would be active stakeholders in the business, not just investors. Start-up funding for RSP Tooling, LLC was raised from The Technology House and Belcan Corporation, plus several individual investors, and through loans from the state of Ohio and a financial institution.

RSP Tooling, LLC negotiated a field of use license agreement with INL for the Rapid Solidification Processing technology for all tooling applications. The first-generation (beta) RSP Tooling machine (Figure 70) was designed and constructed and is being used to develop and understand the spray forming parameters of various alloys, component lifetime, and other factors. The machine is fully operational; RSP Tooling is currently making and shipping tooling inserts. Examples are shown in Figures 71 and 72 .

Engineering design concepts are being developed for a production machine that can produce more than 500 tools per month. Arrangements have been discussed with leasing companies so businesses interested in purchasing RSP Tooling machines can lease them at a monthly rate. The company plans to sell machines and scale the technology for making larger molds and dies.

An Open House held in February, 2003 to introduce the new company was attended by about 200 people. The market potential for this technology is high because it has been demonstrated to reduce cost and turnaround time for production-quality molds and dies. 

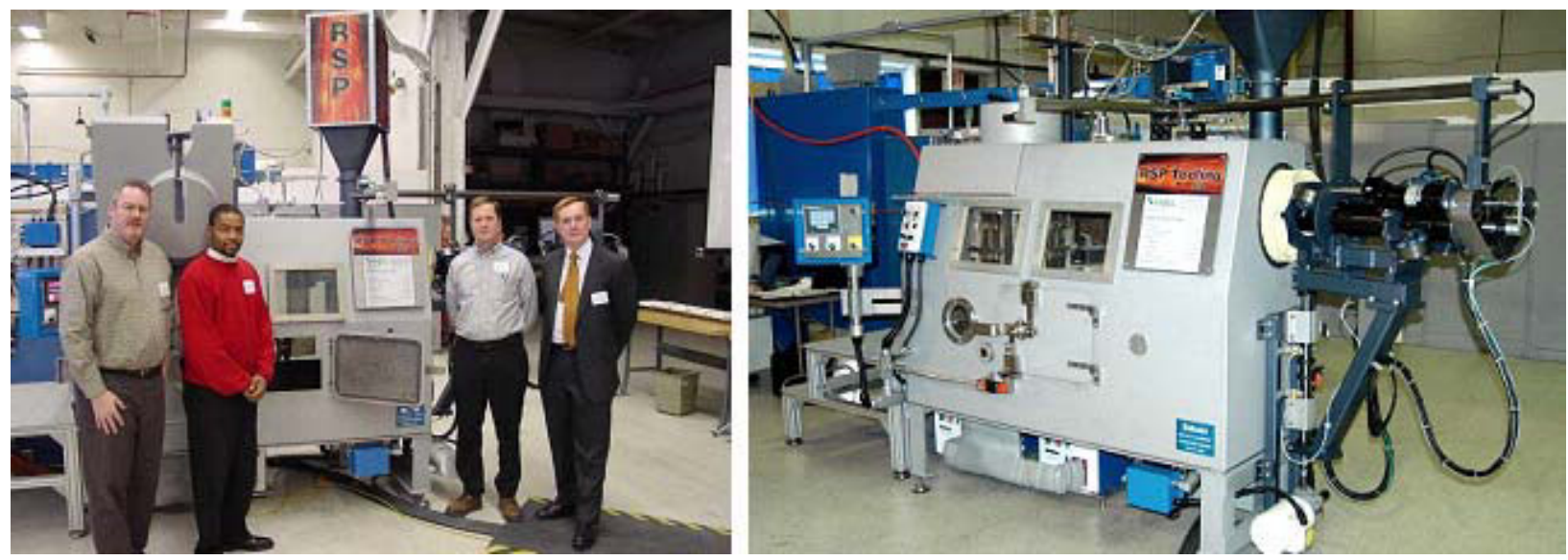

Figure 70. Commercial RSP tooling machine and industry participants.

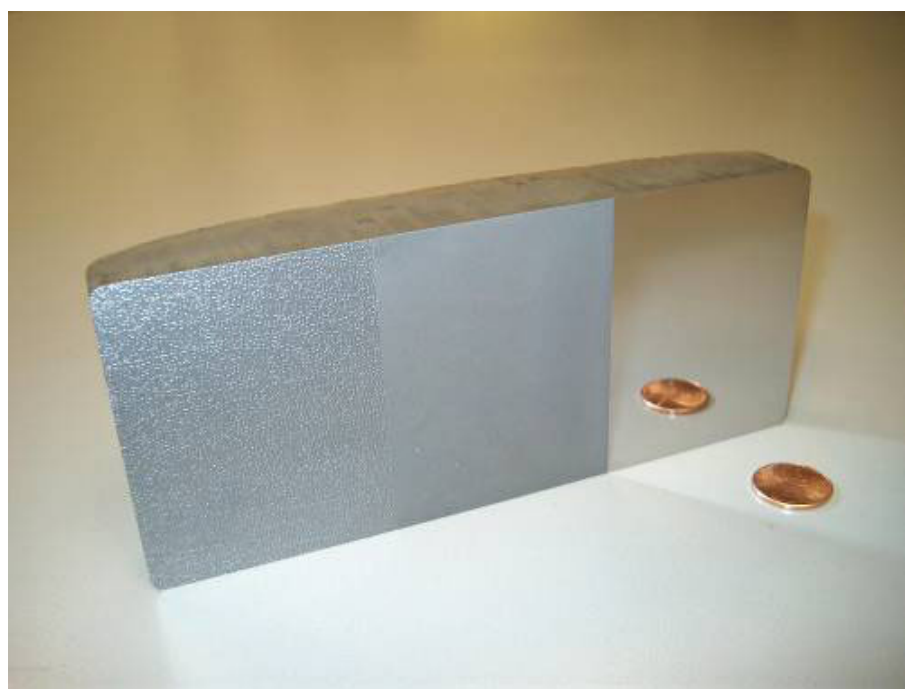

Figure 71. Textured H13 tool steel sample made on commercial RSP tooling machine.
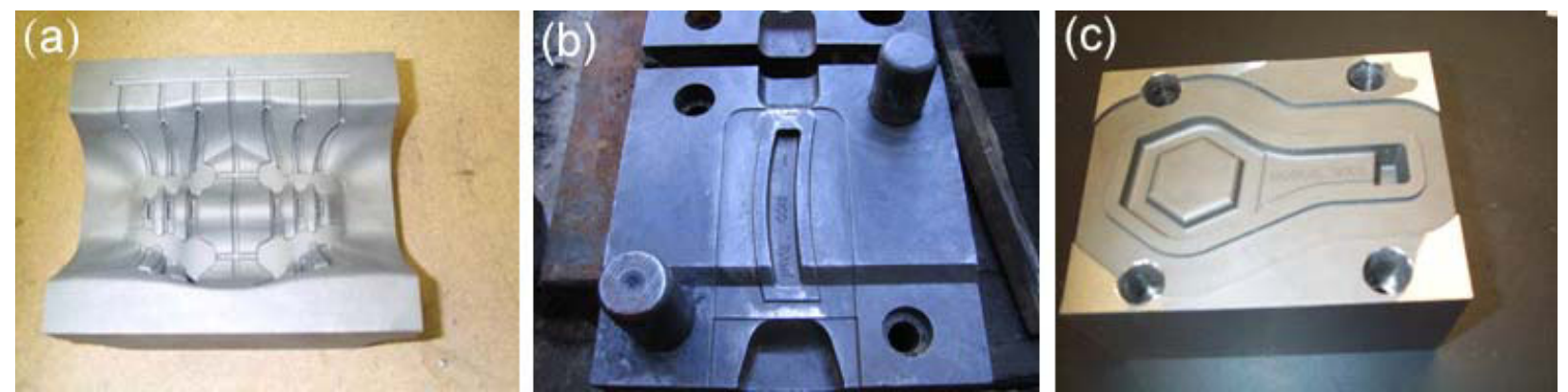

Figure 72. Die inserts manufactured on the commercial RSP tooling machine. (a) P20 injection mold insert. (b), (c) H13 forging die inserts. 


\section{CONCLUSIONS}

This project developed and demonstrated a new rapid tooling technology, RSP Tooling, for manufacturing molds, dies, and related tooling. A collaborative effort of Idaho National Laboratory, University of California-Davis, General Aluminum Manufacturing Company, the Glass Manufacturing Industry Council, and RSP Tooling, LLC, this project was crosscutting and addressed tooling needs in Glass, Forging, Metal Casting, and Steel Industries of the Future. Discussions with industry participants led to the selection of conventional tool steels as well as new commercial steel alloys for processing by RSP Tooling into molds and dies for a variety of forming operations such as plastic injection molding, die casting, forging, extrusion, and glass forming. Five commercial alloys were processed: H13, M2, and A2 tool steels and SHS 727 and XPT-14 metallic glass-forming alloys. In addition, two new tool steels were developed, processed, and analyzed. Extensive microstructure and material property analysis was conducted on these alloys in an effort to understand the interplay of processing conditions with in-service die performance. Spray-forming conditions and post-deposition heat treatment practices leading to optimized properties were established. Analytical techniques employed in the analysis of these alloys included tensile testing, hardness measurement, toughness measurement, SEM, TEM, EDS, DTA, optical microscopy, x-ray diffraction, and neutron diffraction. In addition, modeling tools and computational techniques were used to help develop an understanding of the characteristics of the spray plume (droplet thermo-physical properties, size distribution, velocity, heat content, flux, and spray pattern) and those of the tool pattern during tool formation. The following conclusions were reached:

- $\quad$ RSP Tooling technology can reduce the cost and lead time for tooling by $20-70 \%$ for small dies by eliminating many of the machining, benching, and heat treatment unit operations in conventional tool-making practices. Cost and lead time savings increase as the size and complexity of the die increase.

- With implementation of RSP Tooling technology, industrial energy savings are forecasted to be $0.14 \mathrm{TBtu} / \mathrm{yr}$ in 2010 and 5.56 TBtu/yr in 2020 .

- $\quad$ Rapid solidification provides a powerful means to control segregation of alloying elements during solidification and carbide formation and growth, as well as the ability to create beneficial metastable phases in many tool alloys.

- $\quad$ Low temperature artificial aging heat treatments were developed and shown to be beneficial in tailoring properties such as hardness, toughness, wear resistance, thermal fatigue resistance, and strength in many rapidly solidified tool steels. Unique combinations of die properties were demonstrated.

- These unique properties led to extended die life during production runs in aluminum die casting, extrusion, forging, and other applications.

- RSP Tooling technology was commercialized with the formation of RSP Tooling, LLC in Solon, $\mathrm{OH}$. 


\section{RECOMMENDATIONS}

Very encouraging results were obtained in this project. Suggestions for further development and use of this technology are summarized below:

- To more fully exploit the commercial potential of this technology, scale up to accommodate largescale dies is recommended.

- $\quad$ The spray forming approach applied in this project is quite versatile and should be extended to wear resistant metals and composite materials for industrial applications.

- $\quad$ The feasibility of processing clad metals with this technology for conformal die cooling and other applications has been demonstrated; this capability should be developed. 


\section{REFERENCES}

1. Industrial Materials for the Future Fiscal Year 2004 Annual Report, http://www.eere.energy.gov/industry/imf/pdfs/imf_fy2004.pdf.

2. U.S. Department of Energy, Energy Efficiency and Renewable Energy, Industrial Technologies Program, Industrial Materials for the Future, Government Performance and Result Act (GPRA) 2004 data.

3. Terry Wohlers, "The Rapid Prototyping/Manufacturing Industry," Adv. Mat. Process. 161(1), 35 (2003).

4. Kevin M. McHugh and James R. Knirsch, "Producing Production Level Tooling in Prototype Timing-An Update," Moldmaking Technology $\underline{5}$ (10), (2002), 42.

5. J. E. Folkstad, J. R. Knirsch, and K. M. McHugh, "Die Casting and Rapid Solidification Process (RSP) Tooling-An Applied Research Project," Proceedings of the 2002 NADCA Congress, NADCA, Rosemont, IL, (2002), Paper T02-051.

6. J. R. Knirsch, K. M. McHugh, and J. E. Folkestad, "RSP'M Tooling-A Revolutionary New Process to Manufacture Die Cast Production Tooling in Prototype Timing," Die Casting Engineer $\underline{46}(3),(2002), 56$.

7. Kevin M. McHugh and J.R. Knirsch, "Producing Production Level Tooling in Prototype Timing," Time Compression Technologies, $\underline{6}$ (2), (2001), 23.

8. K. M. McHugh and J. F. Key, "Spray-Formed Tooling," Proceedings of the 1994 Annual Automotive Technology Development Contractors' Coordination Conference, Society of Automotive Engineers, Inc., Warrendale, PA, p. 233, 1994.

9. K. M. McHugh and J. F. Key, "Use of De Laval Nozzles in Spray Forming," J. Thermal Spray Technol., 3 (2), 191 (1994).

10. Kevin M. McHugh, "Microstructure Transformation of Spray-Formed H13 Tool Steel During Deposition and Heat Treatment," Solidification 1998, ed. S. P. Marsh, J. A. Dantzig, R. Trivedi, W. Hofmeister, M. G. Chu, E. J. Lavernia, and J. H. Chun, The Minerals, Metals \& Materials Society, p. 427, 1998.

11. K. M. McHugh, "Rapid Production of Tooling Inserts by Spray Forming," Proceedings of the 1997 Automotive Applications of Thermal Spray Technology Conference, The Engineering Society, Southfield, MI, January 1997.

12. K. M. McHugh, "INEL Spray-Formed Tooling," Proceedings of the Conference on Rapid Tooling Applications for Metalcasting_Advanced Pattern and Foundry Tooling, p. 99, 1996.

13. K. M. McHugh, "Spray-Formed Tooling and Aluminum Strip," Proceedings of the Fourth International Conference on Powder Metallurgy in Aerospace, Defense and Demanding Applications, p. 345, 1995.

14. http://www.eere.energy.gov/industry/metalcasting/pdfs/csu_rsp_tooling.pdf. 
15. http://www.eere.energy.gov/industry/imf/pdfs/ineel_tooling_alloys.pdf.

16. RSP Tooling, LLC website: http://www.rsptooling.com.

17. Die Casting Engineer, May 2002, http://www.diecasting.org/dce.

18. Yaojun Lin, Kevin M. McHugh, Young-Soo Park, Yizhang Zhou, and E. J. Lavernia, "Microstructure and Mechanical Properties of Spray-Formed H13 Steel Tooling," Materials Processing and Manufacturing Division. Sixth Global Innovations Proceedings: Trends in Materials and Manufacturing Technologies for the Transportation Industry and Powder Metallurgy Research and Development in the Transportation Industry. Edited by T. R. Bieler, J. E. Carsley, H. L. Fraser, J. W. Sears, and J. E. Smugersky, TMS, San Francisco, CA, February 13-17, 2005. pp. 45-50 (2005).

19. Kevin McHugh, "Use of RSP Tooling to Manufacture Die Casting Dies," Die Casting Engineer, p. 38, July, 2004.

20. Kevin M. McHugh and James E. Folkestad, "Production of Molds and Dies Using the RSP Tooling Approach," Proceedings of the International Conference on Spray Deposition and Melt Atomization 2003 and the International Conference of Spray Forming V, Bremen, Germany, p. 5-123, (2003).

21. Kevin M. McHugh, "Rapid Solidification Process (RSP) Tooling For Moldmaking," Proceedings of Moldmaking 2003 , Cleveland, OH, April 29-May 1, 2003, p. 23 (2003).

22. P. J. Maziasz, E. A. Payzant, M. E. Schlienger and K. M. McHugh, "Residual Stresses and Microstructure of H13 Steel Formed by Combining Two Different Direct Fabrication Methods," Scripta Materialia $\underline{39}$ (10), 1471-1476 (1998).

23. S. Kuroda, T. Dendo, and S. Kitahara, J. Therm. Spray Technol., 4 , 75-84 (1995). 


\section{Appendix A}

Modeling Analysis of Heat Transfer and Solidification Phenomena 


\section{Appendix A}

\section{Modeling Analysis of Heat Transfer and Solidification Phenomena}

\section{Numerical Model}

For molds and dies, heat conduction within the spray-formed material can be assumed to be onedimensional along the thickness of the spray-formed material because the thickness is usually much smaller than the width or length. The buildup of the deposit occurs via discrete deposition of individual droplets, i.e., there is a time interval between two groups of droplets that successively arrive at the previously deposited material's surface. Accordingly, a one-dimensional Fourier's equation is used to deal with heat conduction within the deposit during a time interval. At the end of this time interval, a new group of droplets is incorporated onto the previously deposited material to generate a new deposit. The one-dimensional Fourier's equation is then implemented to compute heat conduction within the new deposit:

$$
\frac{\partial T}{\partial t}=\frac{\partial}{\partial z}\left(k \frac{\partial T}{\partial z}\right)
$$

where $T$ is temperature, $t$ is time, $z$ is thickness, and $k$ is thermal conductivity.

The boundary condition at the interface between the deposited material and the substrate is described as follows:

$$
-k \frac{\partial T}{\partial z}=h\left(T_{\text {sub }}-T_{0}\right)
$$

where $h$ is the heat transfer coefficient at the interface between the deposited material and the substrate, $T_{\text {sub }}$ is the substrate temperature at the interface, and $T_{0}$ is the deposited material's temperature at the interface.

The boundary condition at the exposed interface of the deposited material is as follows:

$$
k \frac{\partial T}{\partial z}=h\left(T_{\exp }-T_{g}\right)
$$

where $T_{\exp }$ is the deposited material's temperature at the top interface and $T_{\mathrm{g}}$ is the ambient atomization gas temperature.

The alternating-direction explicit (ADE) method is used to discretize the one-dimensional Fourier's equation. The ADE method is an unconditionally stable method with second-order accuracy, which can be briefly described as follows. During a certain time interval during deposition, the deposited metal is divided into $N$ grids, and the temperature within the deposited metal is calculated according to two directions: 1) from the deposit/substrate interface to the exposed surface of the deposit, and 2) from the exposed surface of the deposit to the deposit/substrate interface. Let $u$ and $v$ be the calculated temperatures according to the above two directions: 
$u_{i}^{n+1}=\left[F o_{i}^{n}\left(u_{i+1}^{n}+u_{i-1}^{n+1}\right)+\left(1-F o_{i}^{n}\right) u_{i}^{n}\right] /\left(1+F o_{i}^{n}\right)$

$v_{i}^{n+1}=\left[F o_{i}^{n}\left(v_{i+1}^{n+1}+v_{i-1}^{n}\right)+\left(1-F o_{i}^{n}\right) v_{i}^{n}\right] /\left(1+F o_{i}^{n}\right)$

where $F_{o}=(k / C) \cdot\left(\Delta t / \Delta z^{2}\right)$ is the Fourier's number, $C$ is the volumetric specific heat, $\Delta t$ and $\Delta z$ are the time and space steps during calculation, and $i$ is the number of spatial grid nodes separated by $\Delta z$ along the thickness of the deposited material. Furthermore, let $u$ and $v$ also satisfy the boundary conditions at the deposit/substrate interface,

$$
\begin{aligned}
& u_{0}^{n+1}=\left[2 F o_{0}^{n}\left(u_{1}^{n}+B i_{0}^{n} u_{s u b}^{n}\right)+\left(1-F o_{0}^{n} B i_{0}^{n}\right) u_{0}^{n}\right] /\left[1+F o_{0}^{n}\left(2+B i_{0}^{n}\right)\right] \\
& v_{0}^{n+1}=\left\{2 F o_{0}^{n}\left(v_{1}^{n+1}+B i_{0}^{n} v_{s u b}^{n}\right)+\left[1-F o_{0}^{n}\left(2+B i_{0}^{n}\right)\right] v_{0}^{n}\right\} /\left(1+F o_{0}^{n} B i_{0}^{n}\right),
\end{aligned}
$$

and at the exposed surface,

$$
\begin{aligned}
& u_{N}^{n+1}=\left\{2 F o_{N}^{n}\left(u_{N-1}^{n+1}+B i_{N}^{n} u_{\text {gas }}^{n}\right)+\left[1-F o_{N}^{n}\left(2+B i_{N}^{n}\right)\right] u_{N}^{n}\right\} /\left(1+F o_{N}^{n} B i_{N}^{n}\right) \\
& v_{N}^{n+1}=\left[2 F o n{ }_{N}^{n}\left(v_{N-1}^{n}+B i_{N}^{n} v_{g a s}^{n}\right)+\left(1-F o_{N}^{n} B i_{N}^{n}\right) v_{N}^{n}\right] /\left[1+F o_{N}^{n}\left(2+B i_{N}^{n}\right)\right] .
\end{aligned}
$$

The accurate temperature, $T$, in a certain grid, $i$, is the arithmetic average of the temperatures calculated in the two directions:

$$
T_{i}^{n+1}=\left(u_{i}^{n+1}+v_{i}^{n+1}\right) / 2
$$

The solidification latent heat is included in the temperature calculation by adding the latent heat term to the heat capacity to generate an apparent heat capacity:

$$
C_{a}=C_{m}+L /\left(T_{l}-T_{S}\right) \text { for } T_{S}<T<T_{S} .
$$

The assumption of one-dimensional heat transfer along the thickness and the ADE method also apply to the pattern (substrate), which also has much smaller thickness than width or length, and are used to calculate the pattern's temperature as part of the calculation of the cooling process within the deposit. 